\title{
Finding the Binding Site of Peloruside $A$ and its Secondary Effects in Saccharomyces cerevisiae using a Chemical Genetics Approach
}

\author{
by \\ Reem Hanna
}

A thesis submitted to Victoria University of Wellington in fulfilment of the requirements for the degree of Master of Biomedical Science

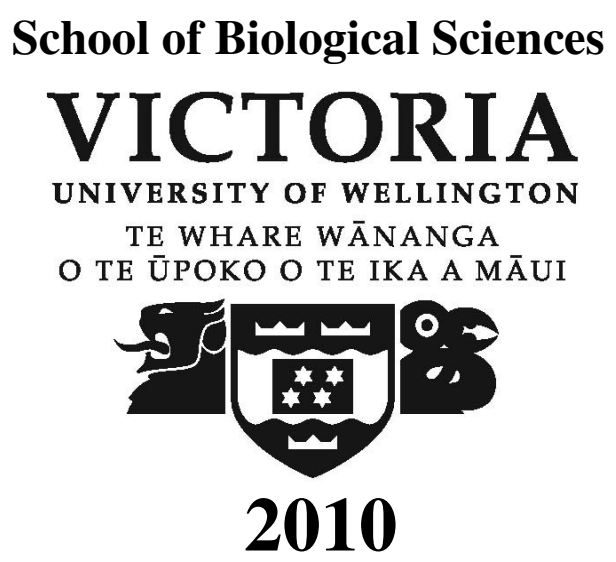




\section{Acknowledgements}

I am deeply indebted to my wonderful supervisor who made this journey enjoyable and unforgettable, Prof John Miller, for his constant support, patient guidance and endless feedback for both experimental and written work, encouragement and excellent advice throughout this study. I would like to express my gratitude to my other wonderful supervisor Dr David Bellows who was abundantly helpful and offered valuable assistance, support, guidance and priceless feedback throughout this research. Deepest gratitude is to Dr David Maass for his guidance, advice and crucial contributions especially the molecular biology part of this thesis. I would also like to thank Prof Paul Atkinson for providing an excellent place to learn and creating a very friendly environment. Many thanks go in particular to Assoc Prof Paul Teesdale-Spittle for his valuable advice in the PelA-predicted mutation part of the thesis and for using his precious time to make the appropriate amino acids changes. Special thanks to Prof Jim Snyder and Dr Pakh Thepchatri of Emory University, Atlanta, Georgia, USA, for providing the current computer modelling studies of PelA/laulimalide binding site.

I am thankful to Dr Anja Wilmes for her advice and guidance from the very early stage of this research, and for her generous assistance during that time. I am grateful Dr Rosemary Heathcote for her valuable advice in microarray set up, supervision of microarray analysis and furthermore, using her precious times to answer some of my unintelligent questions about the microarray data.

I gratefully acknowledge Ariane Chain for her numerous help throughout this study. I would like to thank my best friend Ploi Yibmantisiri for her advice and assistance throughout this research, thanks for being always there for me. I would like to thank James Mathew for his assistant in particular in handling flow cytometry machine. I would also acknowledge Peter Bircham for his valuable assistance with the opera microscope images. It is a pleasure to pay tribute to Manivannan Yegambaram for his advice with PCR troubleshooting and with the phase contrast microscope training. Special thanks to Natelle Quek for sharing her knowledge of the bud index assay. Thanks to Veronica Venture and Christina Roberts for your precious friendship.

Lastly, I would like to express my love and gratitude to my beloved family for their understanding and endless love, through the duration of this study. 


\section{Table of Contents}

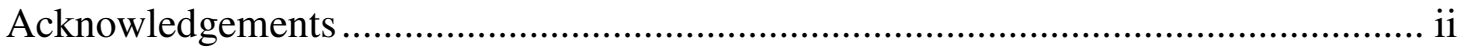

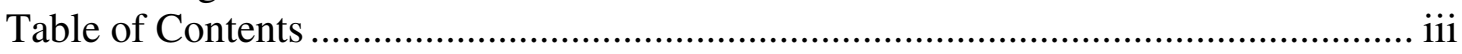

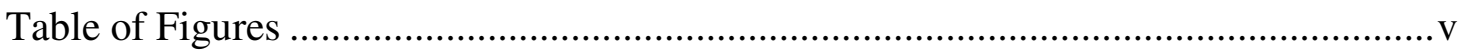

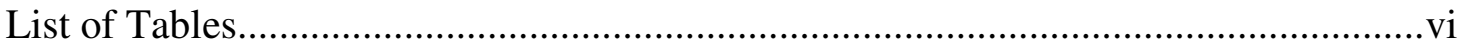

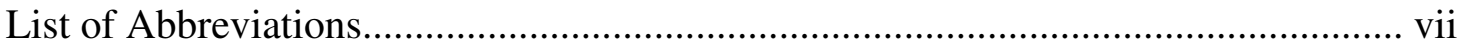

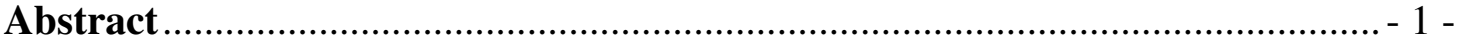

Chapter 1. General introduction ....................................................................... 3 -

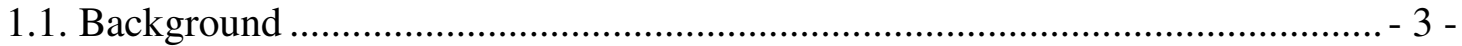

1.2. Microtubule stabilising agents (MSA) ........................................................ 6 -

1.3. Mechanism of action for microtubule-targeting drugs................................... 8 -

1.4. Peloruside A ................................................................................... - 10 -

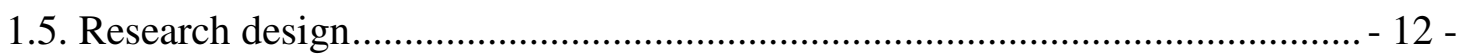

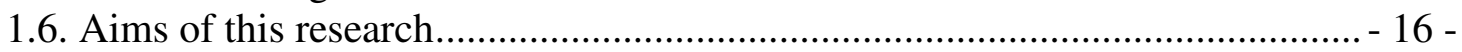

1.6.1. Identify peloruside binding site on yeast tubulin ................................. 16 -

1.6.2. Determining peloruside target............................................................. 16 -

1.6.3. Investigate effects of point mutation using other MSA ......................... 16 -

1.6.4. Identify any secondary drug targets of peloruside HOP microarrays..... - 16 -

Chapter 2. Peloruside binding site on yeast tubulin: Site-directed mutagenesis- 17 -

2.1. Introduction .............................................................................. - 17 -

2.1.1. Introduction to yeast properties ........................................................ 17 -

2.1.2. Introduction to chemical genetics ..................................................... 17 -

2.1.3. Peloruside A properties and applications........................................... - 18 -

2.1.4. Introduction to yeast tubulin genes ................................................ 20 -

2.1.5. Introduction to other microtubule-stabilising agents .......................... 21 -

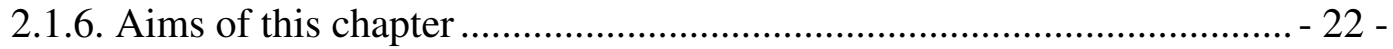

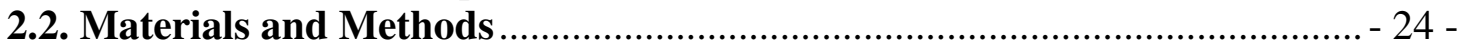

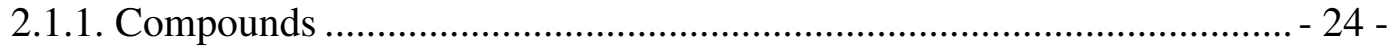

2.2.2. Yeast strains used in this study .......................................................... 24 -

2.2.3. Primer design of PelA-resistant tubulin (TUB2) mutants by overlap PCR- 24 -

2.2.4. Transformation.................................................................................... 27 -

2.2.5. Confirmation PCR primer design .................................................... 27 -

2.2.6. Transformation confirmation by colony PCR..................................... 28 -

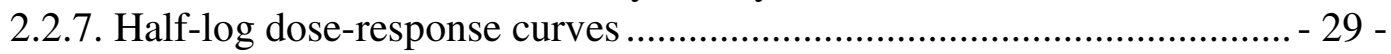

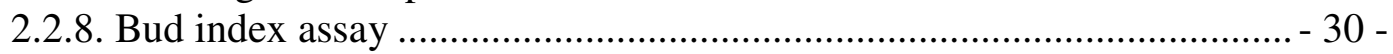

2.2.9. Flow cytometry analysis ................................................................... 31 -

2.2.10. Morphological changes of polymerised $\alpha$-tubulin in TUB3-GFP in

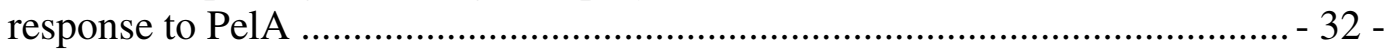

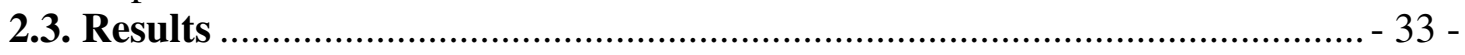

2.3.1. Site-directed mutagenesis and transformation confirmation by colony

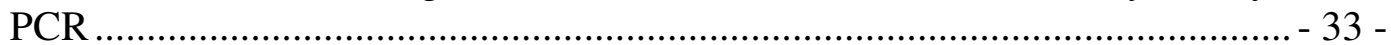

2.3.2. Half-log dose-response curves for mutant strains treated with PelA...... 38 -

2.3.3. The effect of tubulin point mutations on growth responses to ixabepilone

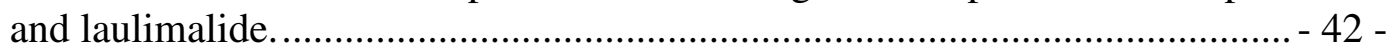

2.3.4. The effect of PelA on the yeast cell cycle using bud index and flow

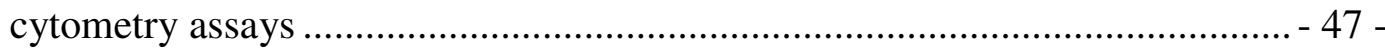

2.3.5. The effect of PelA on microtubule morphology .................................. 50 -

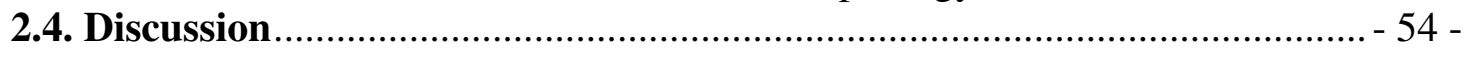


Chapter 3. Finding the secondary targets of peloruside via chemical genetics

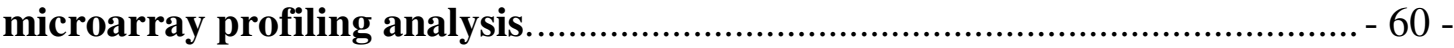

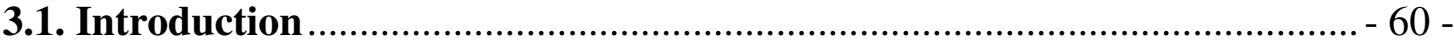

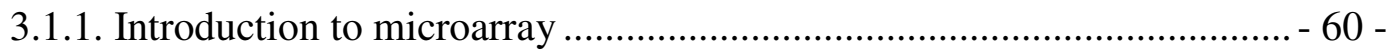

3.1.2. Introduction to homozygous deletion profiling (HOP) ......................... 61 -

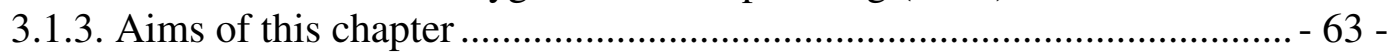

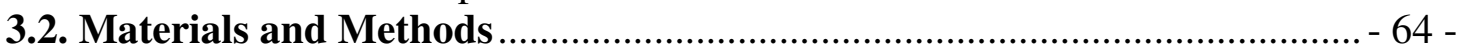

3.2.1. Yeast competitive growth assay....................................................... 64 -

3.2.2. Genomic DNA purification................................................................ 64 -

3.2.3. Barcode amplification and Cy3/Cy5-dye labelling by PCR ................... 65 -

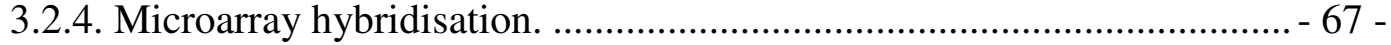

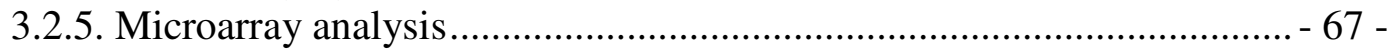

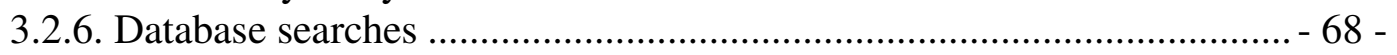

3.2.7. Validation of HOP results: Growth inhibition experiment .................... 68 -

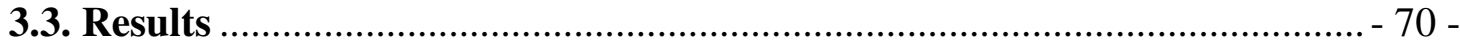

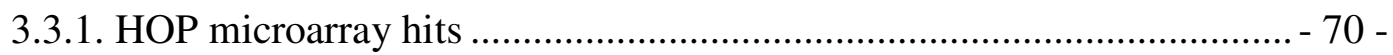

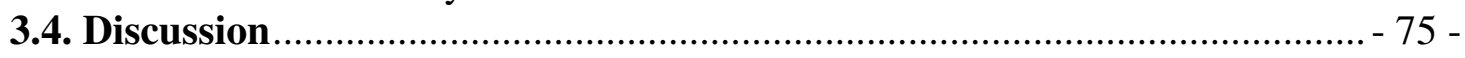

Chapter 4. Overall discussion and future experiments ................................... 81 -

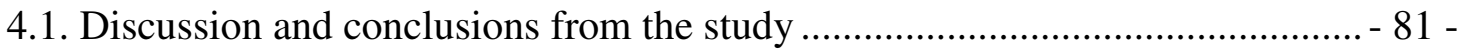

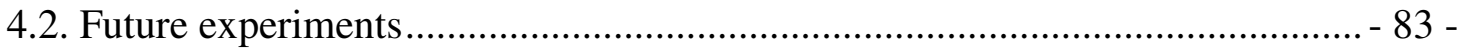

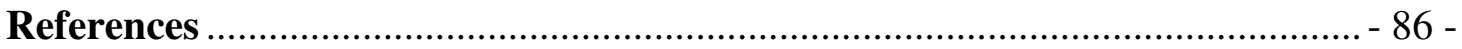

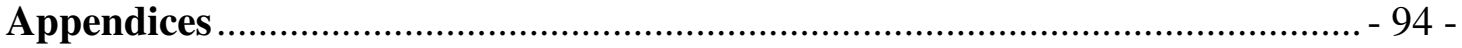

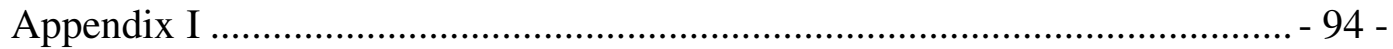

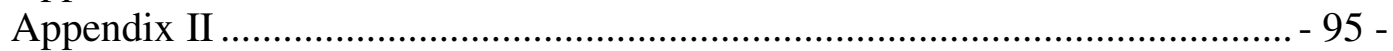

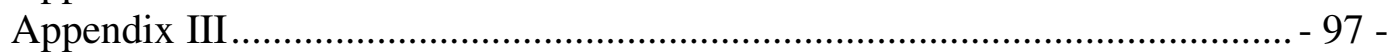

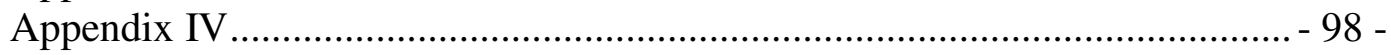

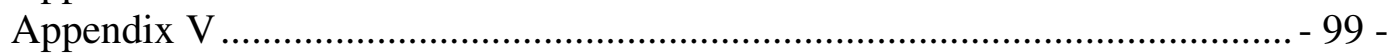




\section{Table of Figures}

Figure. 1.1. Microtubule polymerisation............................................................ - 4 -

Figure. 1.2. Mammalian (left) and Yeast (right) cell cycle .................................... 8 -

Figure. 1.3. Three-dimensional model of $\alpha / \beta$-tubulin heterodimer ....................... 8 -

Figure. 1.4. Chemical structure of drugs that bind to the taxane binding site on $\beta$ tubulin .....

Figure. 1.5. Chemical structre of laulimalide and peloruside A ............................ - 9 -

Figure. 1.6. (a) Sea sponge Mycale hentscheli ................................................. - 10 -

Figure. 1.7. Sequence alignment of Saccharomyces cerevisiae tubulin gene....... - 13 -

Figure. 1.8. Proposed peloruside binding site on $\beta$-tubulin ............................... - 14 -

Figure. 2.1.1. Chemical synthetic lethality (CSL) versus synthetic lethality (SL) - 18 -

Figure. 2.1.2. 2D-schematic view of $\beta$-tubulin-peloruside interactions................ - 19 -

Figure. 2.2.1. Schematic view for overlap PCR ............................................... 26 -

Figure. 2.2.2. Schematic view of colony PCR primers ........................................ 28 -

Figure. 2.2.3. Correlation of yeast bud index with cell cycle phases................... 30 -

Figure. 2.3.1. Confirmation of A296T point mutation, R306H, double mutant, and

NatMX cassette PCR products

Figure. 2.3.2. Confirmation of PCR products of predictive point mutations and

NatMX cassette PCR products................................................................. 34 -

Figure. 2.3.3. Colony PCR for A296T transformation confirmation.................... 35 -

Figure. 2.3.4. The confirmation R306H transformation by colony PCR ............. - 35 -

Figure. 2.3.5. Confirming R306H+A296T transformation via colony PCR........ - 36 -

Figure. 2.3.6. Transformation confirmation for R282Q by colony PCR ............. - 36 -

Figure. 2.3.7. The confirmation for Q291M transformation by colony PCR ....... 36 -

Figure. 2.3.8. Confirmation of V333W transformation via colony PCR ............. - 37 -

Figure. 2.3.9. N337L transformation confirmation via colony PCR ................... 37 -

Figure. 2.3.10. Sensitivity of wild type, $\operatorname{mad} 2 \Delta$, and pump knockout mutants to PelA

-40 -

Figure. 2.3.11. Growth inhibition curves of $\operatorname{mad} 2 \Delta$ and $t u b 2$ mutants treated with PelA. -41 -

Figure. 2.3.12. Growth inhibition curves of the PelA-predicted point mutations and $\operatorname{mad} 2 \Delta$ strain $-41-$

Figure. 2.3.13. Growth inhibition curves for yeast strains treated with different concentrations of aza-epothilone (ixabepilone) ........................................ 44 -

Figure. 2.3.14. Growth inhibition curves of wild type, $\operatorname{mad} 2 \Delta$, and pump mutant strains treated with $50 \mu \mathrm{M}$ laulimalide $-45-$

Figure. 2.3.15. Growth inhibition curves of $\operatorname{mad} 2 \Delta$ and $t u b 2$ mutant strains treated with laulimalide $-46-$

Figure. 2.3.16. Growth inhibition curves of the predicted tub2 point mutation strains treated with $50 \mu \mathrm{M}$ laulimalide $-46-$

Figure. 2.3.17. Bud index for $40 \mu \mathrm{M}$ PelA-treated and untreated mad2 $\Delta$ cells ... - 48 Figure. 2.3.18. Budding index histogram for mad2 $\Delta$ strain treated with $40 \mu \mathrm{M}$ PelA $48-$

Figure. 2.3.19. Flow cytometry for mad2 $\Delta$ cells treated with $40 \mu \mathrm{M}$ PelA.......... - 49 Figure. 2.3.20. Alpha-Tubulin (TUB3)-GFP, RFP and mCherry colour images. . - 51 Figure. 2.3.21. Alpha-Tubulin (TUB3)-GFP grayscale images .......................... 52 Figure. 3.1.1. Constructing yeast deletion mutant collection (YKO) ................... 61 Figure. 3.1.2. Haploid homozygous mutants are used in the HOP assay. ............ - 62 Figure. 3.3.1. PelA-HOP genetic interactions network..................................... - 73 Figure. 4.1. Schematic view of DART ........................................................... 84 - 


\section{List of Tables}

Table. 2.1.1. Predicted PelA-sensitive sites on $\beta$-tubulin. $-19-$

Table. 2.3.1. Percentage of growth inhibition of wild type, $\operatorname{mad} 2 \Delta$, and pump knockout mutants treated with PelA …............................................................ - 40 -

Table. 2.3.2. Percentage of growth inhibition of haploid mutant deletion strains - 45 Table. 2.3.3. $\mathrm{IC}_{50}$ values of yeast strains treated with $50 \mu \mathrm{M}$ PelA and/or laulimalide47 -

Table. 2.3.4. Bud-index summary $49-$

Table. 2.3.5. Percentage of cells with a spindle in PelA-treated and untreated TUB3GFP cells $53-$

Table. 2.4.1. Amino acids properties used in this study ..................................... 55 -

Table.3.2.1. PCR Master Mix ........................................................................ - 66 -

Table. 3.2.2. Primer sequences for yeast microarray......................................... - 66 -

Table. 3.3.1. Microarray hits after $10 \mu \mathrm{M}$ PelA treatment.................................... - 71 -

Table. 3.3.2. Funspec Gene ontology by biological process-Pel A ..................... - 72 -

Table.3.3.3. Individual validation of HOP-microarray hits. ................................ - 74 - 


\section{List of Abbreviations}

\begin{tabular}{|c|c|}
\hline bp & base pair \\
\hline BY4741 & Haploid yeast wild type strain \\
\hline BY4743 & Diploid yeast wild type strain \\
\hline $\mathrm{C}$ & Cytokinesis \\
\hline CSL & Chemical synthetic lethality \\
\hline DARTS & Drug affinity responsive target stability \\
\hline DMSO & Dimethyl Sulfoxide \\
\hline DNA & Deoxyribonucleic acid \\
\hline DTT & Dithiothreitol \\
\hline EMS & Ethyl MethaneSulfonate \\
\hline Epothilone $\mathrm{A}$ and $\mathrm{B}$ & EpoA and $\mathrm{B}$ \\
\hline FACS & Fluorescence Activated Cell Sorting \\
\hline gDNA & Genomic DNA \\
\hline GFP & Green Fluorescence Protein \\
\hline HDX-MS & Hydrogen-Deuterium exchange Mass Spectrometry \\
\hline HEPES & N-2-Hydroxyethyl piperazine-N'-2-Ethanesulfonic Acid \\
\hline HIP & Haploinsufficiency profiling \\
\hline HOP & Homozygous profiling \\
\hline KanMX & Kanamycin resistant cassette \\
\hline LiAc & Lithium acetate \\
\hline M & Mitosis \\
\hline $\operatorname{mad} 2 \Delta$ & Mitotic Arrest Deficient 2 \\
\hline MDR & Multiple-drug resistance \\
\hline MSA & Microtubule stabilising agent \\
\hline MTA & Microtubule-targeting agents \\
\hline NAT & Nourseothricin antibiotic \\
\hline NatMX & Nourseothricin antibiotic resistant cassette \\
\hline ORF & Open reading frame \\
\hline P. $\mu$ primer & Point mutation primer \\
\hline PCR & Polymerase chain reaction \\
\hline Pgp & P-glycoprotein \\
\hline PEG & Polyethylene glycol \\
\hline PelA & Peloruside A \\
\hline PDR & Pleiotropic Drug Resistance \\
\hline Ptx & Paclitaxel \\
\hline RFP & Red Fluorescence Protein \\
\hline S. cerevisiae & Saccharomyces cerevisiae \\
\hline $\mathrm{SC}$ & Synthetic complete plates \\
\hline SD & Standard deviation \\
\hline SEM & Standard error mean \\
\hline SGA & Synthetic Genetic Array \\
\hline SL & Synthetic lethality \\
\hline SPB & Spindle pole body \\
\hline SSL & Synthetic lethality and synthetic sickness \\
\hline TUB2 & Yeast $\beta$-tubulin gene \\
\hline WT & Wild type \\
\hline WT primer & Wild-type primer \\
\hline YPD & Yeast peptone dextrose \\
\hline YKO & Yeast knockout \\
\hline
\end{tabular}




\section{Abstract}

Peloruside A, a natural product isolated from the marine sponge Mycale hentscheli, is a microtubule-stabilising agent that has a similar mechanism of action to the anticancer drug paclitaxel and is cytotoxic to cultured mammalian cells. Peloruside appears to bind to a distinct site on mammalian tubulin that is different from that of the taxoid-site drugs. Because of the high sequence homology between yeast and mammalian tubulin, Saccharomyces cerevisiae (S. cerevisiae) was used as a model organism to characterise the peloruside-binding site with the aim of advancing our understanding about this site on mammalian tubulin. Wild type S. cerevisiae (BY4741) was sensitive to peloruside at $\mu \mathrm{M}$ concentrations; however, a strain that lacks the mad2 (Mitotic Arrest Deficient 2) gene showed increased sensitivity to the drug at much lower $\mu \mathrm{M}$ concentrations. This gene is a component of the spindleassembly checkpoint complex that delays the onset of anaphase in cells with defects in mitotic spindle assembly. The main aims of this project were to define the binding site of peloruside A using yeast tubulin to see if microtubule function and/or morphology is altered in yeast by peloruside, and to identify any secondary drug targets "friends of the target" through chemical genetic interactions profiling (Homozygous deletion profiling microarray).

Site-directed mutagenesis was used to mutate two conserved amino acids (A296T; $\mathrm{R} 306 \mathrm{H})$ known to confer resistance to peloruside in mammalian cells. Based on a published computer model of the peloruside binding site on mammalian tubulin, we also mutated three other amino acids, two that were predicted to affect peloruside binding (Q291M and N337L), and one that was predicted to affect laulimalide binding but have little affect on peloruside binding (V333W). We also included a negative control that was predicted to have no effect on peloruside binding (R282Q) and would affect epothilone binding. We found that of the six point mutations, only Q291M failed to confer resistance in yeast and instead it increased the inhibition to the drug. Using a bud index assay, confocal microscopy, and flow cytometry, 40-50 $\mu \mathrm{M}$ peloruside was shown to block cells in $\mathrm{G}_{2} / \mathrm{M}$ of the cell cycle, confirming a direct action of the drug on microtubule function. 
Homozygous profiling (HOP) microarray analysis of a deletion mutant set of yeast genes was also carried out to identify gene products that interact with peloruside in order to link the drug to specific networks or biochemical pathways in the cells.

From site-directed mutagenesis, we concluded that peloruside binds to yeast $\beta$ tubulin in the region predicted by the published model of the binding site, and therefore mapping the site on yeast tubulin could provide useful information about the mammalian binding site for peloruside. The bud index, flow cytometry, and confocal microscopy experiments provided further evidence that peloruside interacts with yeast tubulin. From HOP we found that peloruside has roles in the cell cycle, as expected, and has effects on protein transport, secretion, cell wall synthesis, and steroid biosynthesis pathways. 


\section{Chapter 1. General introduction}

\subsection{Background}

Yeast is a versatile and robust model system for studying eukaryotic cellular function. The adaptable genetic flexibility of yeast and the high degree of conservation between its cellular processes and those of human cells has made it a favoured model organism for new research in molecular and cell biology over the past four decades (Menacho-Márquez and Murguía, 2007). Technical advantages such as simple growth conditions, rapid cell division, and the simplicity of developing genetic tools for analysis of biological functions have encouraged the use of yeast as a screening tool in the field of drug discovery (Barberis et al. 2005). The yeast genome has approximately 6000 known genes ( 1000 of these are essential). Approximately $73 \%$ ( 4500 genes) of the genes are non-essential i.e. yeast missing any single nonessential gene is still viable (Sherman, 1998). Over 29 human disease genes have been identified and cloned by functional complementation to their yeast homologues (Mushegian et al. 1997). Yeast is a valuable system for the detection of new drug targets, target-based and non-target-based drug screening, and full analysis of the cellular effects of drugs (Hughes, 2002).

Currently, cancer is considered as one of the major health problems and is one of the major causes of death in the world. According to World Health Organisation (WHO), cancer caused approximately 7.4 million deaths (13\% of all deaths worldwide) in 2004 (WHO). It has been estimated that nearly 11 million people are diagnosed with cancer every year worldwide. Currently, there are more than 24.5 million people in the world living with cancer and probably 1 in 3 people will be diagnosed with cancer at some stage of their life. In 2005, statistics showed that 7.6 million people in the world died from cancer. Moreover, scientists predict that these numbers will continue to rise, with 9 million people dying of cancer by the year 2015 and 11.4 million dying in 2030 (WHO). In addition, New Zealand statistics showed that cancer is the second largest cause of death (with $27 \%$ of all deaths), second only to cardiovascular disease (www.stats.govt.nz). In the past decade, the pharmaceutical companies have been searching for a chemotherapeutic agent with novel properties to treat cancer. Current methods for treating cancer include surgery, radiotherapy and 
chemotherapy. The vast majority of the chemotherapeutic drugs are cytotoxic agents that interfere with DNA replication and cell division (Workman, 2001).

Microtubules are major dynamic structural components of the cytoskeleton. Yeast and other eukaryotic cells use microtubules in a variety of cell functions that are important for the development and maintenance of cell shape, cell reproduction and division (mitosis and meiosis), cell signalling, intracellular transport and cell movement (Anders and Botstein, 2001). Microtubules self-assemble from individual $\alpha / \beta$-tubulin dimers (Fig. 1.1). Tubulin is one of the most abundant cellular proteins. Tubulin plays an important role in cell division, and with the fact that aberrant cell division is the hallmark of cancer, has made tubulin and microtubules prime targets for cancer chemotherapy. In fact, microtubule-targeting drugs like Taxol $^{\circledR}$ (paclitaxel) are the most effective class of anticancer agents and are currently in clinical use (Zhou and Giannakakou, 2005).

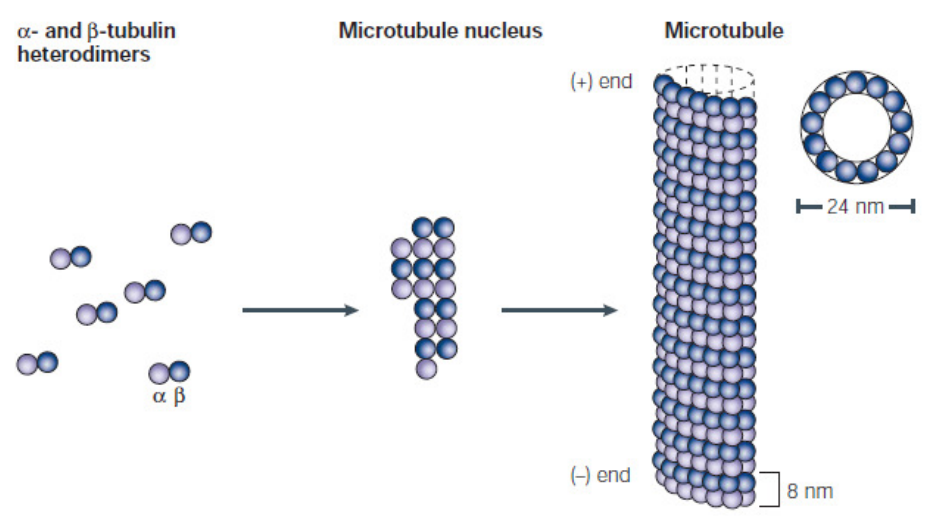

Figure. 1.1. Microtubule polymerisation. Tubulin heterodimers form a microtubule nucleus, followed by the assembly of 13 protofilaments that forms the microtubule. The plus end contains $\beta$ tubulin at the outside and the minus end contains $\alpha$-tubulin on the outside (Jordan and Wilson, 2004).

The vast majority of microtubule-targeting agents (MTA) are natural products, but their chemical structures are remarkably diverse. These MTA are divided into two major groups (Jordan and Wilson, 2004): those that bind to the tubulin dimers and destabilise microtubules, such as the vinca alkaloids, cryptophycins, and colchicines, and those that bind to the microtubule polymer and stabilise microtubules, such as the taxanes (paclitaxel, docetaxel), epothilones, discodermolide, laulimalide, and peloruside. These MTA bind to different sites on the tubulin dimer and at different positions within the microtubule, and they have different effects on microtubule dynamics. However, they all block mitosis at the metaphase/anaphase transition, and because of mitotic block, they induce cell death. Paclitaxel showed excellent preclinical activities (Horwitz, 1992) and is now in general use for treatment of solid tumours of the breast, ovary, and lung (He et al. 2001; Stachel et al. 2001). 
Laulimalide is a potent microtubule-stabilising agent (MSA) that was originally isolated from the sponge Cacospongia mycofijiensis (Mooberry et al. 1999). Similar to other MSA, laulimalide increases the number of interphase microtubules and induces microtubule bundles and abnormal mitotic spindles, effects that lead to mitotic arrest and initiation of cell death i.e. apoptosis (Pryor et al. 2002). Laulimalide binds to a unique site on tubulin relative to the taxoid site where most of the other microtubule stabilising agents bind. Peloruside A (PelA), a MSA from the marine sponge Mycale hentscheli (West et al. 2000), has a similar anti-mitotic effect to paclitaxel, laulimalide, and the other MSA. Competition for binding studies between peloruside, paclitaxel, and laulimalide revealed that peloruside and laulimalide competes with each other for binding, but not with paclitaxel, indicating that peloruside occupies the same or an overlapping site with laulimalide (Gaitanos et al. 2004).

Determining the cellular function of a gene generally requires a method that can alter the gene's product i.e. protein. Chemical genetics implies that a small bioactive molecule (drug) can bind to and alter the function of a gene, effectively creating a functional deletion mutant (synthetic lethal mutants or double mutants (refer to chapter 2 section 2.1.2)). Thus, the small molecule effect is similar to a mutation, and therefore the rules of genetics apply. Disrupting gene function is a valuable research tool in the field of genetics and helps in the understanding of gene function (Giaever et al. 2002). Chemical genetics is divided into two types: forward chemical genetics and reverse chemical genetics (Spring, 2004). Forward genetic screens are often used to characterise a mutated gene (phenotype to genotype); whereas, reverse genetics starts with a mutated gene in order to find a phenotype (genotype to phenotype). Chemical genetic screens can use either forward or reverse genetic approaches. One major advantage of using yeast as a model organism in chemical genetics is that a complete set of gene deletion mutant strains (96\% of yeast open reading frames (ORF)) is available for screening (Winzeler et al. 1999). Yeast knockout studies have been used successfully for many years as a model organism for studying the pathways involved in mammalian diseases (Hartwell, 2002). The deletion mutants were created by homologous recombination in which each gene was deleted from start to stop codon and replaced with a kanamycin resistance cassette (Giaever et al. 2002). Chemical genetic interaction techniques such as microarray apply the rules of chemical genetics to uncover synthetic lethal interactions of a drug. A microarray is a 
collection of DNA spots that generally each represent a single gene. The DNA spots are directly synthesised or covalently attached to chemically suitable matrix or solid surface (Marchionni et al. 2008). The technique is particularly efficient and useful to study drugs that are in limited supply as it allows the whole experiment to be carried out in a small liquid volume (Pan et al. 2004).

Understanding the biological targets and the mode of action of new compounds is essential for the process of developing new therapeutic compounds, and this understanding enhances the development of even more effective second-generation compounds.

\subsection{Microtubule stabilising agents (MSA)}

Tubulin interacts with a wide array of natural products, and as mentioned before, these compounds all differ in terms of their species of origin, molecular structure, and mechanism of interaction with the target. In the last decade, the number of distinct antimicrotubule compounds isolated from natural sources has more than doubled, and many of these compounds have been extraordinarily cytotoxic. They are of great interest as potential agents for the treatment of human diseases, particularly cancer (Wilson and Jordan, 2004), and they provide new tools for the study of the roles of microtubules in cell biology.

MSA promote tubulin polymerisation into microtubules and block microtubule dynamics, leading to abnormal mitosis and subsequent apoptosis (Jordan, 2002). Paclitaxel, the first MSA discovered (Schiff et al. 1979), promotes the in vitro assembly of mammalian tubulin in the absence of GTP, a co-factor that is normally required for microtubule assembly, and the microtubules formed are stable against conditions normally favouring depolymerisation, such as cold temperatures, high $\mathrm{Ca}^{2+}$, and dilute solutions (Schiff et al. 1979). Paclitaxel induces microtubule stabilisation in vivo and causes formation of characteristic microtubule bundles in the cytoplasm of interphase cells (Schiff and Horwitz, 1980). The clinical successes of paclitaxel $\left(\right.$ Taxol $\left.^{\circledR}\right)$ and docetaxel $\left(\right.$ Taxotere $\left.^{\circledR}\right)$ have triggered a search for new agents with similar mechanisms of action but without the disadvantages of paclitaxel (refer to section 1.4) and docetaxel (Buey et al. 2005). Screenings of natural products from various sources like corals, marine sponges, and bacteria have led to the discovery of 
huge number of structurally unrelated drugs that stabilise microtubules and mimic the activity of paclitaxel/docetaxel (Wang et al. 2002; Buey et al. 2005). The MSA drugs are usually classified into three groups with respect to their binding site on tubulin (Buey et al. 2005). The first group includes those that bind to the paclitaxel site in microtubules. This group comprises paclitaxel (taxoid), docetaxel (He et al. 2001), the epothilones (Bollag el al. 1995) and discodermolide (Ter Haar et al. 1996). The second group of compounds includes the two that bind to the laulimalide binding site. This group comprises two compounds, laulimalide (Pryor et al. 2002) and peloruside A (Hood et al. 2002). The third group includes compounds that have, actually or potentially, microtubule-stabilising activity but whose binding to microtubules has not been described. This group includes the plant steroids taccalonolides A and E (Tinley et al. 2003) and the marine sponge compound zampanolide (Field et al. 2009).

Laulimalide and peloruside are effective in paclitaxel-resistant cells that carry $\beta$ tubulin gene mutations that modify the taxoid binding site (Pryor et al. 2002; Gaitanos et al. 2004). MSA can also be classified into three groups based on their chemical structure: i) the terpenoids (taxanes), ii) the macrolides (epothilone, laulimalide, peloruside, and zampanolide), and iii) the polyhydroxylated alkatetraene lactones (discodermolide) (Gaitanos et al. 2004). Both peloruside and the epothilones have a 16-membered ring structure; whereas, laulimalide and zampanolide have a 20-membered ring structure.

Although paclitaxel and the other MSA promote tubulin assembly in mammalian cells (Schiff et al. 1979), paclitaxel has no effect on isolated yeast tubulin (Bode et al. 2002). Epothilone on the other hand, stabilises yeast microtubules in vitro, but it is relatively ineffective in inhibiting yeast growth in vivo. Gupta et al. (2003) showed that the differences in the mode of action of paclitaxel on yeast tubulin and mammalian tubulin lay in five key amino acids that differed between the two types of tubulin. By changing these amino acids in yeast to those found in bovine brain tubulin, paclitaxel was able to polymerise purified yeast tubulin in a similar manner to mammalian tubulin (Gupta et al. 2003). 


\subsection{Mechanism of action for microtubule-targeting drugs}

The main effect of microtubule-targeting drug is to block the cell cycle in mitosis at the $\mathrm{G}_{2} / \mathrm{M}$ phase (Fig. 1.2).
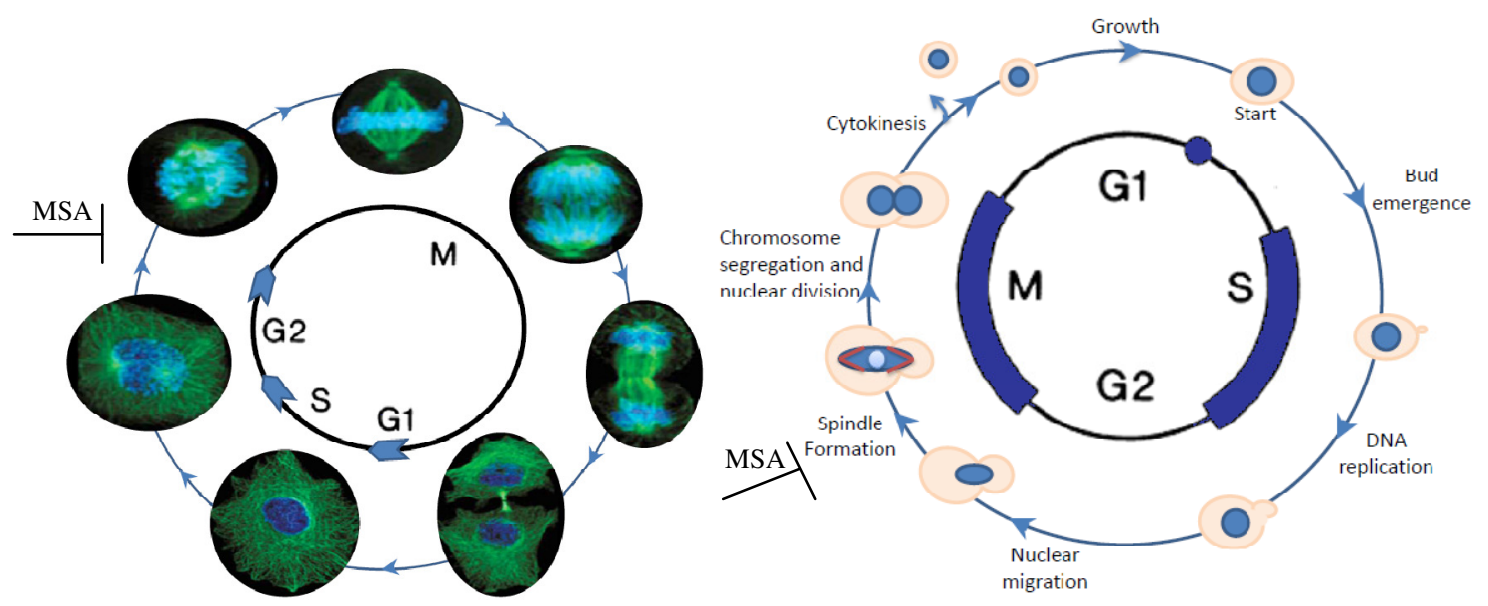

Figure. 1.2. Mammalian (left) and Yeast (right) cell cycle. The cell cycle is divided into interphase and mitosis. In interphase the genetic material of the cell is doubled; in the case of yeast it is the bud emergence state. In mitosis, the genetic component of the cell is divided equally between two daughter cells; in the case of the yeast between the mother and daughter cell. Most MSA arrest the cells at the $\mathrm{G}_{2} / \mathrm{M}$ phase of cell division (mammalian cell cycle figure adopted from Wan Laboratory website, 2003; yeast cell cycle figure adopted from Herskowitz, 1988). Note that cycle diagrams are not representative of the actual time spent in each phase.

Currently, there are four known drug-binding sites on tubulin: three that are well characterised and a fourth that is not yet fully established. The names of the binding sites have been assigned according to the drug that was originally found to bind that specific site. The taxane binding site on $\beta$-tubulin is shared by most drugs that stabilise microtubules and bind preferentially to the microtubule polymer (Fig. 1.3) (Rao et al. 1992; Löwe et al. 2001).

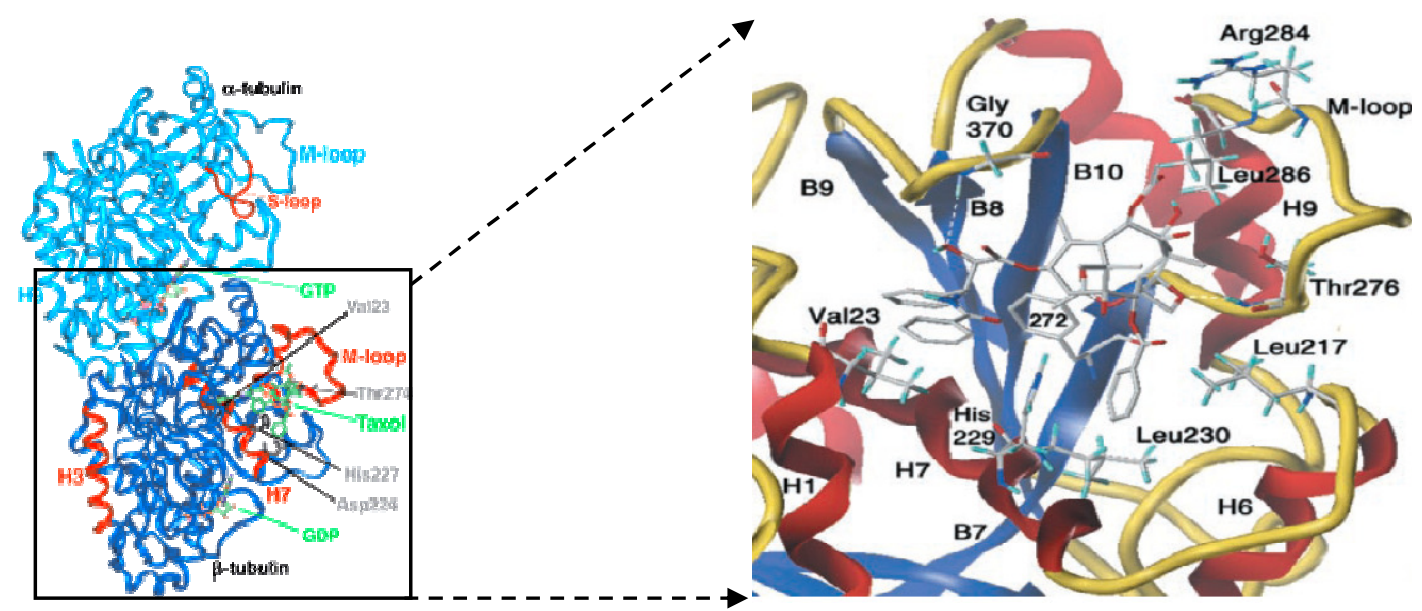

Figure. 1.3. Three-dimensional model of $\boldsymbol{\alpha} / \boldsymbol{\beta}$-tubulin heterodimer. The Taxol-binding site on $\beta$ tubulin is close to the M-loop (red). Figure on the right shows the key amino acids that are involved in the paclitaxel-binding site on $\beta$-tubulin (Orr et al. 2003; Synder et al. 2001).

An example of a drug that binds to this site is paclitaxel (Fig. 1.4) (Eisenhauer and Vermorken, 1998), but other members of the microtubule-stabilising group bind as 
well, including the epothilones (Bollag et al. 1995), discodermolide (Ter Haar et al. 1996), eleutherobin and the sarcodictyins (Long et al. 1998).

(a)

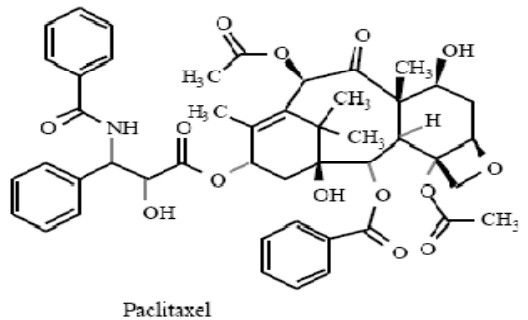

(c)

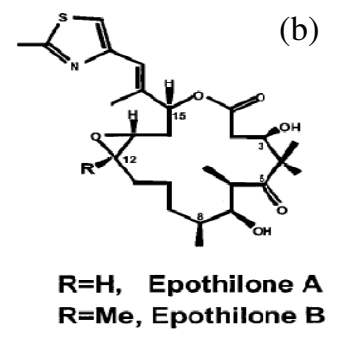

$\mathbf{R}=\mathrm{Me}$, Epothilone $\mathbf{B}$<smiles>C=C/C=C\[C@H](C)[C@H](OC(N)=O)[C@@H](C)[C@H](O)[C@@H](C)C/C(C)=C\C(C)[C@H](O)C(C)/C=C\[C@H](O)CC1OC(=O)[C@H](C)[C@H](O)[C@H]1C</smiles>

Figure. 1.4. Chemical structure of drugs that bind to the taxane binding site on $\beta$-tubulin. (a) paclitaxel, (b) epothilone A and B, and (c) discodermolide (Zhou and Giannakakou, 2005; He et al. 2001).

The two other well-characterised binding sites on tubulin are shared by drugs that bind preferentially to unpolymerised tubulin and thus inhibit tubulin assembly, the colchicine site (Taylor, 1965) and the vinca alkaloid site (Bai et al. 1990). A fourth binding site on tubulin has only recently been discovered. This new site belongs to the MSA laulimalide (Pryor et al. 2002) and peloruside A (Gaitanos et al. 2004) (Fig. 1.5). Laulimalide was the first MSA discovered that bound to a site other than the taxane site on the microtubule polymer.
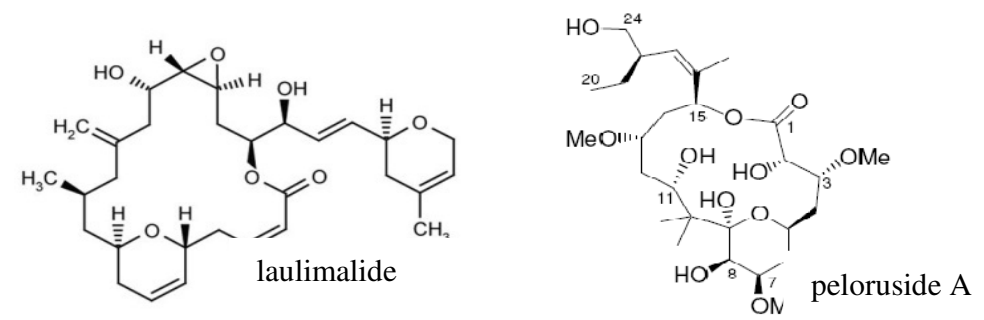

Figure. 1.5. Chemical structre of laulimalide and peloruside A. Both drugs bind to a binding site, other than the taxane site, on the microtubule polymer (Pryor et al. 2002; Gaitanos et al. 2004).

Since laulimalide and peloruside can compete with each other, but not with paclitaxel, for binding (Gaitanos et al. 2004), the binding sites of laulimalide and peloruside are probably identical or at least overlapping. The tubulin isotype involved in this fourth binding site appear to be $\beta$-tubulin (Huzil et al. 2008); however, the evidence is based on computer modelling of drug-tubulin interactions. Other modelling studies have suggested that the site is on $\alpha$-not $\beta$-tubulin (Pineda et al. 2004; Jimenez-Barbero et al. 2006). Huzil et al. (2008) using computer docking studies and deuterium-hydrogen exchange mass spectrometry (HDX-MS) proposed 
the peloruside binding site to be on $\beta$-tubulin. There is still uncertainty as to which binding site is correct, and the sorting out of this controversy is one of the aims of this thesis.

\subsection{Peloruside A}

Peloruside A (peloruside), a polyoxygenated metabolite with a 16-membered macrolactone, was isolated by West, Northcote and Battershill in 1999 (West et al. 2000) from the marine sponge Mycale hentschelli collected in Pelorus Sound on the north coast of the South Island of New Zealand. Sponges of the Mycale genus (Figure 1.6a) are a rich source of bioactive secondary metabolites. In addition to peloruside, $M$. hentschelli had already yielded protein synthesis inhibitor mycalamide $\mathrm{A}$ and $\mathrm{B}$ and the immunosuppressant pateamine (Figure $1.6 \mathrm{~b} \& \mathrm{c}$ ), both antineoplastic cytotoxins that had previously been isolated from specimens of the sponge found at other locations than Pelorus Sound (Page et al. 2005a, b).

(a)

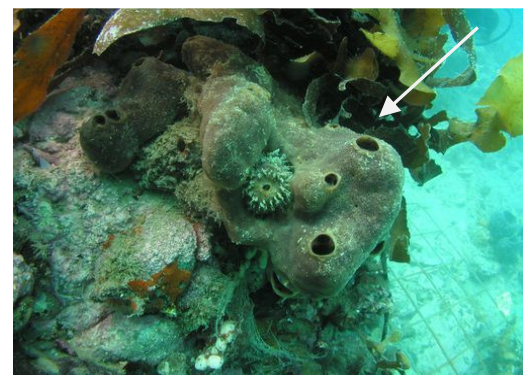

(b)

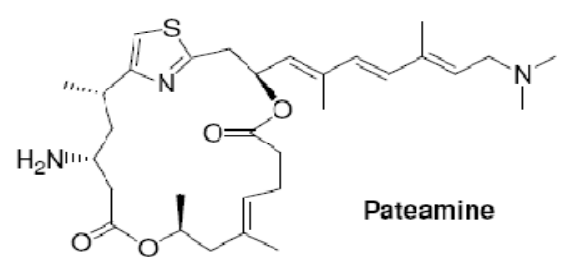

(c)

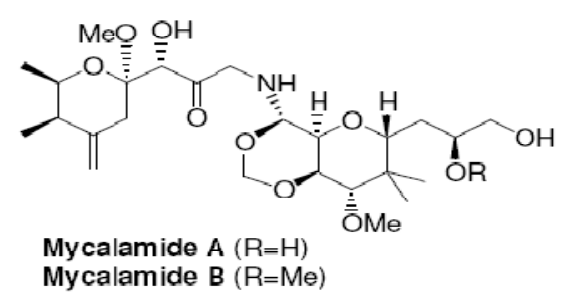

Figure. 1.6. (a) Sea sponge Mycale hentscheli. Mycale sponges grow in Pelorus Sound, Marlborough and produce the natural compound called peloruside A, pateamine and mycalamide (figure from biotechlearn.org). (b) The structures of pateamine and (c) The structures of mycalamide A (Northcote et al. 1991; Perry et al. 1988).

Key structural features of peloruside are found in the 16-membered macrolactone that has its origins in polyketide biosynthesis (Williams et al. 2008). Initial studies have shown that peloruside induces apoptosis in transformed and untransformed cells in a dose-dependent manner (Miller el al. 2004). The action of peloruside on its primary target tubulin is remarkably similar to that of paclitaxel in cell lines and with purified tubulin (Hood et al. 2002); however, it does not activate either caspase-8 or 
caspase-9 to any significant extent in HL60 cells (Miller el al. 2004). After two-day exposures to either peloruside or paclitaxel at $100 \mathrm{nM}$ concentration, human lung adenocarcinoma H441 cells showed multiple micronuclei that increased upon longer exposures. Microtubule fibre bundles and multiple asters (the centres of the ends of the spindle formed during metaphase), were observed to form, observations consistent with those seen for other MSA, including discodermolide and the epothilones (Miller el al. 2004; Williams et al. 2008).

The unique structure and properties of peloruside may convey benefits over the widely used chemotherapeutic agent paclitaxel. Paclitaxel is lipophilic, having low aqueous solubility, and therefore is administered to the patient dissolved in polyoxyethylated castor oil (Cremophor EL). This substance contributes to paclitaxel's undesirable side effects, including hypersensitivity reactions. Moreover, paclitaxel's hydrophobicity contributes to the development of multiple-drug resistance (MDR), a phenotype that tumour cells can develop which results in the efflux of a broad range of organic compounds (including paclitaxel) from the cell. This phenotype has generally been associated with over-expression of the Pglycoprotein (Pgp) efflux pump (Horwitz, 1992). Peloruside is considerably less lipophilic than paclitaxel, suggesting that it should be both easier to administer, and active in MDR cell lines who also acquired a mutation in the paclitaxel binding site on $\beta$-tubulin (Giannakakou et al. 1997; Hood et al. 2002). Indeed, it has been shown that peloruside is less susceptible than paclitaxel to MDR arising from overexpression of the Pgp pump (Gaitanos et al. 2004). Peloruside cytotoxic action was furthermore not affected in cell lines with mutations that alter the taxoid binding site on $\beta$-tubulin (Gaitanos et al. 2004). These observations are similar to those reported for laulimalide, which had been shown to bind to a different site to paclitaxel (Mooberry et al. 1999; Pryor et al. 2002). The binding properties of peloruside (and laulimalide) are therefore distinctly different from other microtubule stabilising agents such as paclitaxel, the epothilones and discodermolide. Importantly, this suggests that they may be very useful chemotherapeutic agents against tumour cells that have developed the MDR phenotype. Peloruside cytotoxicity is comparable to other MSA, with $\mathrm{IC}_{50}$ values ranging from $4 \mathrm{nM}$ to 15 $\mathrm{nM}$ in different mammalian cell lines. To date, all peloruside research has been done with mammalian cell line. Along with the study by Wilmes (PhD thesis, 2008), this is the first study that utilises budding yeast as a model organism to apply the principle of chemical genetics. 


\subsection{Research design}

Extensive research has been directed towards understanding the tubulin-peloruside interaction. The aim of this project is to study the mode of action of peloruside on yeast microtubules and to identify tubulin key amino acid residues involved in peloruside binding. Yeast and human brain tubulin share about $75 \%$ sequence homology (Fig. 1.7) (Barnes et al. 1992).

Homologous recombination occurs more frequently in yeast than in higher eukaryotes (Symington, 2002); hence, homologous recombination been considered as one of the most important tools in yeast genetics (Court et al. 2002). Therefore, yeast can be used to make knockout and/or mutant strains by using PCR to replace a yeast entire gene in through designed oligonucleotides that share sequence homologies with a deletion cassette or to create point mutations into the gene of interest. Peloruside-resistant yeast cells can be generated by site-directed mutagenesis based on the key amino acids in the peloruside binding site on tubulin (using PCR). These mutations may prevent peloruside from binding to tubulin and with high affinity and may interfere with normal microtubule dynamics. For example, paclitaxel-resistant mammalian cell lines, in some cases, contain 'hypostable' microtubules in which the equilibrium between the dimer and polymer is shifted towards the former, making the cells drug-dependent. The stability of the polymer is apparently perturbed to such an extent that normal cell function is compromised, and the cells require low concentrations of paclitaxel for survival (Derry et al. 1995). Since low concentrations of MSA can inhibit microtubule dynamics without altering polymer mass, this drug-dependence phenomenon is not so surprising (Derry et al. 1995; Wilson and Jordan, 1995; Jordan and Wilson, 1998; Goncalves et al. 2001).

Huzil et al. (2008) used a combination of HDX-MS data and local docking simulations to reveal individual peptides that could be directly involved in the binding pocket of the drug on tubulin. These peptides, as shown in Fig. 1.8, are ß294-301 (H9-H9'loop), $\beta 302-314$ (H9'-S8), and $\beta 332-340$ (H10-loop). 


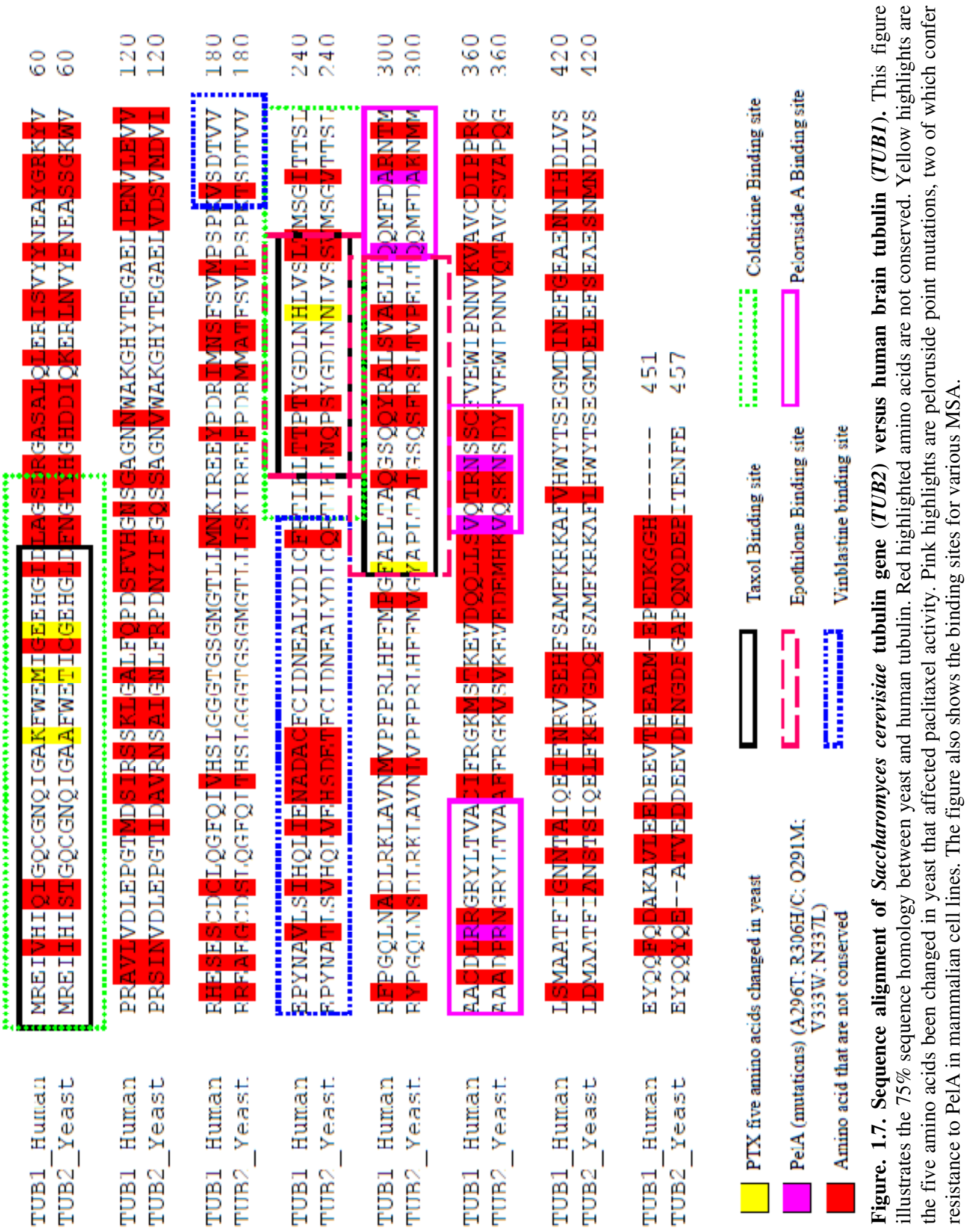




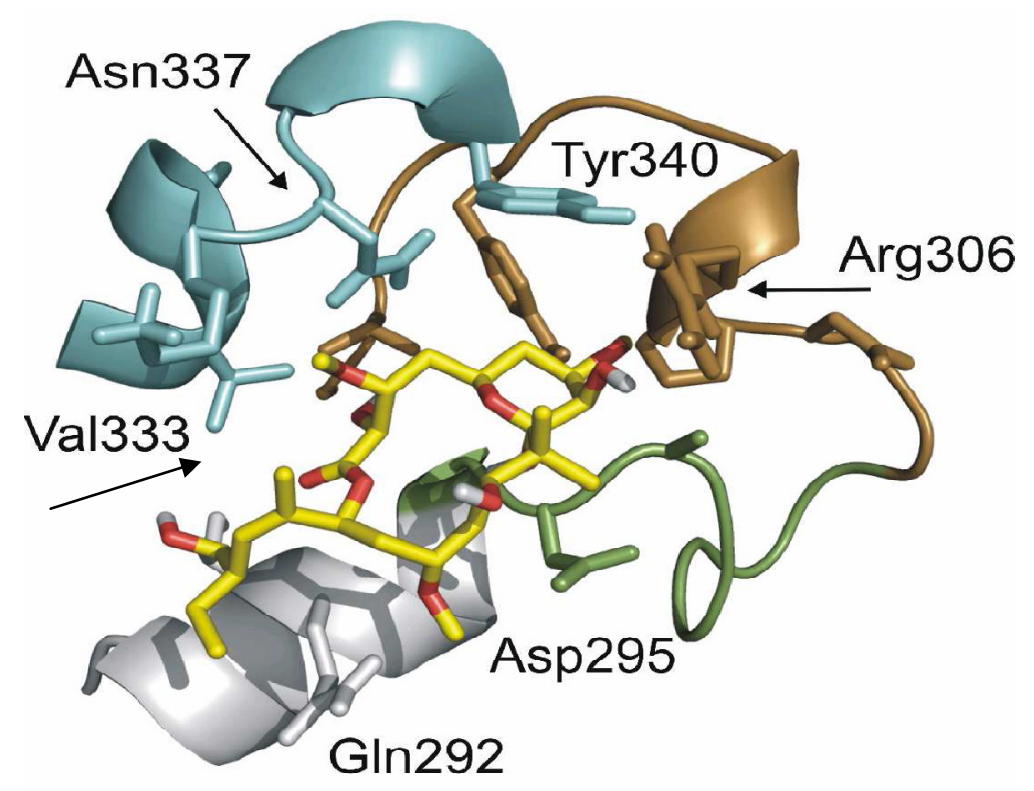

Figure. 1.8. Proposed peloruside binding site on $\beta$-tubulin as determined by a combination of labelling data and local docking simulations. Individual peptides detected by HDX-MS are indicated in colour: green: H9-H9'loop; brown: H9'-S8; cyan: H10-loop. Helix H9 is in gray ( $\beta 286-$ 293). Select side-chains suggested to be significant in defining the binding pocket are labelled. Oxygens of peloruside are coloured in red (Huzil et al. 2008).

Wilmes ( $\mathrm{PhD}$ thesis, 2008) noted that a single point mutation that changed amino acid 296 from alanine to threonine led to increased resistance in the PelA-R1 cells and PelA-R2 cells, giving a 5-fold resistance to peloruside compared to the parental 1A9 cells. Giannakakou from the Weill Medical College of Cornell University (unpublished data) found a single amino acid mutation R306H/C in a 1A9-L4 cell line increased resistance to laulimalide by 40 -fold. Generating a single amino acid change in yeast is relatively much easier to do via PCR because of its genome simplicity and the high incidence of homologous recombination in yeast.

Chemical genetic interactions profiling (like homozygous and heterozygous microarray profiling) usually follow a three-step procedure: i) deletion mutant strains of yeast are grown, ii) a high-throughput screen for ligands (drugs) that affect the biological process of interest is carried out (usually growth), and iii) protein targets of the active ligands are identified (Stockwell, 2000). Both heterozygous profiling (HIP) and homozygous profiling (HOP) rely on microarray DNA analysis, which uses the same three steps. The use of heterozygotes, as well as the homozygous, has proven to be particularly powerful for drug target identification in in vitro and in vivo studies. Yeast genetic screens for resistant cell lines can be carried out either by transferring the mutagenised yeast strains from control medium to drug-containing medium by replica plating, or antibiotics-containing medium can also be used such 
as NatMX or G418 when the drug is in limited supply. Drug-resistant colonies (or antibiotics-resistant) would grow, in the drug-treated medium compared to the control medium. Alternatively, if the drug of interest is in limited supply, as mentioned before, an oligonucleotide (primers) could be designed to carry the desired amino acid point mutation to insert into the yeast genome via transformation. Ultimately, via colony PCR (where DNA genomic purification is unnecessary), and with the aid of the designed synthetic oligonucleotide (primers), a single colony that has the desired point mutation could be selected at random. This precious colony then would be subjected to the drug to test its hypersensitivity or resistance level. From cell division to cancer, yeast has helped researchers to grasp biological principles and the work of this thesis continues that tradition. 


\subsection{Aims of this research}

The aims of this thesis are:

\subsubsection{Identify peloruside binding site on yeast tubulin}

The peloruside binding site will be determined by site-directed mutagenesis of $S$. cerevisiae yeast tubulin. This approach will map the amino acid positions that play an important role in the binding of peloruside to yeast tubulin. Site-directed mutagenesis will be used to mutate $\beta$-tubulin specific amino acids (A296T; R306H) that have been previously identified in resistant mammalian cell lines. Both mutations (individually) confer resistance to peloruside in mammalian cells (Wilmes $\mathrm{PhD}$ thesis, 2008). Besides those two mutations, and based on a published computer model of the peloruside binding site on mammalian tubulin, three other amino acids will also be modified to test their predicted effect on peloruside binding to $\beta$-tubulin. Two out of the three amino acids are predicted to affect peloruside binding (Q291M and N337L), one is predicted to affect laulimalide binding but have little affect on peloruside binding (V333W). In addition, one amino acid is included as a negative control that is predicted to have no effect on peloruside (R282Q). This information will help advance our understanding, by extension, of the mammalian peloruside binding site on tubulin.

\subsubsection{Determining peloruside target}

Provide evidence that peloruside is targeting the microtubules in yeast by a) validating the effect of mutation sites on yeast tubulin; that confer resistance to known mammalian peloruside binding site; b) looking for microtubule morphological effects using confocal microscopy; c) examining cell cycle block in yeast by peloruside, using budding index and flow cytometry.

\subsubsection{Investigate effects of point mutation using other MSA}

Testing the colonies that are resistant to peloruside, with other MSA to determine the effects of the point mutation on peloruside binding site on tubulin, and to look at the differences in the binding interaction between different MSA.

\subsubsection{Identify any secondary drug targets of peloruside HOP microarrays.}

The HOP was used to identify secondary targets. This assay will yield valuable information to identify genes that are required for cell survival or buffer the cell response in the presence of peloruside. 


\section{Chapter 2. Peloruside binding site on yeast tubulin: Site-directed mutagenesis}

\subsection{Introduction}

\subsubsection{Introduction to yeast properties}

Yeast cells are robust, fast growing (one generation every 90 min under normal laboratory conditions) and can be easily manipulated in 96- or 384-multiwell formats. Yeast cultures do not require sterile techniques or complex media and can be stored in standard refrigerators. Furthermore, there is a wide range of strains, vectors and genetic tools that allow researchers to quickly develop yeast-based bioassays (Birrell et al. 2001). This range of techniques facilitates the analysis of complex pathways in yeast that is difficult in more complex organisms. A significant advantage of budding yeast is the ability to incorporate DNA fragments into the genome by homologous recombination. This allows the precise insertion of DNA sequences at specific locations in the yeast genome (Menacho-Márquez and Murguía, 2007).

The budding yeast is a valuable system to study cell cycle regulation. The cell cycle machinery is highly conserved between yeast and humans; hence, yeast studies are directly relevant to anticancer drug discovery since cell cycle dysregulation is a hallmark of cancer. Besides, studies in yeast have greatly contributed to our understanding of the drug biological targets and its modes of action. Understanding the mode of action of clinically relevant compounds is essential for the design of improved second-generation molecules (Qaddouri et al. 2009).

\subsubsection{Introduction to chemical genetics}

Synthetic lethality and synthetic sickness (collectively known as SSL) are genetic interactions in which two separate strains with a single mutation are viable but result in reduced or no growth when those mutations are combined in a double mutant. SSL was the concept behind the development of Synthetic Genetic Array analysis (SGA). SGA is a high-throughput technique for exploring synthetic lethal and synthetic sick 
genetic interactions (SSL) that was initially developed by Tong et al. in 2001. Genetic enhancement is a phenomenon in which a mutant phenotype is altered to enhance growth by the addition of a second mutation that rescues the deleterious effect of the first mutation. The synthetic lethality (SL) technique is able to reveal "friends" of the target gene, that is, genes that are required to buffer cellular responses against the cytotoxic effects of a compound when the compound's target function has been knocked out or knocked down.

Chemical synthetic lethality (CSL) is a concept that aids in the characterisation of a novel compound's bioactivity. In CSL, a compound acts as a 'second mutation' that alters the activity of a specific protein of the corresponding gene. Mutants hypersensitive to a drug represent CSL interactions and point directly to the drug target (Fig. 2.1.1).

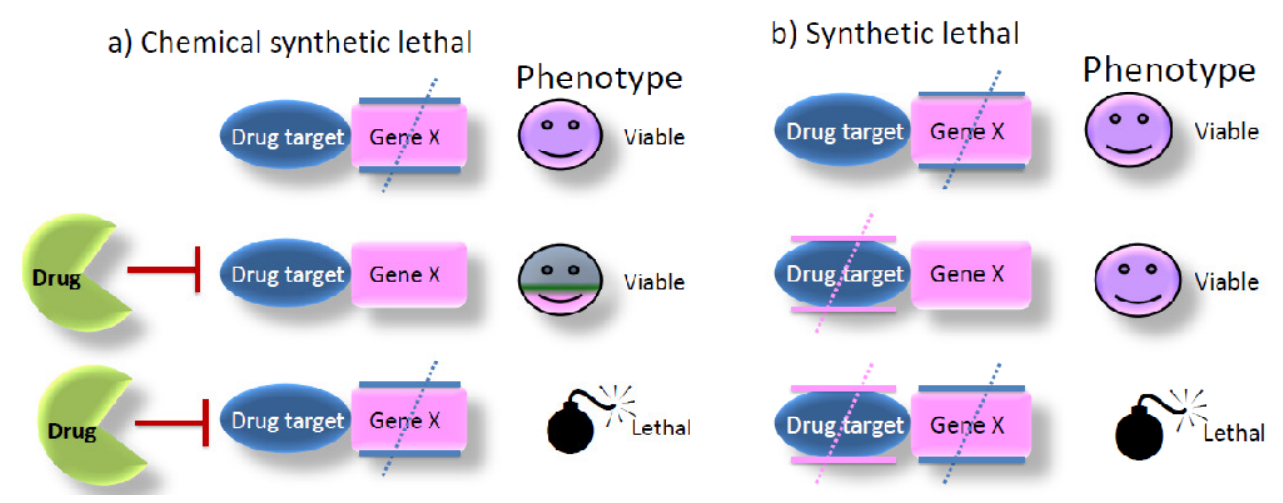

Figure. 2.1.1. Chemical synthetic lethality (CSL) versus synthetic lethality (SL). In CSL, a drug (or compound) acts as the second mutation (figure adopted from Boone et al. 2007).

\subsubsection{Peloruside A properties and applications}

Peloruside A (PelA), is a potent antitumor macrolide that shares a molecular target with $\operatorname{Taxol}^{\circledR}$, a cancer therapy agent that is been developed for use against ovarian and breast cancer. Taxol ${ }^{\circledR}$ gross sales were more than \$US2 billion a year, but the pharmaceutical industry is looking for a replacement with similar mechanisms of action but improved properties. Peloruside is one of the compounds that is being assessed as a second generation Taxol $^{\circledR}$-like anti-cancer agent. PelA is under development as an anti-cancer drug by REATA Pharmaceuticals Inc., a Dallas-based biopharmaceutical company in Texas, USA and REATA are hoping to start clinical trials soon. 
The chemical properties of PelA (Fig. 2.1.2) show that this drug has five donor hydrogen bonds (a hydrogen atom attached to a relatively electronegative atom like oxygen is a hydrogen bond donor), and eleven hydrogen acceptor bonds (an electronegative atom such as oxygen or nitrogen is a hydrogen bond acceptor). Hydrogen bonds form important interaction points with the targeted protein in the binding site region. In one study that used a combination of hydrogen-deuterium exchange mass spectrometry (HDX-MS) labelling data and local docking simulations, it was proposed that PelA binds to the H1-S2 loop and the M loop of $\beta$ tubulin (Huzil el al. 2008). The binding was localised (as mentioned in Chapter 1 section 1.5) to the exterior surface of $\beta$-tubulin, at peptides $\beta 294-301, \beta 302-314$, and 3332-340 (Huzil el al. 2008). However, other modelling studies have suggested that the site is on $\alpha$ - not $\beta$-tubulin (Pineda et al. 2004; Jimenez-Barbero et al. 2006). Taking advantage of yeast homologous recombination and using site-directed mutagenesis, one or more of these amino acids (shown in Fig. 2.1.2) and (Table. 2.1.1) can be tested to confirm the importance of these binding interactions and further validate the direct involvement of these specific amino acids in the binding interactions with PelA.

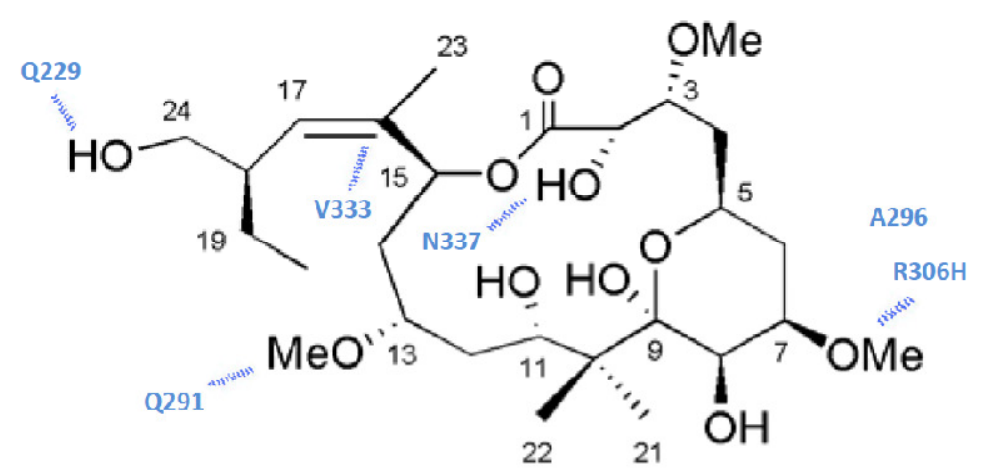

Figure. 2.1.2. 2D-schematic view of $\beta$-tubulin-peloruside interactions. Interactions are based on computer docking modelling. Q229, N337 and Q291 are H-donors; whereas, R306 is an H-acceptor. The choice of amino acid residues for $\beta$-tubulin mutagenesis was adopted from computer modelling studies carried out by Prof Jim Snyder and Dr Pahk Thepchatri at Emory University, Chemical Biological Discovery Centre, Department of Chemistry, Atlanta, Georgia, USA (unpublished data).

Table. 2.1.1. Predicted PelA-sensitive sites on $\beta$-tubulin.

\begin{tabular}{c|c|c|c} 
Functional Group & Residues & Importance & Predicted effect \\
\hline \hline 7 OMe & R306 & $\begin{array}{c}\text { Direct interaction with } \\
\text { R306 }\end{array}$ & Resistance to PelA \\
\hline $2 \mathrm{OH}$ & $\mathrm{N} 337$ & H-bond & Resistance to PelA \\
\hline $13 \mathrm{OMe}$ & Q291 & H-bond & Resistance to PelA \\
\hline $16 \mathrm{Me}$ & V333 & weak hydrophobic bond & $\begin{array}{c}\text { Resistance to laulimalide } \\
\text { but have less of an effect } \\
\text { to PelA }\end{array}$
\end{tabular}

This table shows likely sites on $\beta$-tubulin that should be involved with PelA binding, based on the computer modelling data of Snyder and Thepchatri at Emory University, Chemical Biological Discovery Centre, Department of Chemistry, Atlanta, Georgia, USA (unpublished data). 
Besides these point mutations listed above that should interfere with PelA binding to yeast tubulin, a negative control is also required to determine the non-specific effect of inducing a single point mutation in yeast tubulin, since this amino acid is not located in the proposed binding site. Previous studies done by Giannakakou et al. (1997; 2000) have developed $\beta$-tubulin mutations in amino acid $\beta 282$ in the 1A9 human ovarian carcinoma cell line (B10 cell line) that have resulted in resistance to epothilone A and B (EpoA and B). In our laboratory, a PelA-resistant cell line (PelAR1 cells) was generated in 1A9 cells by exposing the parental cells to gradually increasing concentrations of drug in the presence of verapamil, a drug that blocks the P-glycoprotein (Pgp) drug efflux pump.

Using this method it should have been possible to generate resistant cells that carry a mutation in either $\alpha$-tubulin or $\beta$-tubulin. However, the amino acid change in PelAR1 cells was at position 296 in $\beta$-tubulin that changed alanine to threonine and resulted in 5-fold resistance to PelA compared to the parental 1A9 cells (Wilmes $\mathrm{PhD}$ thesis, 2008). In addition, in another study with 1A9 cells by Dr Paraskevi Giannakkaou (unpublished data), mutations at amino acid R306 in $\beta$-tubulin gave $66 \% \mathrm{R} 306 \mathrm{H}$ expression and 33\% R306C expression in the mutant cells. This 1A9-L4 cell line was found to be approximately 40-fold resistance to laulimalide, a microtubule-stabilising drug that binds to a similar site on tubulin to PelA (Gaitanos et al. 2004). The site of such a mutation would provide valuable information about the possible interaction of PelA and laulimalide with the microtubule and whether the $\alpha$ - or $\beta$-monomer was involved. Thus, identification of two independently derived cell lines resistant to PelA following mutations in the Huzil et al. (2008) location on $\beta$-tubulin provides good evidence that the PelA binding site is on $\beta$-, not $\alpha$-tubulin. Using this information together with computer docking approaches could help decipher the PelA binding site on tubulin and determine whether PelA and laulimalide bind to the same or an overlapping site on the tubulin molecule.

\subsubsection{Introduction to yeast tubulin genes}

The $S$. cerevisiae TUB2 gene encodes the single essential $\beta$-tubulin of yeast (Neff et al. 1983). Tub2p belongs to the tubulin superfamily, which, in addition to $\beta$-tubulin, includes $\alpha$-tubulin (TUB1 and TUB3) (Schatz et al. 1986a, b) and $\gamma$-tubulin. $\beta$ - and $\alpha$ tubulin form tubulin heterodimers that polymerise into microtubules. Yeast tubulin 
shows about $75 \%$ homology to human brain tubulin (Barnes et al. 1992). All microtubules in S. cerevisiae emanate from a microtubule-organising centre called the spindle pole body (SPB) that is embedded in the nuclear envelope (Knop et al. 1999). There are several synthetic lethal interactions with either $\alpha$ - or $\beta$-tubulin in yeast. A strain that lacks the Mitotic Arrest Deficient $2(\operatorname{mad} 2 \Delta)$ gene is known to have synthetic lethal interactions with either of the two main tubulin genes in yeast (Hardwick et al. 1999; Parsons et al. 2004). This gene is a component of the spindleassembly checkpoint complex that delays the onset of anaphase in cells with defects in mitotic spindle assembly. The haploid deletion mutant $(\operatorname{mad} 2 \Delta)$ strain was used in this study as a background strain, because earlier studies showed this strain was sensitive to PelA at much lower concentrations than the haploid wild type strain (BY4741) (Wilmes PhD thesis, 2008).

\subsubsection{Introduction to other microtubule-stabilising agents}

Microtubules play key roles in many cellular processes including cell division. Normal cell division is dependent on the dynamic instability of microtubules during the course of mitosis and cytokinesis. Interruption of microtubule dynamics has proven to be an effective target for cancer chemotherapy (Wilson and Jordan, 1995). Microtubule-stabilising agents (MSA) bind to polymerised tubulin and stabilise the microtubule spindles, leading to mitotic arrest followed by cell death. The growing clinical expediency of the taxoids (Eisenhauer and Vermorken, 1998) and the discovery of new natural products such as the epothilones (Bollag et al. 1995), laulimalide (Mooberry et al. 1999), and PelA (West et al. 2000) with the same mechanism of action have all occurred simultaneously. The key aspect of the mechanism of action of the different MSA is the binding of these compounds to microtubules, resulting in stabilisation of the tubulin polymers (Schiff et al. 1979) and blocking of their dynamic properties (Derry et al. 1995). Cells exposed to such drugs are unable to form a normal mitotic spindle, cannot divide after DNA replication, and soon undergo apoptosis.

Laulimalide is a cytotoxic natural product that acts like other MSA. The compound enhances tubulin assembly, and laulimalide is quantitatively comparable to paclitaxel in its effects on the reaction. Laulimalide is also active in Pgp overexpressing cells in which paclitaxel is ineffective. Previous studies have shown that laulimalide and 
paclitaxel probably bind at different sites on the tubulin polymer (Pryor et al. 2002). Mooberry et al. (1999) reported that laulimalide induced tubulin assembly, caused cells to accumulate at the $\mathrm{G}_{2} / \mathrm{M}$ phase of the cell cycle, and caused paclitaxel-like microtubule bundles to appear in cultured cells.

The epothilones have also generated significant interest, as they also retain activity against paclitaxel-resistant cell lines (Bollage et al. 1995; Kowalski et al. 1997; Ter Haar et al. 1996). Ixabepilone (aza-EpoB) is the first epothilone analogue that has made it into the clinic (Ixempra®, Bristol-Myers Squibb). Although having a similar mode of action to paclitaxel, ixabepilone is structurally distinct from the taxanes and therefore has unique properties. Importantly, ixabepilone binds to the taxoid-site but has reduced susceptibility to the drug efflux transporter Pgp, which is frequently associated with multidrug resistance and limits the effectiveness of taxanes, vinca alkaloids, and other chemotherapeutic agents (Lee et al. 2008).

\subsubsection{Aims of this chapter}

To date there still uncertainty as to the location of the PelA binding site. Some computer modelling suggested that it is on $\beta$-tubulin (Huzil et al. 2008); however, previous modelling studies have suggested that the site is on $\alpha$ - not $\beta$-tubulin (Pineda et al. 2004; Jimenez-Barbero et al. 2006). Sorting out of this controversy is one of the aims of this thesis.

The first aim of this chapter is to test whether PelA binds to yeast tubulin at the site proposed by Huzil et al. (2008) and to determine if a mutation of the specific amino acids at this site will generate resistance to the action of the drug. This will advance our understanding of the PelA binding site on mammalian tubulin. To achieve the first aim, yeast will be used to map the key amino acids that play an important role in the binding of PelA to yeast tubulin. Using site-directed mutagenesis at single amino acid sites likely to be involved in PelA binding (e.g. A296 and R306 of $\beta$-tubulin), we will be looking at validating the effect of mutations of these amino acids on yeast sensitivity to PelA.

The second aim is to take advantage of PelA modelling studies to test other mutations that would be predicted to affect PelA binding to $\beta$-tubulin, based on the modelling of Huzil et al. (2008) and Snyder and Thepchatri (unpublished data). 
However, some but not all amino acids that confer resistance to PelA will also confer resistance to laulimalide. It would be interesting to test mutations in both $\alpha$ - and $\beta$ tubulin to see which set of mutations lead to PelA resistance, but this would be beyond the scope of an MSc project. We therefore concentrated on the proposed $\beta$ tubulin site, in part because of the existence of two mammalian cell lines that linked mutations at this site with PelA resistance in mammalian cells. Since site-directed mutagenesis would be very difficult to carry out in mammalian cells, we used yeast as our model organism.

The third aim is to examine the differences in the binding interactions between different MSA by testing other MSA, such as laulimalide and epothilone, crossresistance in the PelA-resistant colonies. Mapping the PelA-tubulin binding site in yeast will enhance our understanding of the MSA interactions with mammalian tubulin. Unfortunately, paclitaxel cannot be tested since it is ineffective in yeast without humanising the taxoid site sequence of $\beta$-tubulin (Bode et al. 2002; Gupta et al. 2003).

Our fourth aim is to provide some growth-independent evidence that PelA effects are at the level of the microtubules and not some other unrelated target. We will therefore look for changes in microtubule morphology by confocal microscopy and examine cell cycle block by bud index measurements, and flow cytometry to provide more direct evidence that PelA targets tubulin in yeast and is not affecting growth by a microtubule-independent mechanism. 


\subsection{Materials and Methods}

\subsubsection{Compounds}

PelA and laulimalide were provided by Assoc Prof Peter Northcote, School of Chemical and Physical Sciences, Victoria University, Wellington. Ixabepilone (azaepothilone, a derivative of epothilone B) was purchased from Bristol-Myers Squibb (NZ) Limited, 88 Shortland Street, Auckland. Marine sponges (Mycale hentscheli) containing PelA were collected from Pelorus Sound, Marlborough Sounds, NZ, and PelA was purified from the sponges as previously described by West et al. (2000). Laulimalide was purified from Cacospongia mycofijiensis sponges collected from 'Eua, Tonga. All drugs were dissolved in DMSO at $10 \mathrm{mM}$ and stored at $-80^{\circ} \mathrm{C}$.

\subsubsection{Yeast strains used in this study}

\begin{tabular}{|c|c|c|}
\hline ORF & Strain & Genotype \\
\hline YCG160 & BY4741 & $M A T$ a $u r a 3 \Delta 0$ leu $2 \Delta 0$ his $3 \Delta 1$ met $15 \Delta l$ \\
\hline YJL030W & $\operatorname{mad} 2 \Delta$ & 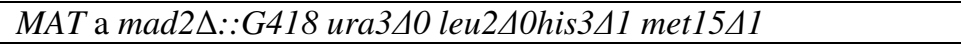 \\
\hline YCG141 & $p d r l \Delta$ & 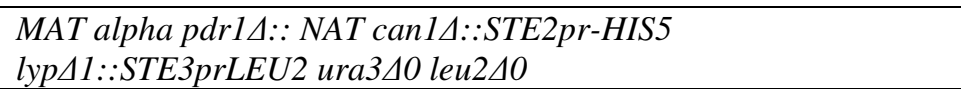 \\
\hline YOR153W & $p d r 5 \Delta$ & MAT a pdr5::G418 ura340 leu240his341 met1541 \\
\hline $\begin{array}{l}\text { YCG198 } \\
\end{array}$ & $p d r l \Delta \& p d r 3 \Delta$ & 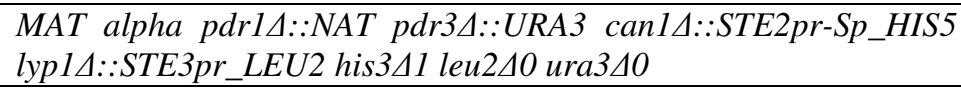 \\
\hline YML124C & TUB3-GFP & $\begin{array}{l}\text { MAT a TUB3-GFP ura3A }:: N L S-\text { RedStar } 2:: \text { hph lyp } 1 \Delta 0:: \text { mCherry- } \\
\text { NAT his } 3 \Delta 1 \text { met } 15 \Delta 0 \text { leu } \triangle \triangle 0\end{array}$ \\
\hline
\end{tabular}

All haploid deletion mutant strains, as well as the haploid wild type (BY4741), were obtained from a $-80^{\circ} \mathrm{C}$ glycerol freezer stock, and streaked out on $10 \mathrm{~cm}$ yeast extract peptone dextrose plates (YPD: see Appendix I) or synthetic complete plates (SC: see Appendix I) supplemented with the appropriate antibiotics for growth selection $(200 \mu \mathrm{g} / \mathrm{mL} \mathrm{G} 418$ antibiotic (Geneticin, Gibco, Invitrogen) and/or 100 $\mu \mathrm{g} / \mathrm{mL}$ nourseothricin (NAT) antibiotic (Werner BioAgents)). Once strains were streaked, the plates were incubated at $30^{\circ} \mathrm{C}$ (Contherm Digital Incubator) for $48 \mathrm{hr}$ to allow the yeast to grow, and then the plates were kept at $4^{\circ} \mathrm{C}$. The background strain of the haploid deletion mutant strains listed above is the haploid wild type (BY4741). The deletion mutant strains $p d r 5 \Delta$ and mad2 $\Delta$ were part of the yeast genome deletion collection obtained from Open Biosystems.

\subsubsection{Primer design of PelA-resistant tubulin (TUB2) mutants by overlap PCR}

To insert a mutation in the TUB2 gene by overlap PCR, a set of point mutation primers were designed for each mutation as follows. Overlap PCR was used to introduce the desired point mutation into the yeast genome at the TUB2 locus, and to insert the NatMX cassette (selectable marker) 300 bp downstream (3' end) of the TUB2 gene. The seven site-directed point mutations were A296T, R306H, 
A296T+R306H (double mutant), R282Q, Q291M, V333W and N337L. For each point mutation, a $5^{\prime} \rightarrow 3^{\prime}$ primer A (all primer sequences are in Appendix II) was designed to have $45 \mathrm{bp}$ homology with the TUB2 gene. This is the minimum length for effective homologous recombination to occur for the introduction of the point mutation into the yeast genome (Fig. 2.2.1 shows a schematic view of the overlap PCR technique). A $3^{\prime} \rightarrow 5^{\prime}$ primer B (primer B is complementary to primer C) was designed to have $21 \mathrm{bp}$ homology to NatMX cassette plus 25 bp homology to genomic DNA downstream of the TUB2 gene. Two insertion primers (primer $\mathrm{C}$ and primer D) were designed to have $21 \mathrm{bp}$ (22 bp for primer D) sequence homology to the NatMX cassette plus 25 bp (45 bp for primer D) homology to genomic DNA downstream of the TUB2 gene. NatMX encodes a nourseothricin (NAT) antibiotic resistance marker that is used as a standard selection agent for molecular genetic research work (Werner BioAgents). PCR amplification was carried out using purified plasmid p4339 (refer to Appendix III) containing the NatMX cassette as a template. The PCR products were used to transform the haploid starting strain mad2 $\Delta$. PCR was carried out in a $0.2 \mathrm{~mL}$ Thermo Scientific ABgene PCR tube using a PCR Thermal Cycler (Eppendorf Mastercycler EP ${ }^{\circledR}$ gradient S-96 well, Germany). The PCR cycling times were done according to the method of Janke et al. 2004: $15 \mathrm{~min}$ of initial activation at $95^{\circ} \mathrm{C}$, followed by 10 cycles of: 1 min of DNA denaturation at $97^{\circ} \mathrm{C}, 30 \mathrm{~s}$ of annealing at $56^{\circ} \mathrm{C}$, and $2 \mathrm{~min}$ and $40 \mathrm{~s}$ of extension at $68^{\circ} \mathrm{C}$. This is then followed by another 25 cycles of: $1 \mathrm{~min}$ of DNA denaturation at $97^{\circ} \mathrm{C}, 30 \mathrm{~s}$ of annealing at $56^{\circ} \mathrm{C}$, and $2 \mathrm{~min}$ and $40 \mathrm{~s}$ of (with the addition of $20 \mathrm{sec} / \mathrm{cycle}$ ) extension at $68^{\circ} \mathrm{C}$. Once the 35 amplification cycles finish, a final $10 \mathrm{~min}$ of extension at $72^{\circ} \mathrm{C}$, and pause at $4^{\circ} \mathrm{C}$. Following PCR, $5 \mu \mathrm{L}$ of each PCR product was electrophoresed on a $1 \%$ agarose gel for $1 \mathrm{hr}$ at $100 \mathrm{~V}$. The PCR reaction was performed by means of a Qiagen HotstarTaq DNA polymerase kit using the following reaction conditions:

\begin{tabular}{lcc} 
Reagents & Amount $(\mu \mathrm{L})$ & Final Concentration \\
\hline 10 x PCR buffer & 5 & $1 \mathrm{x}$ \\
dNTPs Mix $(20 \mathrm{mM})$ & 1 & $0.4 \mathrm{mM}$ \\
Forward Primer $(100 \mu \mathrm{M})$ & 1 & $2 \mu \mathrm{M}$ \\
Reverse Primer $(100 \mu \mathrm{M})$ & 1 & $2 \mu \mathrm{M}$ \\
Hotstar Taq enzyme $(5 \mathrm{U} / \mu \mathrm{L})$ & 0.5 & $2.5 \mathrm{U} /$ reaction \\
DNA Template $^{\star}$ & 1 & - \\
Distilled water & 40.5 & -
\end{tabular}




\section{PCR amplification program (Janke et al. 2004)}

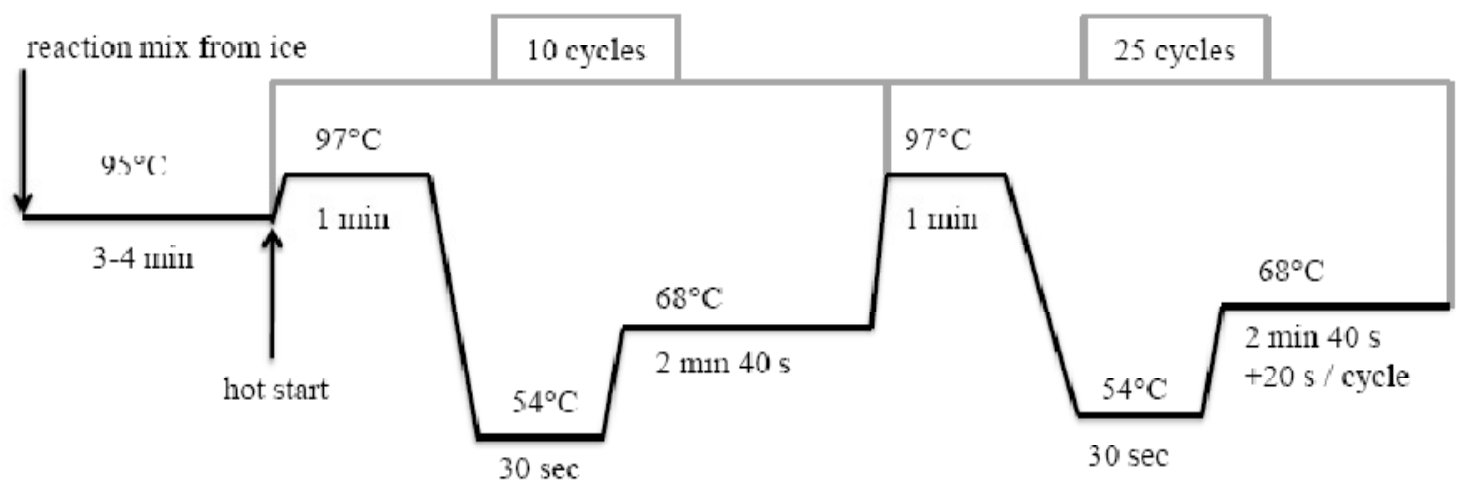

These special conditions were specifically used for the amplification of NatMX cassettes (figure adopted from Janke et al. 2004).

(i)

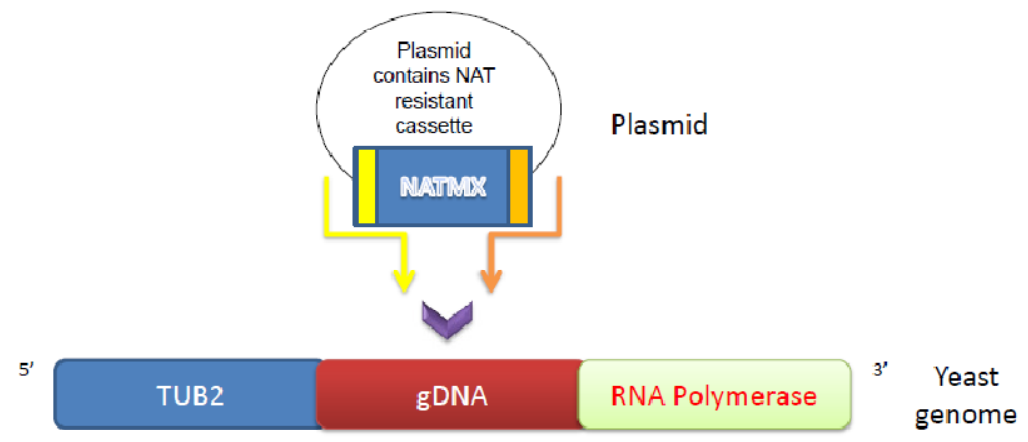

\section{(ii) Overlapping PCR}

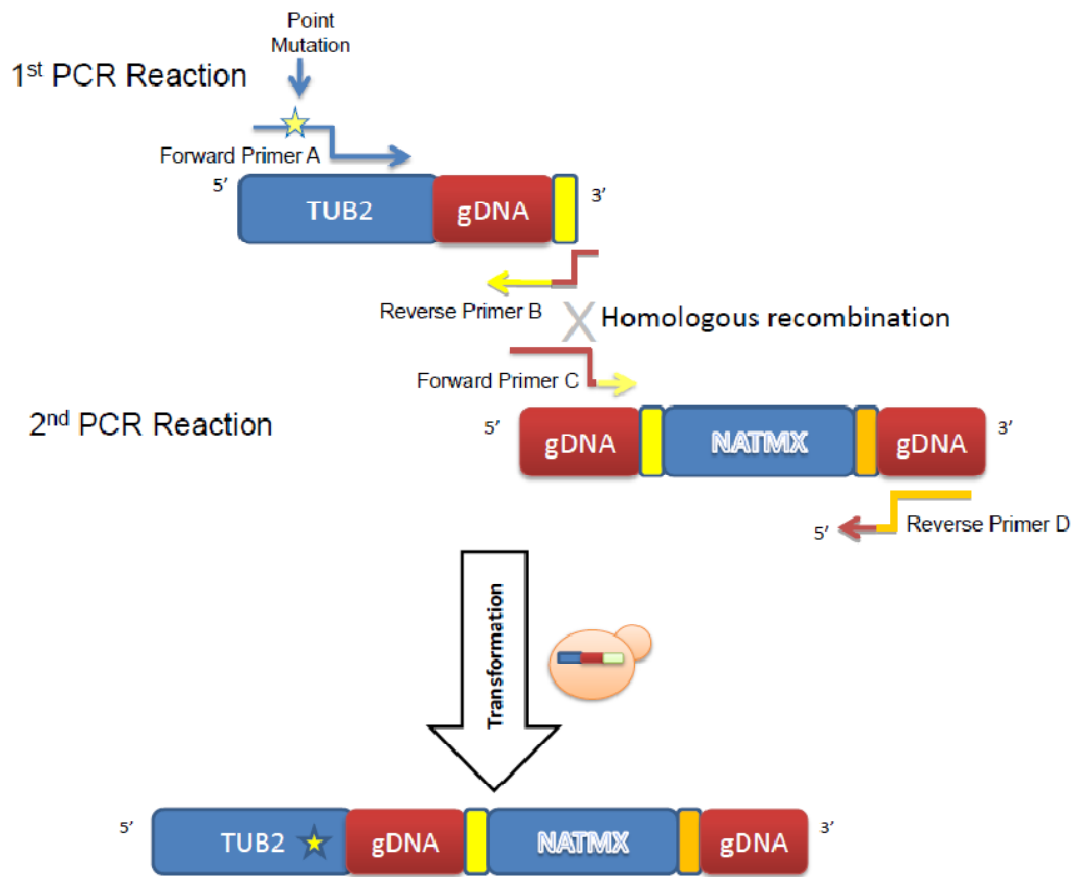

Final product

Figure. 2.2.1. Schematic view for overlap PCR. (i) Experimental schematic procedure was used to insert the NatMX cassette into the yeast genome downstream TUB2 gene. (ii) The two overlap PCR reactions were carried out separately. The first reaction (primers A and B) was designed to introduce the point mutation, and the second PCR reaction (primers $C$ and D) was designed to amplify and insert the NatMX cassette. The two PCR products were then inserted into the yeast genome at the TUB2 locus by allowing homologous recombination to occur. 


\subsubsection{Transformation}

High efficiency transformation protocol was performed according to the method of Gietz and Woods (2002). Briefly, to generate transformants, a single colony of the haploid starting strain $\operatorname{mad} 2 \Delta$ was inoculated into a BD Falcon ${ }^{\mathrm{TM}} 50 \mathrm{~mL}$ conical tube with $10 \mathrm{~mL}$ YPD medium and grown overnight at $30^{\circ} \mathrm{C}$ on a shaker (Edwards Instrument Company, Australia). The next morning, the cells were diluted by pipetting $5 \mu \mathrm{L}, 10 \mu \mathrm{L}$, or $15 \mu \mathrm{L}$ into $50 \mathrm{~mL}$ YPD in three separate conical flasks and grown for $18 \mathrm{hr}$ at $30^{\circ} \mathrm{C}$ on a shaker. When the cells had grown to give an OD of 1-2 at $600 \mathrm{~nm}$ wavelength, $10 \mathrm{~mL}$ of the cells were pelleted in a benchtop Eppendorf centrifuge (Model 5810R) for $5 \mathrm{~min}$ at $2500 \mathrm{rpm}$. After discarding the supernatant,

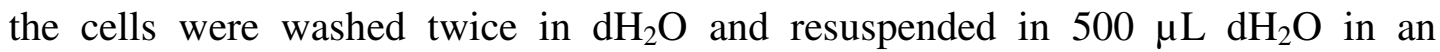
Eppendorf tube. Li-PEG solution $(276 \mu \mathrm{L})(1.2 \mathrm{~mL}$ 90\% PEG (50\% w/v), $0.15 \mathrm{~mL}$ $\mathrm{dH}_{2} \mathrm{O}$, and $0.15 \mathrm{~mL} 1 \mathrm{M} \mathrm{LiAc}$ ) was added to the pelleted cells, and the suspension was mixed by pipetting the solution gently. Then $50 \mu \mathrm{L}$ of salmon sperm DNA (salmon sperm DNA at a concentration of $90 \mathrm{mg} / \mathrm{mL}$ was boiled for $10 \mathrm{~min}$ and stored on ice) and $34 \mu \mathrm{L}\left(10 \mu \mathrm{L}\right.$ of each of the PCR products $+14 \mu \mathrm{L}$ of $\left.\mathrm{dH}_{2} \mathrm{O}\right)$ of PCR product were added to the Li-PEG mixture. The solution was then heat-shocked in a $42^{\circ} \mathrm{C}$ water bath for $40 \mathrm{~min}$. At the end of the heat-shock treatment, the cells were spun down at maximum speed in an Eppendorf Centrifuge (Model 5415R) for 1 min, the supernatant was removed by pipette, and the pellet was re-suspended in 1 $\mathrm{mL}$ YPD and incubated at $30^{\circ} \mathrm{C}$ for $2 \mathrm{hr}$. After $2 \mathrm{hr}$, the cells were spun down at $13,000 \mathrm{rpm}$, the supernatant was removed and the pellet was re-suspended in $250 \mu \mathrm{L}$ YPD. Transformed cells were plated on a selection plate (YPD+ ClonNAT 200 $\mathrm{mg} / \mathrm{mL}$ ) and left to grow in a $30^{\circ} \mathrm{C}$ incubator for 2 days.

\subsubsection{Confirmation PCR primer design}

In order to confirm the successful transformant colonies, colony PCR was used. The growth of transformed cells on a selection plate (YPD+ ClonNAT $200 \mathrm{mg} / \mathrm{mL}$ ) was excellent evidence that the transformation efficiency was very high; however, confirmation via a colony PCR approach is more reliable and further confirms that the transformed colony has the desired point mutation. It also reduces the amount of PelA needed since its resources are very limited. The advantage of this technique is that it does not require genomic DNA purification of individual colonies. For this 
PCR, two transformation confirmation primers were designed as follows: from the $3^{\prime} \rightarrow 5^{\prime}$ end of the gene, two primers were designed. The first primer was designed to start at the changed amino acid (i.e. at the point mutation) and was designed to either have the point mutation base pairs ( P. $\mu$ primer) or designed similarly but with the wild-type sequence (WT primer) i.e. having the normal TUB2 sequence rather than the point mutation sequence (all primer sequences are in Appendix II). The length of each primer was $18 \mathrm{bp}$. Approximately $400 \mathrm{bp}$ up-stream of these reverse primers, a $18 \mathrm{bp}$ forward primer was designed $\left(5^{\prime} \rightarrow 3^{\prime}\right.$ to go in the forward direction of the gene). Fig. 2.2.2 shows a schematic view of the primer design.

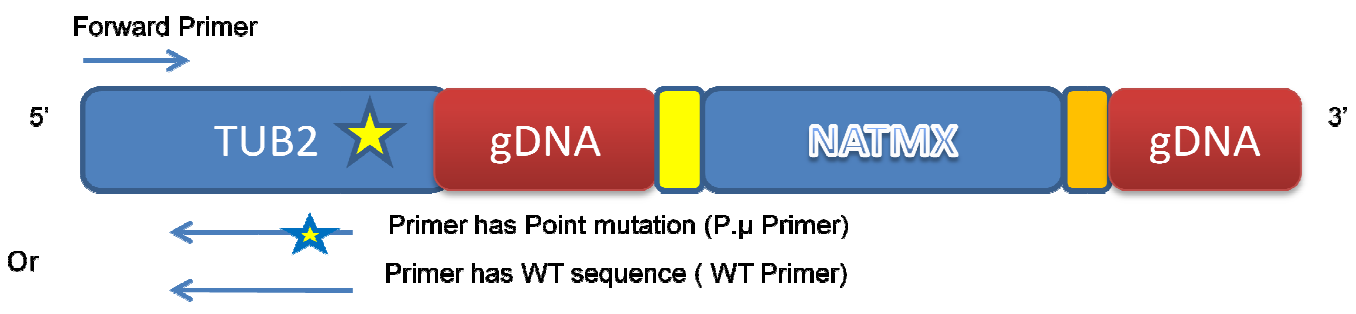

Figure. 2.2.2. Schematic view of colony PCR primers. Two reverse primers $\left(3^{\prime} \rightarrow 5^{\prime}\right)$ were designed for each point mutation either to carry that point mutation or to have the wild-type sequence. Another primer, the forward primer, was designed to go in the forward direction approximately $400 \mathrm{bp}$ upstream $\left(5^{\prime} \rightarrow 3^{\prime}\right)$ of the point mutation.

The strains with the desired point mutation were inoculated into $1 \mathrm{ml}$ of $25 \%$ glycerol solution and stored at $-80^{\circ} \mathrm{C}$ and are presented in Appendix IV.

\subsubsection{Transformation confirmation by colony PCR}

Using a Pipetman tip, a small portion of a randomly chosen colony was transferred into an Eppendorf tube containing $10 \mu \mathrm{L}$ of $1 \mathrm{mg} / \mathrm{mL}$ of Zymolyase $20 \mathrm{~T}(1 \mathrm{mg} / \mathrm{ml}$ Zymolyase dissolved in $1 \mathrm{ml}$ of $2 \mathrm{M}$ sorbitol (AMS Biotechnology (Europe) Ltd)). Zymolyase, purified from culture fluid of Arthrobacter luteus, has strong lytic activity against living yeast cell walls (www.amsbio.com). The Zymolyase solution was incubated at $30^{\circ} \mathrm{C}$ for $15 \mathrm{~min}$. The PCR cycling times were as follow: $15 \mathrm{~min}$ of initial activation at $95^{\circ} \mathrm{C}$, followed by 30 cycles of: 1 min of DNA denaturation at $95^{\circ} \mathrm{C}, 30 \mathrm{~s}$ of annealing at $54^{\circ} \mathrm{C}$ and $1 \mathrm{~min}$ of extension at $72^{\circ} \mathrm{C}$, then followed by 10 min of extension at $72^{\circ} \mathrm{C}$, and finally pause at $4^{\circ} \mathrm{C}$. For each colony two reactions were prepared, one with the wild type primer and one with the point mutation primer. Two $\mu \mathrm{L}$ of the Zymolyase solution was used as a DNA template for each reaction and added to the following reaction mixture: 
$10 \times$ PCR buffer

dNTPs mix (20 mM)

Forward Primer $(50 \mu \mathrm{M})$

Reverse Primer $(50 \mu \mathrm{M})$

Hotstar Taq enzyme ( $5 \mathrm{U} / \mu \mathrm{L})$

DNA Template

Distilled water
2

0.4

0.4

0.4

0.1

2

14.6
$1 \mathrm{x}$

$0.4 \mathrm{mM}$

$1 \mu \mathrm{M}$

$1 \mu \mathrm{M}$

$0.5 \mathrm{U} /$ reaction

Total

$20 \mu \mathrm{L}$

Following PCR, $5 \mu \mathrm{L}$ of each PCR product was electrophoresed on a $1 \%$ agarose gel for $40 \mathrm{~min}$ at $100 \mathrm{~V}$. Colonies that showed the correct band size (Fig. 2.3.3- 2.3.9) were subjected to another colony PCR experiment to confirm their status before been tested for resistance to PelA in a half-log dose-response experiment.

\section{Colony PCR amplification program}

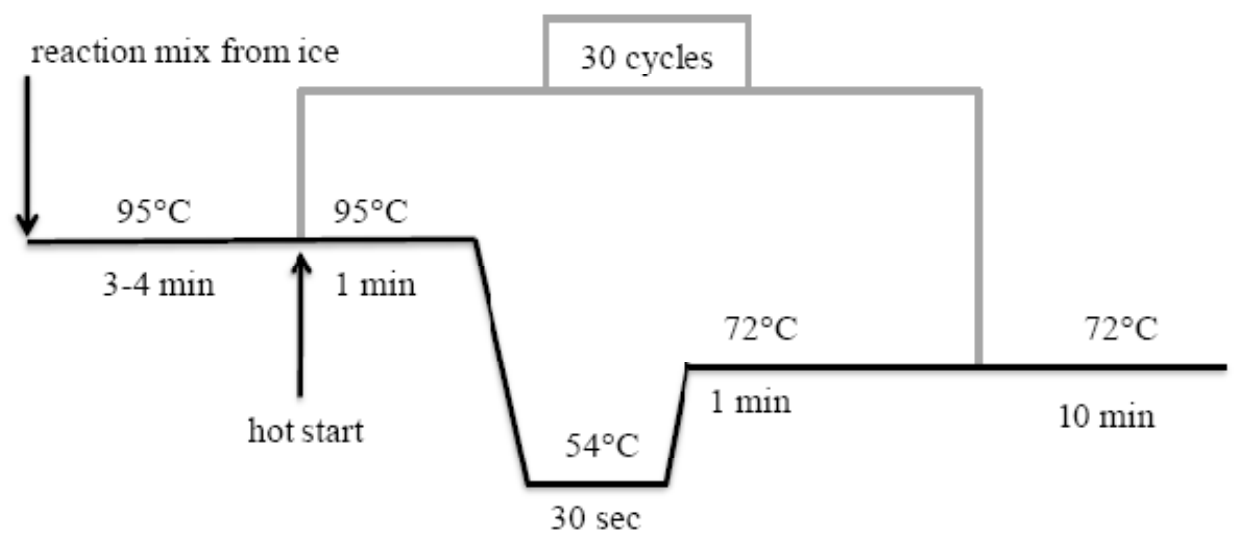

\subsubsection{Half-log dose-response curves}

For all dose-response experiments, a single colony was inoculated in $2 \mathrm{~mL} \mathrm{SC}$ medium (Appendix I) supplemented with $2 \%$ glucose and grown overnight using a Glascol ${ }^{\circledR}$ rotator (TotalLabSystems) set to a speed of $50 \mathrm{rpm}$. For the haploid wild type strain (BY4741), $25 \mathrm{mM}$ of HEPES was included with the drug to adjust the $\mathrm{pH}$ of the medium to approximately 6.5; therefore, creating a better growth conditions during drug treatment. The following day, the number of cells in the cultures was determined using a haemocytometer, and the cultures were diluted in $10 \mathrm{~mL}$ medium (YPD or SC) to a final cell concentration of $5 \times 10^{5}$ cells $/ \mathrm{mL}$. Then, $100 \mu \mathrm{L}$ of the diluted cells were plated out in $\mathrm{BIOFIL}^{\circledR}$ tissue culture 96-well plates, giving a final concentration of $5 \times 10^{4}$ cells per well. Cells were treated with $50 \mu \mathrm{M}$ PelA or $1 \%$ DMSO (control/solvent) for $18 \mathrm{hr}$ at $30^{\circ} \mathrm{C}$ in a Contherm Digital series incubator 
(Contherm Z011, Contherm Scientific Ltd, New Zealand). After 18 hr, plates were vortexed at $1000 \mathrm{rpm}$ for $15 \mathrm{sec}$ to resuspend the culture, and the absorbance of the plates was read at $600 \mathrm{~nm}$ wavelengths on a multiwell plate reader (Versamax, Molecular Devices, Sunnyvale, CA). The \% residual growth was calculated as:

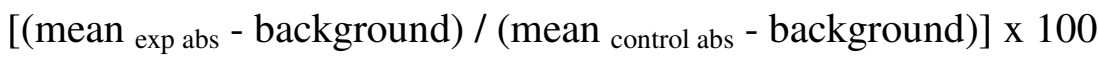

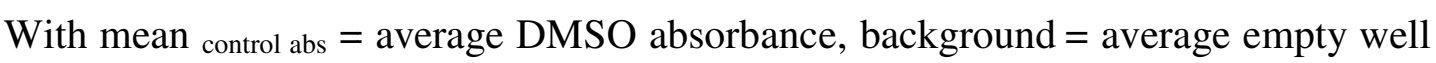
absorbance.

\subsubsection{Bud index assay}

To determine whether the PelA mode of action in yeast involved block at $G_{2} / M$ phase of the mitotic cell cycle, a bud index assay was carried out. This assay was done within the mad2 $\Delta$ background strain by inoculation in $2.5 \mathrm{~mL} \mathrm{SC}$ medium supplemented with $2 \%$ glucose and grown at $30^{\circ} \mathrm{C}$ overnight using a Glascol ${ }^{\circledR}$ rotator (TotalLabSystems) set to a speed of $50 \mathrm{rpm}$. The next day, cells were counted using a haemocytometer and diluted to obtain cells in mid-log phase $\left(1-2 \times 10^{7}\right.$ cells $\left./ \mathrm{mL}\right)$ (Amberg et al. 2005). Cells were then incubated at $30^{\circ} \mathrm{C}$ for $4 \mathrm{hr}$, following which $100 \mu \mathrm{L}$ aliquots were transferred to the wells of a 96-well plate. To the $100 \mu \mathrm{L}$ aliquots, $40 \mu \mathrm{M}$ PelA or $1 \%$ DMSO (control) was added, and the cells were incubated at $30^{\circ} \mathrm{C}$ for another $4 \mathrm{hr}$. Approximately 350 cells were counted at random in a haemocytometer, under an Olympus CX41 phase-contrast, confocal microscope at 40x, from each of the drug-treated and control wells and classified to the different phases of the cell cycle by their bud morphology (Fig. 2.2.3). Images of the cells were taken with an Olympus AX70 light microscope with brightfield and phase contrast, at 100x (oil immersion) magnification. Before observing them under the microscope, a 2-5 $\mu \mathrm{L}$ aliquot of the culture was placed on a slide, and the cover slip was sealed with clear nail polish.

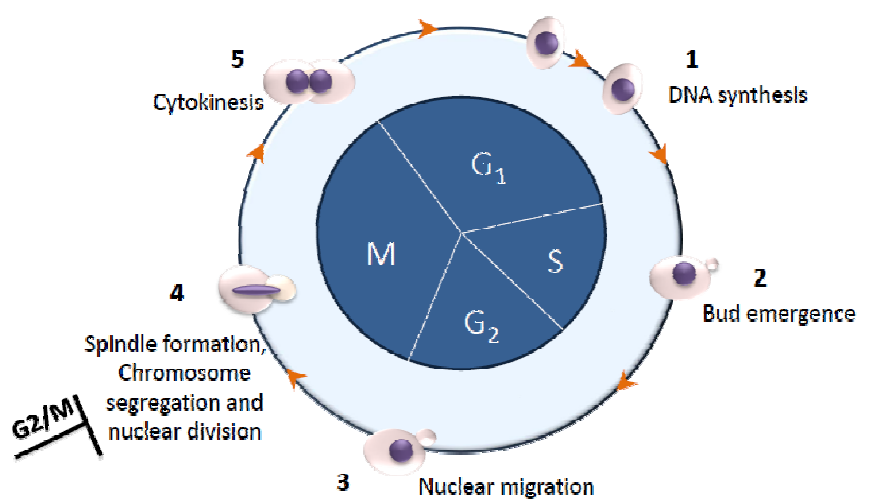

Figure. 2.2.3. Correlation of yeast bud index with cell cycle phases. Stage 1 has no bud, indicating that the cell is in the $G_{1}$ phase of the cell cycle. Cells at stage 2 have a tiny bud, and this stage is equivalent to the $S$ phase. Cells at stage 3 have a medium size bud, and cells at stage 4 have a large bud size compared to the previous stages. $\mathrm{G}_{2} / \mathrm{M}$ block occurs between stage 3 and 4 . 


\subsubsection{Flow cytometry analysis}

Along with the bud index determination, and to further validate the mode of action of PelA in yeast i.e. that PelA blocks cells at $\mathrm{G}_{2} / \mathrm{M}$, a flow cytometry assay was carried out to quantify the amount of DNA present in the treated versus the untreated cells. Flow cytometry is commonly used to distinguish growing cells in different phases of the cell cycle (Haase and Reed, 2002). In $2 \mathrm{~mL}$ SC medium, the haploid strain $(\operatorname{mad} 2 \Delta)$ was inoculated and supplemented with $2 \%$ glucose. The cells were grown at $30^{\circ} \mathrm{C}$ overnight in a Glascol ${ }^{\circledR}$ rotator (TotalLabSystems) set to a speed of $50 \mathrm{rpm}$. The next day, cells were counted using a haemocytometer and diluted to $1-2 \times 10^{7}$ cells/mL to obtain cells in mid-log phase (Amberg et al. 2005). Diluted cells (500 $\mu \mathrm{L}$ ) were then incubated for $4 \mathrm{hr}$ with $40 \mu \mathrm{M}$ PelA or $1 \%$ DMSO (control) and were grown for either $6 \mathrm{hr}$ or overnight in a $30^{\circ} \mathrm{C}$ shaker. The rest of the experiment was performed following the method of Haase (2003). In brief, cells were harvested by centrifuging at $4000 \mathrm{rpm}$ for $5 \mathrm{~min}$ and washed twice with $5 \mathrm{~mL}$ Tris buffer $(50 \mathrm{mM}$ Tris/ $\mathrm{HCl}, \mathrm{pH}$ 7.5). The cells were then re-suspended in $1.5 \mathrm{~mL}$ of distilled water, and $3.5 \mathrm{~mL}$ of $100 \%$ ethanol was added for $1 \mathrm{hr}$ at room temperature (to fix the cells). The ethanol was removed by centrifugation followed by pipetting off the supernatant, and the cells were resuspended in $5 \mathrm{~mL}$ Tris buffer. In order to each to separate the cells, they were sonicated in an Ultrasonic Elma ${ }^{\circledR}$ T460 sonicator (Global Science) 3x for 5-10 sec. Two mL of 1x RNAse solution was added, and the samples were incubated for $1 \mathrm{hr}$ at $37^{\circ} \mathrm{C}$ in a shaker at $250 \mathrm{rpm}$ (Edwards Instrument Company, Australia). Samples were then treated for $5 \mathrm{~min}$ with $2 \mathrm{~mL}$ of freshly prepared pepsin solution (50 mg of pepsin (Sigma) dissolved in $10 \mathrm{~mL} \mathrm{dH}_{2} \mathrm{O}$ plus 45 $\mu \mathrm{L}$ of concentrated $\mathrm{HCl}$ ). Cells were then stained with $2 \mu \mathrm{M}$ SYTOX green (to stain the DNA) and were collected for analysis in a FACS Cellquestpro machine (Becton Dickinson, Franklin Lakes, NJ, USA). Cell cycle analysis was performed using BD Cell Quest ${ }^{\mathrm{TM}}$ Pro software (Becton Dickenson). Histogram analysis was used to plot the number of cells against the stain intensity, and cells were grouped into $G_{1}, S$, and $\mathrm{G}_{2} / \mathrm{M}$ phase according to the amount of DNA that was present in the cells. 


\subsubsection{Morphological changes of polymerised $\alpha$-tubulin in TUB3- GFP in response to PelA}

The haploid TUB3-GFP strain (that also has RFP associated with a nuclear marker and mCherry associated with a cytoplasmic signal) was used in this part of the study. Dr. David Maass of the Chemical Genetics Laboratory, School of Biological Sciences, Victoria University, Wellington, constructed this strain. A single colony was inoculated into $50 \mu \mathrm{L}$ SC medium plus $2 \%$ glucose in a well of a Perkin Elmer CellCarrier 384-well black, clear bottom plate without a lid (Perkin Elmer 6007439). Cells were incubated with and without $50 \mu \mathrm{M}$ PelA for $4-6 \mathrm{hr}$ in a $30^{\circ} \mathrm{C}$ incubator. During the incubation, images were captured with a Perkin Elmer Evotec Opera Fluorescent Confocal Microscope (Opera ${ }^{\mathrm{TM}}$, Alphatech System Limited, Auckland, New Zealand), with two light filters from two cameras (camera 1: 520/35; camera 2: 600/40). Laser excitation wavelengths were $488 \mathrm{~nm}$ (GFP) and $561 \mathrm{~nm}$ (RFP), magnification was 60x water immersion (60xW_NA=1.2), and the exposure duration was 400 millisecond. At 5-10 hr intervals, the fluorescence of the cells was analysed using Evotec Acapella image analysis software. The haploid TUB1-GFP strain was also examined under the Opera laser confocal microscope, but the analysed images that were taken were not very informative, and PelA did not seem to be effective against this strain. In addition, the yeast cells were blurry, possibly due to differences in the response of the two strains to the medium and/or the drug, or due to experimental error (incorrect focusing or laser intensity). Technically the amount of GFP-protein that is expressed from either TUB1 or TUB3 $\alpha$-tubulin protein should be approximately equivalent (Carminati and Stearns, 1997). 


\subsection{Results}

\subsubsection{Site-directed mutagenesis and transformation confirmation by colony PCR}

The PCR products that were generated by site-directed mutagenesis for all point mutations were confirmed by agarose gel electrophoresis (Fig. 2.3.1 and Fig. 2.3.2). Six (and one double mutant) point mutations were generated in this study. The first two were A296T and R306H (and the combined double mutant) which are known to confer resistance to PelA in mammalian ovarian carcinoma cells. These amino acids are highly conserved between yeast and mammalian cells. Four other point mutations, besides the A296T and R306H mutations, were transformed into yeast genome based on predictions of PelA- $\beta$-tubulin interactions from computer modelling studies of Snyder and Thepchatri (unpublished data), and with the help of Assoc Prof Paul Teesdale-Spittle of the School of Biological Sciences, Victoria University of Wellington. These point mutations were Q291M, N337L, and V333W plus one negative control that was known to confer resistance to epothilone B in mammalian cells, but not to PelA, R282Q. These amino acids are also highly conserved between yeast and mammalian tubulin. The fragment sizes of PCR products were within the expected range of $650-775 \mathrm{bp}$ for TUB2 mutations (sizes varied depending on the position of the amino acid) and $1200 \mathrm{bp}$ for NatMX cassette. PCR products were then transformed into the yeast genome, and colony PCR was used to confirm the transformation (Fig. 2.3.3- Fig. 2.3.9). Fragment sizes of colony PCR products were within the expected range of 400-500 bp (sizes varied depending on the position of the amino acid). For each point mutation transformation, at least one colony was identified. To identify a transformed colony, about 30-50 colonies needed to be screened for each point mutation to get the right colony that had the right point mutation. 
Figure. 2.3.1. Confirmation of A296T point mutation, R306H, double mutant, and NatMX cassette PCR products

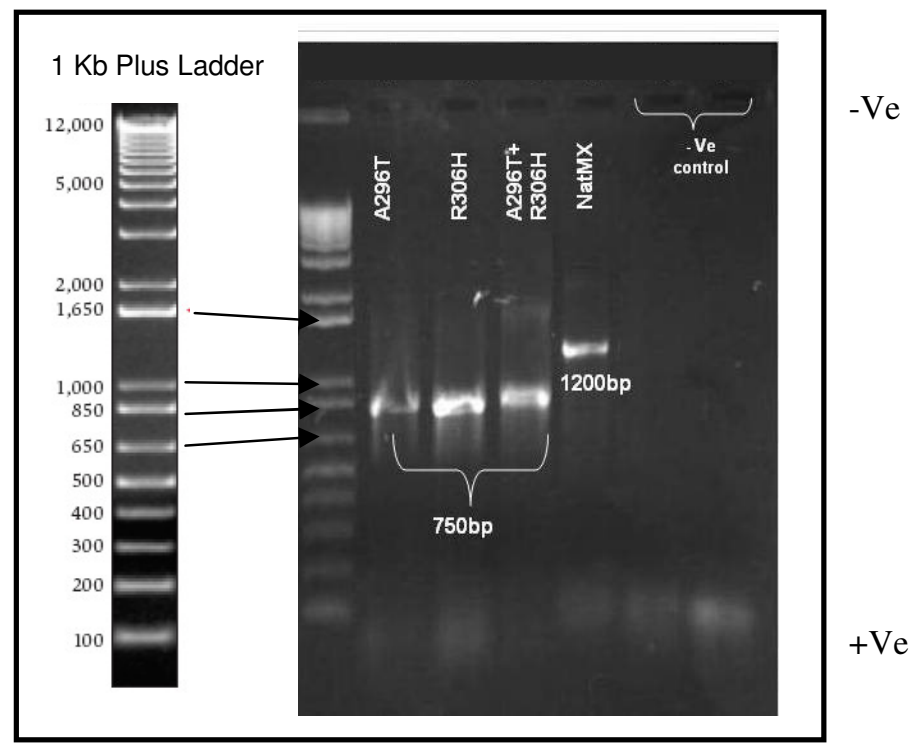

PCR product fragment size for mutant primer sets and the NatMX cassette. Lane $1=1 \mathrm{~Kb}$ plus DNA ladder, Lane 2= A296T PCR product, Lane 3= R306H PCR product, Lane 4= the combined double mutant PCR product, Lane 5= NatMX PCR product, Lane 6 \& $7=$ negative controls (tubes with only PCR mix and no DNA template i.e. NatMX or BY4741 DNA). Fragment sizes were in the expected range: $750 \mathrm{bp}$ for TUB2 mutations and $1200 \mathrm{bp}$ for NatMX.

Figure. 2.3.2. Confirmation of PCR products of predictive point mutations and NatMX cassette PCR products

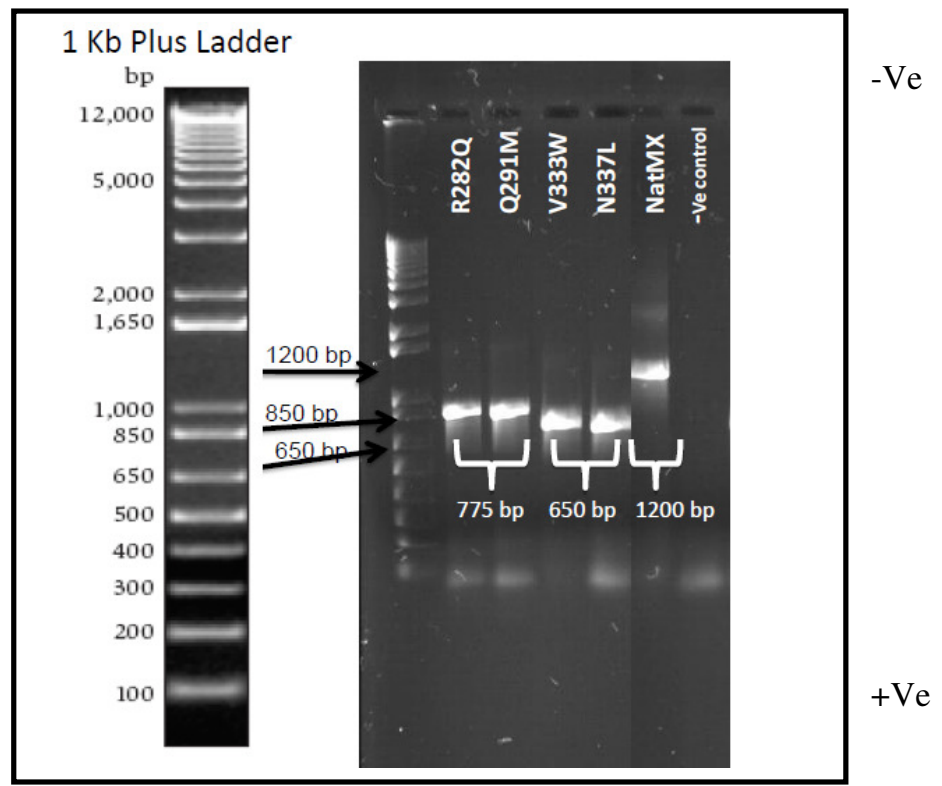

PCR product fragment size for predictive mutant primer sets and the NatMX cassette. Lane $1=$ $1 \mathrm{~Kb}$ plus DNA ladder, Lane 2= R282Q PCR product, Lane 3= Q291M PCR product, Lane 4= V333W PCR product, Lane 5= N337L PCR product, Lane $6=$ NatMX PCR product, and Lane 7= negative control (no DNA). Fragment sizes were at the expected range between 650-775 bp for TUB2 mutations and $1200 \mathrm{bp}$ for NatMX. 
Figure. 2.3.3. Colony PCR for A296T transformation confirmation

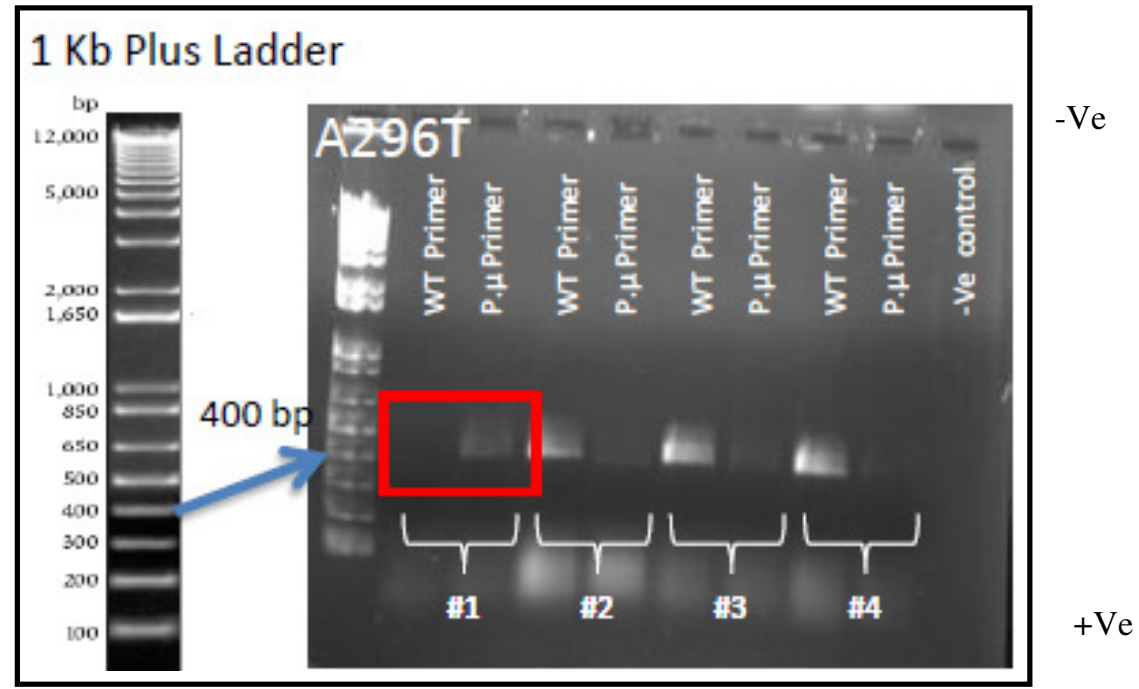

Transformation confirmation by colony PCR for A296T point mutation. Two primers were used for the confirmation of A296T mutant colonies. Along with the forward primer that was designed, to be $400 \mathrm{bp}$ upstream of the desired point mutation, the reverse primer was designed to have either the WT sequence or the point mutation. Two PCR reactions were performed for each colony picked at random, so that if transformation had occurred, a band would only be present if the colony had the expected WT sequence or the expected point mutation for the primer set used. Only colony \#1 has the successful point mutation (red box), with a product for the mutant primer set but not the wild type primer set.

Figure. 2.3.4. The confirmation R306H transformation by colony PCR

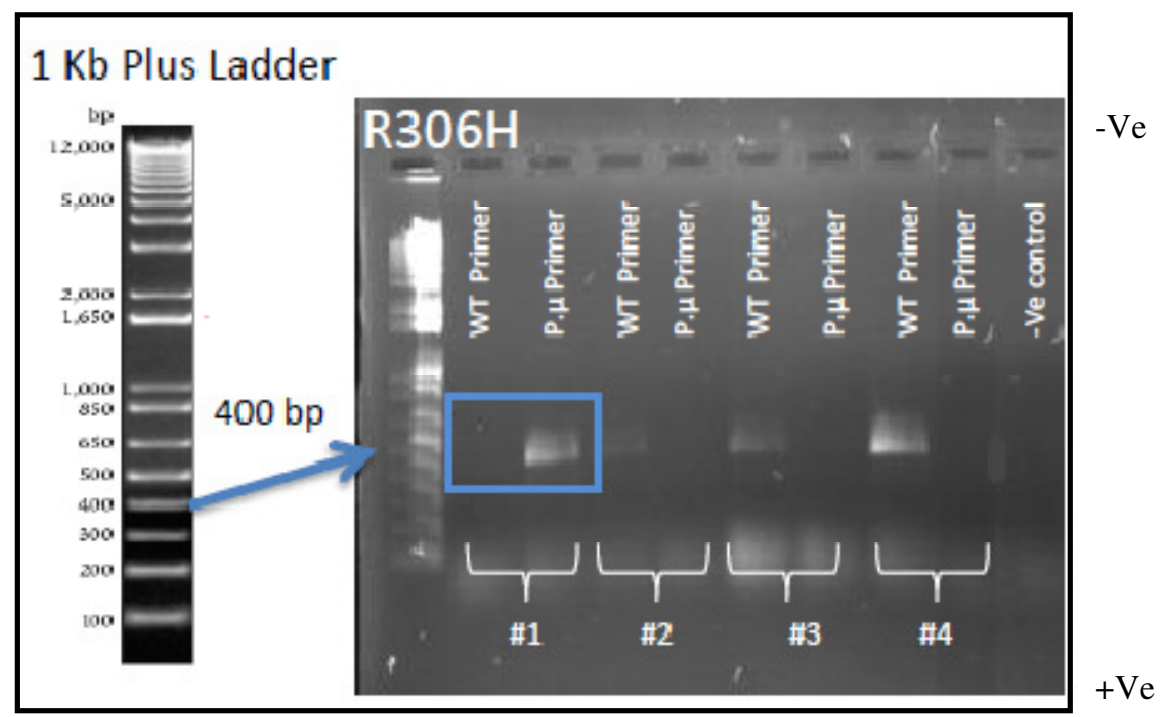

In this figure, colony \# 1 shows the correct $\mathrm{R} 306 \mathrm{H}$ point mutation (blue box). For more details on the primer sets used, see Fig. 2.3.3 legend. 
Figure. 2.3.5. Confirming R306H+A296T transformation via colony PCR

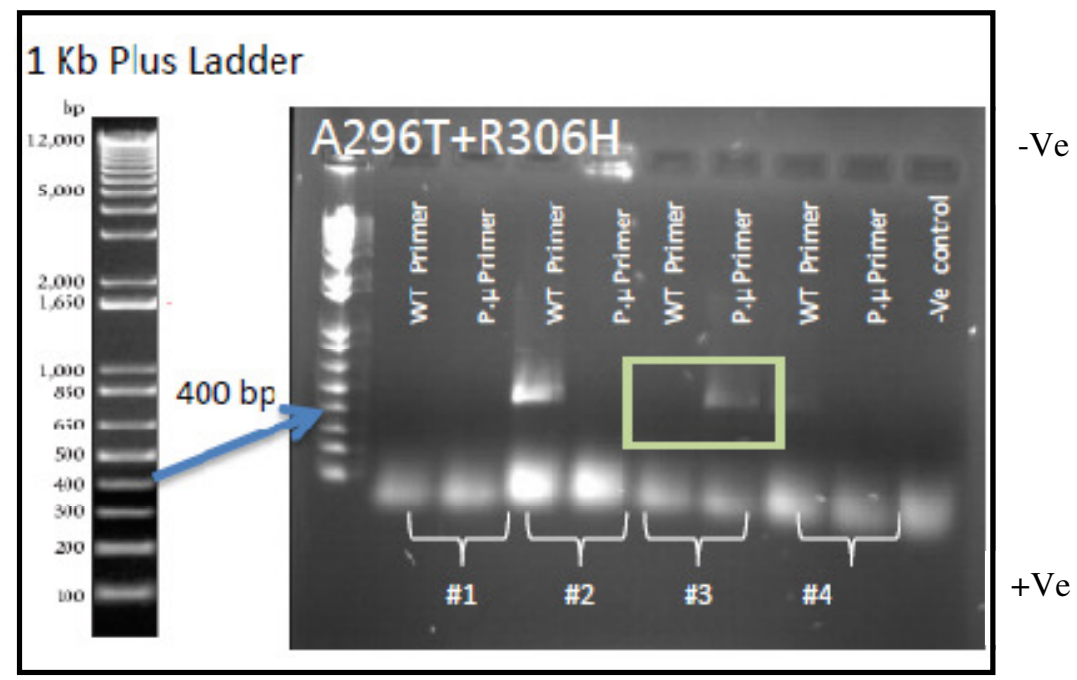

Colony \# 3 has the correct point mutations A296T+ R306H (olive green box).

Figure. 2.3.6. Transformation confirmation for $R 282 Q$ by colony PCR

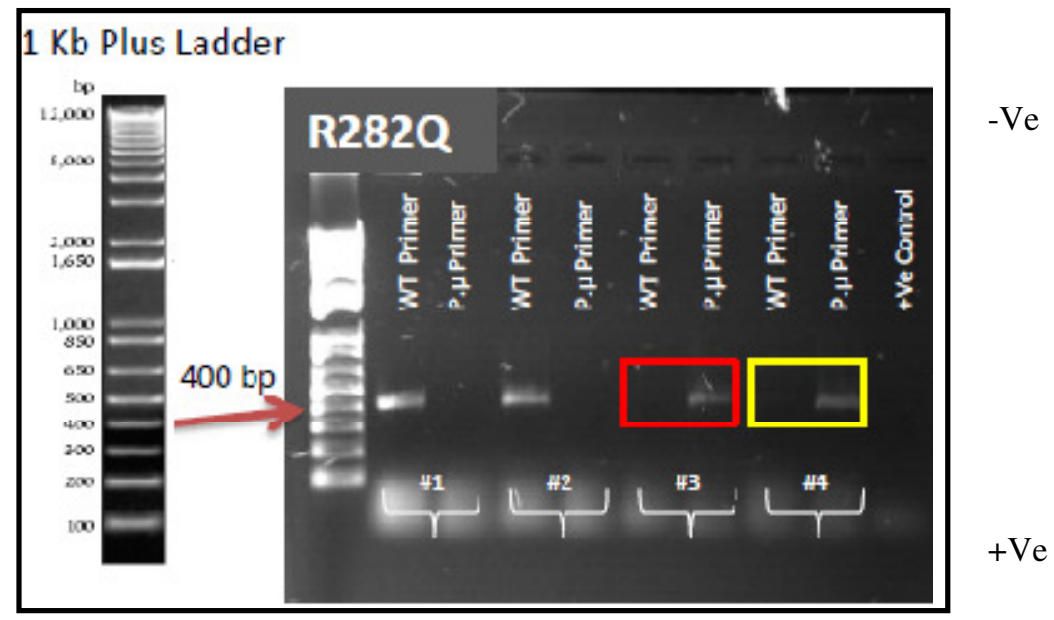

In this confirmation, two mutant colonies were recovered via colony PCR. Colony \# 3 (orange box) and \# 4 (yellow box) have the correct R282Q point mutation.

Figure. 2.3.7. The confirmation for Q291M transformation by colony PCR

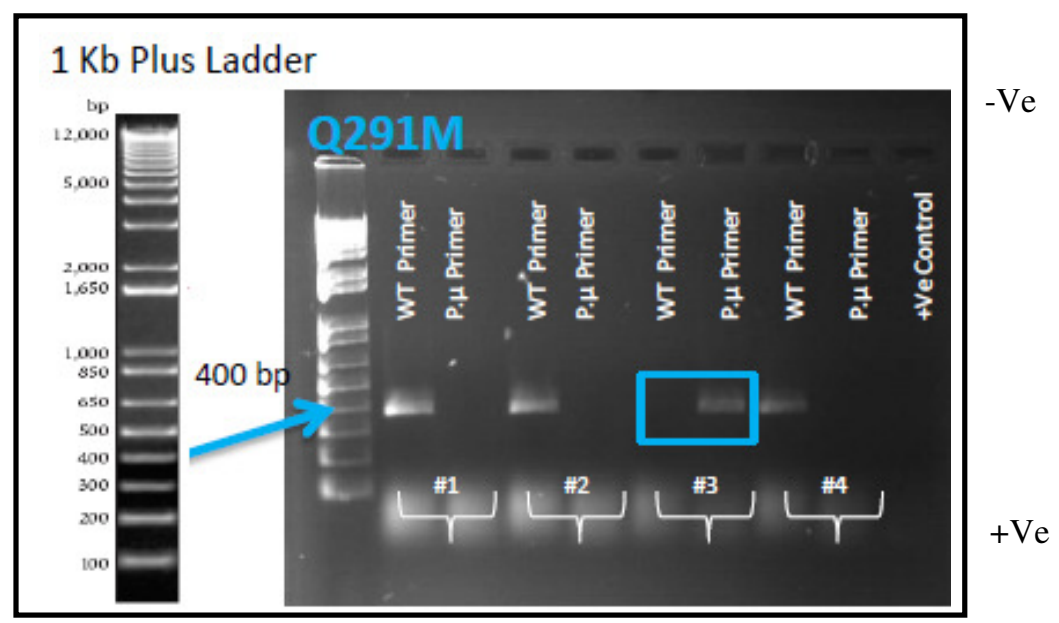

This figure shows that colony \# 3 has the correct Q291M mutation (blue box) that was transformed into the yeast genome. 
Figure. 2.3.8. Confirmation of V333W transformation via colony PCR

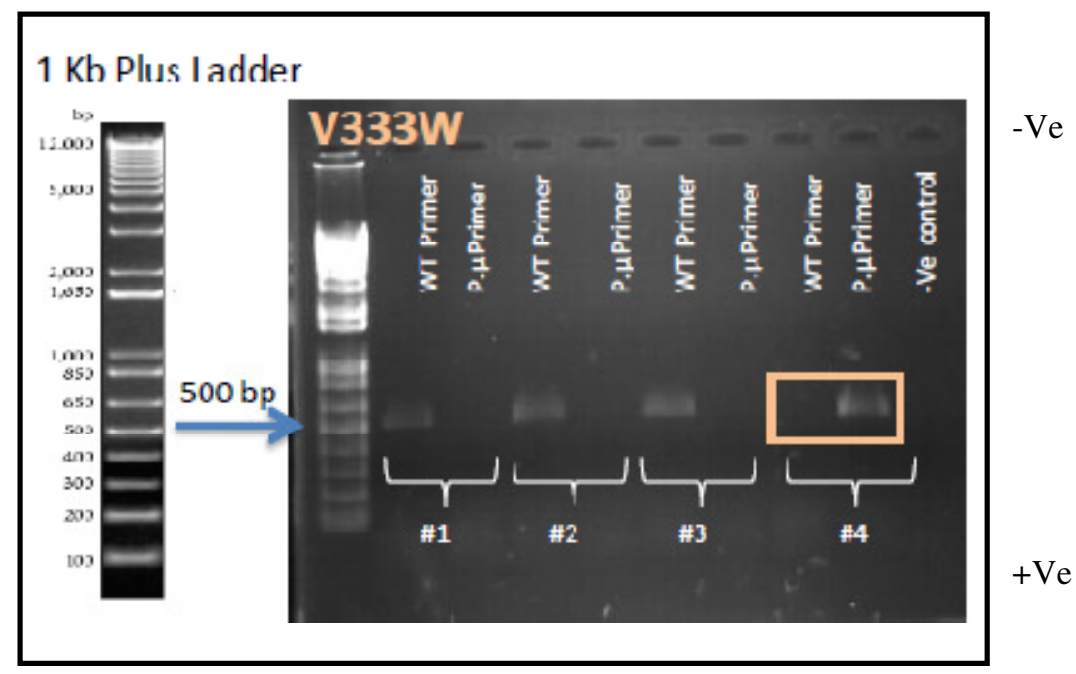

The image above shows that colony \# 4 has the right V333W mutation (light orange box) that was successfully transformed into the genome.

Figure. 2.3.9. N337L transformation confirmation via colony PCR

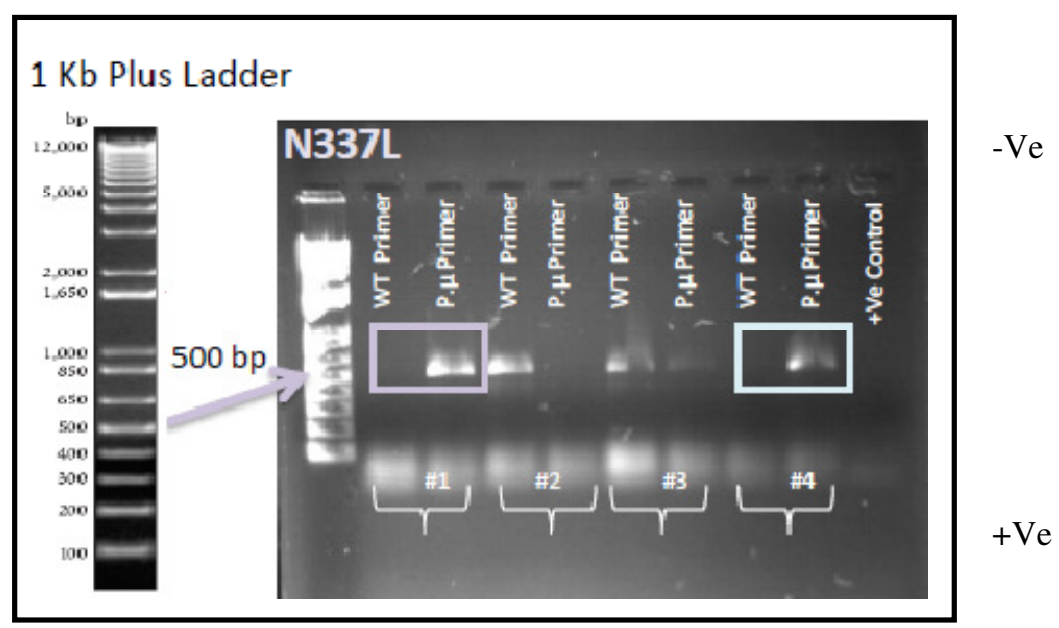

Colonies \# 1 (light purple box) and \# 4 (white box) both have the correct N337L point mutation. 


\subsubsection{Half-log dose-response curves for mutant strains treated with PelA}

\section{Testing for growth inhibition in wild type and deletion mutant strains}

In preliminary experiments, the haploid wild type strain (BY4741) along with several haploid deletion mutants were tested (Fig. 2.3.10) to determine whether PelA could inhibit growth of these strains. The results from these experiments for the wild type and $\operatorname{mad} 2 \Delta$ were consistent with other results that were obtained from earlier studies carried out by Anja Wilmes in her PhD research (Wilmes PhD thesis, 2008). The wild type strain was inhibited by approximately $50 \%$ at the highest drug concentration ( $50 \mu \mathrm{M}$ PelA), and mad $2 \Delta$ growth was inhibited by $94 \%$ with an $\mathrm{IC}_{50}$ value of $36 \pm 1 \mu \mathrm{M}$. The most sensitive strain amongst the deletion mutants that were tested were the pleiotropic efflux pumps regulators (transcription factors) $P D R$ deficient strain ( $p d r 1 \Delta \& p d r 3 \Delta$ ) with $93 \%$ growth inhibition and $\mathrm{IC}_{50}$ value of $22 \pm$ $1 \mu \mathrm{M}$, and the pleiotropic efflux pumps deletion mutant strain $p d r 5 \Delta$ with $92 \%$ growth inhibition and $\mathrm{IC}_{50}$ value of $29 \pm 1 \mu \mathrm{M}$. Growth inhibition measurements for the other deletion mutant strains are presented in Table. 2.3.1, and calculated $\mathrm{IC}_{50}$ values are presented in Table. 2.3.3. It is worth noting that pump knockout deletion strains residual growth were similar to $\operatorname{mad} 2 \Delta$, which makes them good candidates for future site-directed mutagenesis experiments.

\section{Testing for resistance in PelA-tub2-mutant strains}

The tub2 mutant strains that showed the correct point mutation were then subjected to half-log dose-response analyses to examine their sensitivities to PelA. All the generated mutant strains were treated with the highest PelA concentration $(50 \mu \mathrm{M})$ (Fig. 2.3.11-2.3.12).

\section{a) Effect of A296T and $\mathrm{R306H}$ point mutations on growth responses to PelA}

The single amino acid mutations A296T and R306H (and the combined double mutant) all were resistance to PelA in yeast (Fig. 2.3.11) with $\mathrm{IC}_{50}$ values $>50 \mu \mathrm{M}$, suggesting that homologue mutations retain resistance in yeast. This compares to the sensitive strain $\operatorname{mad} 2 \Delta$ whose growth was completely inhibited at $50 \mu \mathrm{M}$. The effect of the two individual point mutations (A296T and R306H) was consistent with that seen in mammalian cell lines (Wilmes PhD thesis, 2008). In PelA-R1 cells an amino acid change at position 296 in $\beta$-tubulin from alanine to threonine resulted in 5-fold 
resistance to PelA compared to the parental 1A9 cells, and the single amino acid mutation R306H gave L4 40-fold resistance.

\section{b) Effect of predicted point mutations on growth responses to PelA}

The results for the point mutations predicted from modelling, on the other hand, were not as expected. Q291M and N337L were predicted to give resistance to PelA, but only $\mathrm{N} 337 \mathrm{~L}$ gave resistance with $\mathrm{IC}_{50}$ values $>50 \mu \mathrm{M}$. This compares to the sensitive strain mad $2 \Delta$ whose growth was completely inhibited at $50 \mu \mathrm{M}$ PelA (Fig. 2.3.12). V333W was predicted to give resistance to laulimalide but have little effect on PelA, and R282Q should have been a neutral mutation for PelA but should confer resistance to EpoB. V333W colony was resistance to PelA, despite no resistance being expected, with $\mathrm{IC}_{50}$ values $>50 \mu \mathrm{M}$, compared to the sensitive strain mad2 $\Delta$ whose growth was completely inhibited at $50 \mu \mathrm{M}$ PelA. R282Q unexpectedly conferred resistance to PelA, also an unexpected result, with $\mathrm{IC}_{50}$ values $>50 \mu \mathrm{M}$. Its effect on ixabepalone responses could not be measured as ixabepilone has no effect on yeast growth (Fig. 2.3.13). At the highest PelA concentration $(50 \mu \mathrm{M})$, almost all mutant strains were therefore PelA-resistant i.e. they grew with and without the drug; whereas, the mad2 $\Delta$ strain showed almost no growth in the presence of the drug. Only strain Q291M was sensitive to PelA, although it had been predicted that it would confer resistance on the cells. This indicates that the change in this particular residue did not confer resistant to the drug. 
Figure. 2.3.10. Sensitivity of wild type, $\operatorname{mad} 2 \Delta$, and pump knockout mutants to PelA

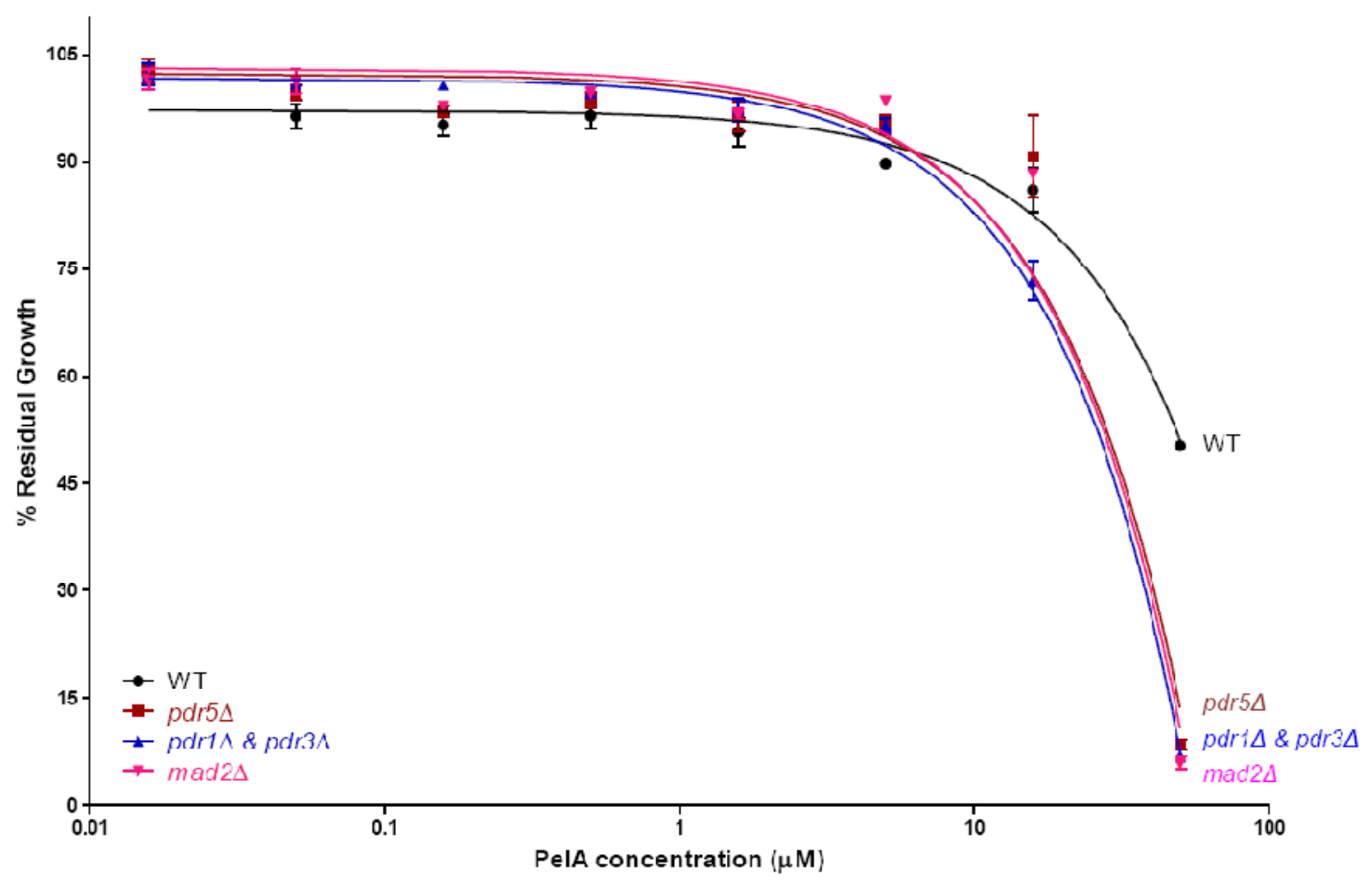

Half-log dose-response curves for the haploid wild type BY4741 (WT), and the deletion mutant strains pdr5 $\Delta$, PDR-deficient strain (pdr14 \& pdr34), and mad2A. These strains were treated with PelA at concentrations up to $50 \mu \mathrm{M}$ for $18 \mathrm{hr}$. At $50 \mu \mathrm{M}$ PelA, the WT growth was only inhibited by 51\%; whereas, at the same drug concentration the strains mad2A, pdr5 $\Delta$ and PDR-deficient strain ( $p d r 1 \Delta \& p d r 3 \Delta$ ) growth were inhibited by $92-94 \%$. Refer to Table 2.3 .1 for a summary of growth inhibition results of these strains. Data are presented as the mean \pm SD of three independent experiments ( $\mathrm{n}=3$ experiments with one biological replicate). $\mathrm{IC}_{50}$ values were calculated are presented in Table. 2.3.3.

Table. 2.3.1. Percentage of growth inhibition of wild type, mad2s, and pump knockout mutants treated with PelA

\begin{tabular}{|c|c|}
\hline Yeast strain & $\begin{array}{c}\text { \% residual growth } \\
\text { (relative to DMSO-treated cells at } \mathbf{5 0} \boldsymbol{\mu M} \pm \mathbf{S D} \text { ) }\end{array}$ \\
\hline $\mathrm{WT}(\mathrm{BY} 4741)$ & $49.6 \pm 0.3 \%$ \\
\hline$m a d 2 \Delta$ & $6 \pm 1 \%$ \\
\hline$p d r 5 \Delta$ & $8 \pm 1 \%$ \\
\hline$p d r 1 \Delta \& p d r 3 \Delta$ & $7 \pm 1 \%$ \\
\hline
\end{tabular}

The haploid wild type strain BY4741 and three haploid deletion strains were treated with $50 \mu \mathrm{M}$ PelA for $18 \mathrm{hr}$. The percent of growth (relative to DMSO-treated cells) at the highest concentration $(50 \mu \mathrm{M})$ is presented in this table. Please note that the data present in this table are the same results as in Fig. 2.3.10. $\mathrm{IC}_{50}$ values were calculated are presented in Table. 2.3.3. Data are presented as the mean $\pm \mathrm{SD}$ of three independent experiments ( $n=3$ experiments with one biological replicate). 
Figure. 2.3.11. Growth inhibition curves of $\operatorname{mad} 2 \Delta$ and $t u b 2$ mutants treated with PelA

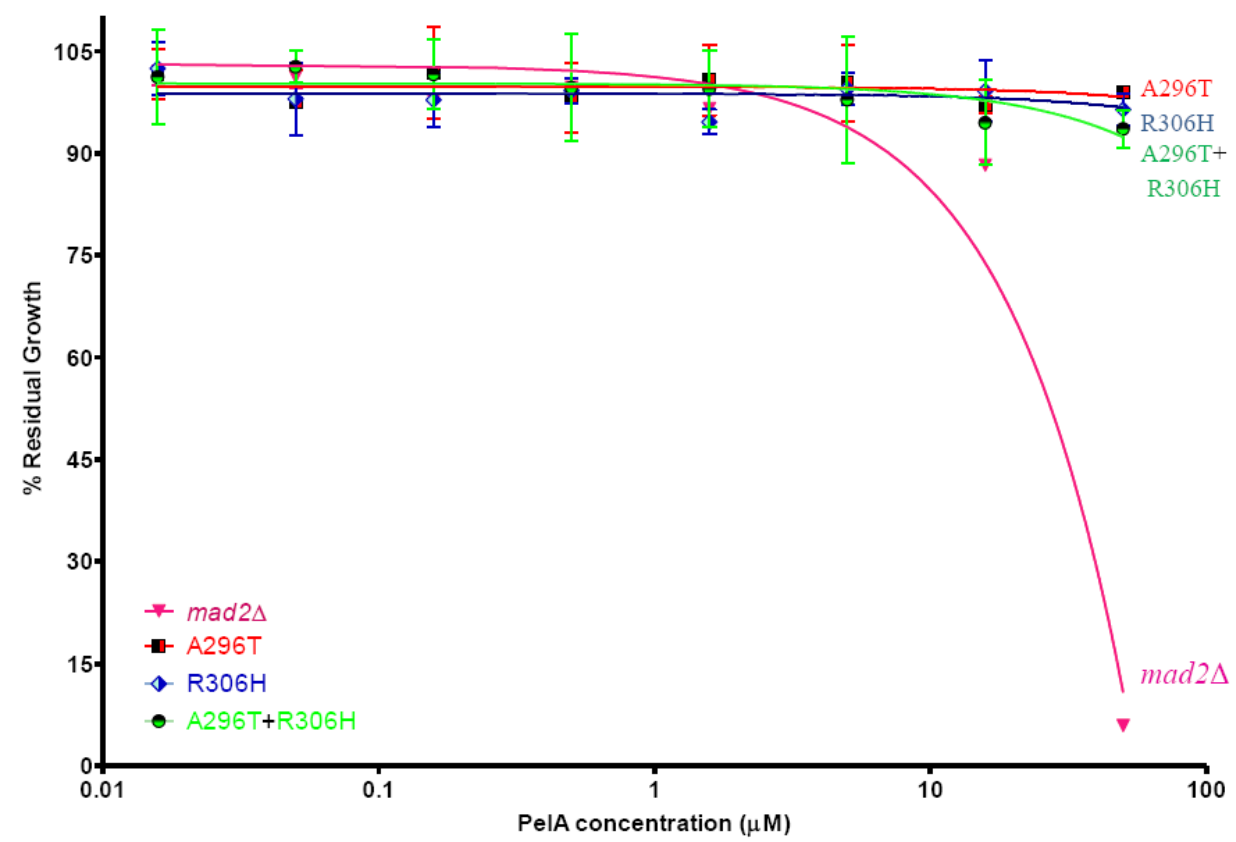

The three tub2-mutant strains (A296T; R306H; A296T+R306H), and the haploid deletion mutant background strain mad $2 \Delta$ (positive control) were treated with up to $50 \mu \mathrm{M}$ PelA for $18 \mathrm{hr}$. At $50 \mu \mathrm{M}$ all three mutant colonies were PelA-resistant i.e. their growth was not inhibited in the presence of the drug compared to the positive control $(\operatorname{mad} 2 \Delta)$. Data are presented as the mean \pm SD of three independent experiments ( $\mathrm{n}=3$ experiments with one biological replicate).

Figure. 2.3.12. Growth inhibition curves of the PelA-predicted point mutations and $\operatorname{mad} 2 \Delta$ strain

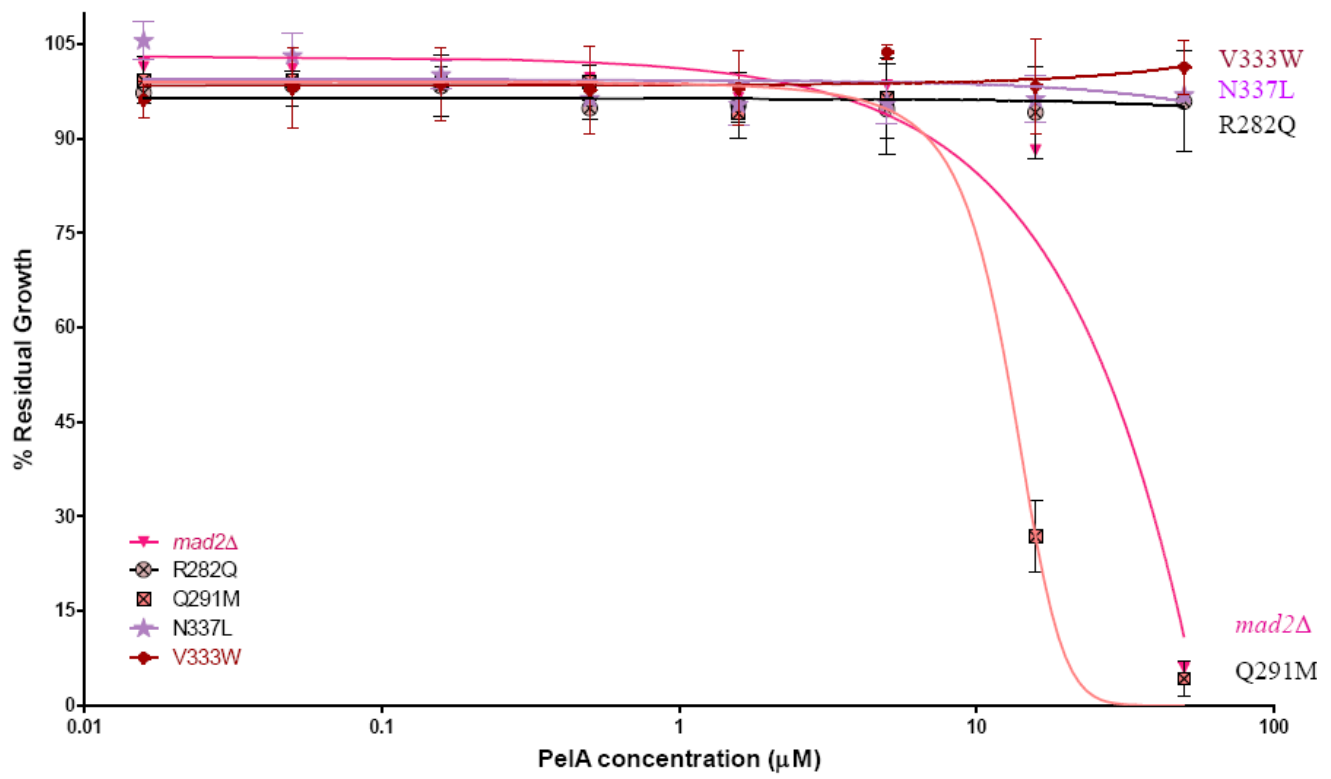

The four predictive tub2-mutant strains (Q291M, N337L, and V333W and R282Q) as well as the haploid deletion mutant background strain mad2 $\Delta$ (positive control) were treated with up to $50 \mu \mathrm{M}$ PelA for $18 \mathrm{hr}$. Data are presented as the mean \pm SD of three independent experiments $(n=3$ experiments with one biological replicate). Please note that the mad2 $\Delta$ growth curve is the same as presented in Fig. 2.3.11 and the four mutant curves were determined simultaneously with the other three mutant strains, but the results are graphed separately for clarity. 


\subsubsection{The effect of tubulin point mutations on growth responses to ixabepilone and laulimalide.}

Other MSA were tested to see whether the generated point mutations were PelAspecific or if there was some overlap with other drugs that bind to the same or a different binding site on tubulin. Laulimalide should be more similar in its effects to PelA than ixabepalone.

\section{Growth inhibition studies of various Ixabepilone-treated yeast strains}

Ixabepilone (aza-epothilone B) was included as a positive control because its binding site (the taxoid site on $\beta$-tubulin) is well defined, and it binds to a different site than PelA on mammalian tubulin. Epothilone is also known to stabilise yeast microtubules in vitro, although it is relatively ineffective in inhibiting yeast growth in vivo (Gupta et al. 2003). We obtained similar results to Gupta et al. with growth of yeast. Ixabepilone was ineffective against all the yeast strains tested (Fig. 2.3.13) at concentrations up to $300 \mu \mathrm{M}$. The drug had no effect even in the presence or absence of the permeability agent sodium dodecyl sulfate (SDS). SDS is an anionic surfactant commonly used in conjunction with polyacrylamide gel electrophoresis. However, it has been successfully used as an effective permeabilising agent of yeast cell membranes, facilitating the uptake of a drug into the cell (Pannunzio et al. 2004). SDS concentrations were recommended by Christina Roberts (Chemical Genetics Laboratory, Victoria University of Wellington) who had carried out preliminary experiments to determine the SDS concentration that provides the optimal balance between permeabilising the membrane and not affecting cell growth. The drug was also was not effective against the pump knockout deletion strains. This might indicate that ixabepilone has no effect on yeast tubulin or growth.

\section{Growth inhibition studies of various laulimalide-treated $t u b 2$-mutant strains}

Laulimalide is a potent MSA that binds to a different site on tubulin to paclitaxel. Competition for binding studies has revealed that laulimalide occupies the same or an overlapping site with PelA. Dose-response studies were performed with the haploid wild type strain (BY4741) along with several haploid deletion mutants (Fig. 2.3.14) to determine the optimal drug concentration to use and to see if yeast was sensitive to laulimalide. Laulimalide proved to be even more potent than PelA. At 50 $\mu \mathrm{M}$, laulimalide exhibited about the same level of inhibition of growth as PelA. The WT growth was inhibited by $65 \%$ with an $\mathrm{IC}_{50}$ value of $36 \pm 1 \mu \mathrm{M}$; whereas, the deletion mutant strain mad2A exhibited 92\% inhibition at the same drug 
concentration but with $\mathrm{IC}_{50}$ value of $24 \pm 1 \mu \mathrm{M}$ so it was 1.5 fold sensitive to the drug compared to wild-type. The drug seemed to be more potent in the haploid pump knockout deletion strains: $p d r 5 \Delta$ and $P D R$-deficient strain ( $p d r 1 \Delta \& p d r 3 \Delta)$, as their growth was inhibited by $93-94 \%$ with an $\mathrm{IC}_{50}$ value of $2-3 \pm 1 \mu \mathrm{M}$. Thus, these strains were hypersensitive to laulimalide (Fig. 2.3.14) compared to PelA (Fig. 2.3.10) and their growth curves were shifted to a lower $\mu \mathrm{M}$ range. For more detailed information on growth inhibition values at the maximum laulimalide dose, see Table. 2.3.2. For more information about the $\mathrm{IC}_{50}$ values that were calculated for each strain, see Table. 2.3.3.

\section{Effect of laulimalide on PelA-mutants strains}

Furthermore, the two point mutations known to confer resistance to PelA in mammalian cells (A296T and R306H) were also highly laulimalide resistant (Fig. 2.3.15). At $50 \mu \mathrm{M}$ laulimalide, the three mutant strains that were resistant to PelA were also resistance to laulimalide. The mad $2 \Delta$ growth was inhibited completely at $50 \mu \mathrm{M}$ laulimalide. In the presence of laulimalide, A296T and R306H were resistance to laulimalide with $\mathrm{IC}_{50}$ values $>50 \mu \mathrm{M}$. The mutant strains growth curves were compared to $\operatorname{mad} 2 \Delta$ (Fig. 2.3.15).

Moreover, two of the three predicted mutations failed to show resistance to laulimalide; thus, laulimalide was not exactly mirroring the effects of PelA. At the highest concentration of laulimalide $(50 \mu \mathrm{M})$, two of the predicted PelA-mutant strains were laulimalide-resistant. V333W strain and N337L strain were resistance to laulimalide with $\mathrm{IC}_{50}$ values $>50 \mu \mathrm{M}$; whereas, the $\operatorname{mad} 2 \Delta$ strain showed almost no growth in the presence of the drug compared to growth in untreated cells. At $50 \mu \mathrm{M}$ laulimalide, the third predicted mutation $($ Q291M) behaved in the same manner against laulimalide as for PelA i.e. the cells were hypersensitive to the drug, with $\mathrm{IC}_{50}$ value of $12 \pm 1 \mu \mathrm{M}$ i.e. 2 -fold sensitive to the drug compared mad2 $\Delta$ control that had an $\mathrm{IC}_{50}$ value of $24 \pm 1 \mu \mathrm{M}$. The R282Q mutation, that was predicted to give resistance to epothilone but not to PelA or laulimalide, was semi-sensitive to the laulimalide compared to $\operatorname{mad} 2 \Delta$. $M a d 2 \Delta$ was completely growth inhibited at $50 \mu \mathrm{M}$ laulimalide. Mutant strain R282Q was sensitive to the drug with an $\mathrm{IC}_{50}$ value of $28 \pm$ $1 \mu \mathrm{M}$ (Fig. 2.3.16), indicating that there are some differences in the effects of laulimalide relative to PelA since R282Q strain was completely resistant to PelA (Fig. 2.3.12). 
As stated earlier laulimalide was more potent than PelA in several deletion mutant strains. The $\mathrm{IC}_{50}$ values showed that laulimalide showed 10-fold the activity of PelA in pump knock out deletion strains, 1.5 -fold the activity in the mad2 $\Delta$ strain, and the same activity in the haploid wild type strain (BY4741) (Table. 2.3.3).

Figure. 2.3.13. Growth inhibition curves for yeast strains treated with different concentrations of aza-epothilone (ixabepilone)
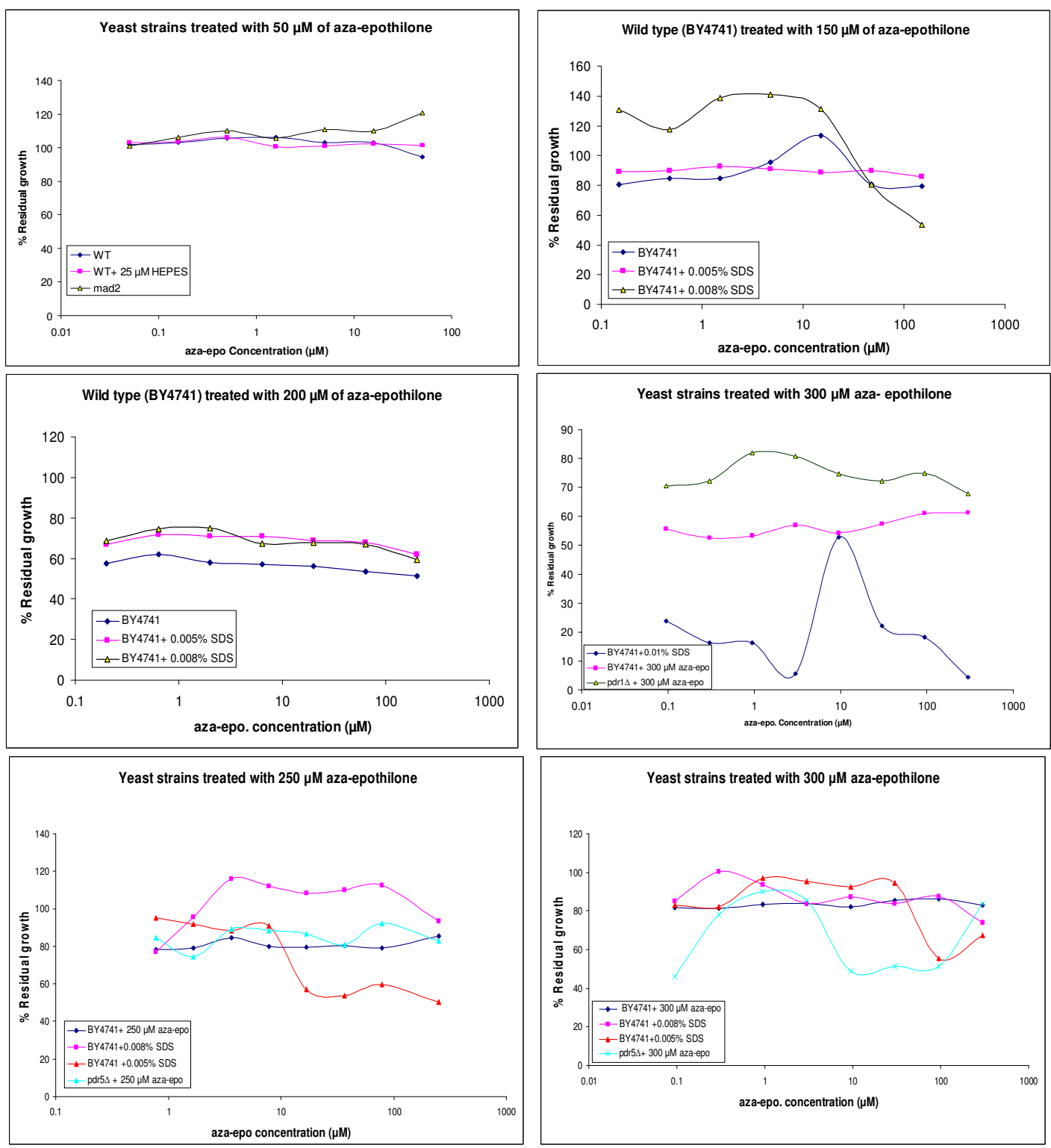

Yeast growth inhibition curves for ixabepilone (single representative experiments) are presented for different yeast strains. The haploid wild type (BY4741) strain and the other deletion mutant strains $\operatorname{mad} 2 \Delta, p d r 1 \Delta$, and $p d r 5 \Delta$ were treated with ixabepilone for $18 \mathrm{hr}$. 
Figure. 2.3.14. Growth inhibition curves of wild type, $\operatorname{mad} 2 \Delta$, and pump mutant strains treated with $50 \mu \mathrm{M}$ laulimalide

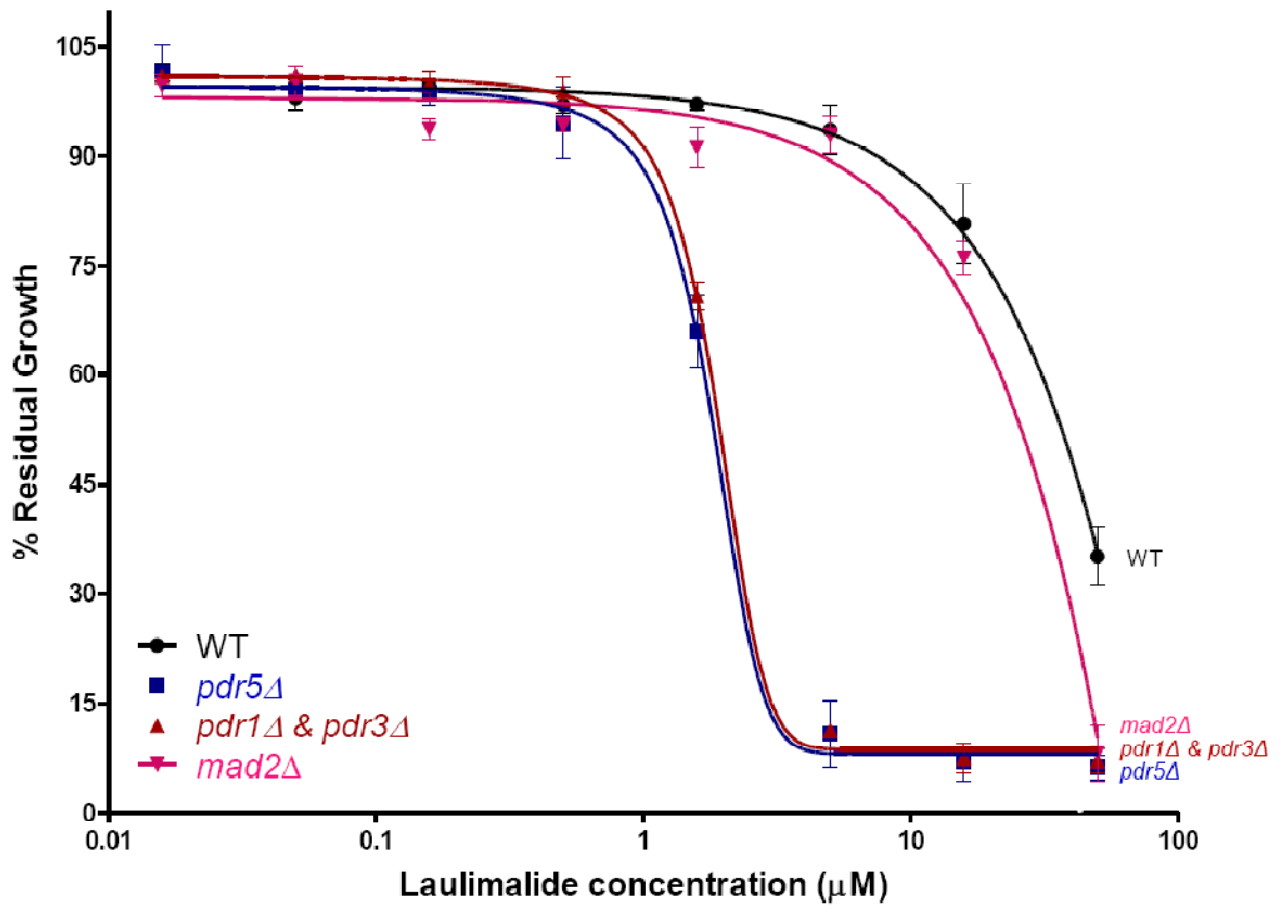

The half-log dose-response curves for the haploid wild type BY4741 (WT), as well as the deletion mutant strains $p d r 5 \Delta, P D R$-deficient strain ( $p d r 1 \Delta \& p d r 3 \Delta)$, and mad2 $\Delta$ treated with laulimalide for $18 \mathrm{hr}$ are presented. Refer to Table 2.3 .2 for a summary of growth inhibition results at $50 \mu \mathrm{M}$. Data are presented as the mean \pm SD of three independent experiments $(n=3$ experiments with one biological replicate) $\pm \mathrm{SD}$. $\mathrm{IC}_{50}$ values were calculated and are presented in Table. 2.3.3.

\section{Table. 2.3.2. Percentage of growth inhibition of haploid mutant deletion} strains treated with laulimalide

\begin{tabular}{|c|c|}
\hline Yeast strain & $\begin{array}{c}\text { \% residual growth } \\
\text { (relative to DMSO-treated cells at } 50 \boldsymbol{\mu M} \pm \mathbf{S D})\end{array}$ \\
\hline $\mathrm{WT}(\mathrm{BY} 4741)$ & $35 \pm 4 \%$ \\
\hline$m a d 2 \Delta$ & $8 \pm 4 \%$ \\
\hline$p d r 5 \Delta$ & $6 \pm 2 \%$ \\
\hline$p d r 1 \Delta \& p d r 3 \Delta$ & $7 \pm 2 \%$ \\
\hline
\end{tabular}

The haploid strain BY4741 and three haploid deletion strains were treated with $50 \mu \mathrm{M}$ laulimalide for $18 \mathrm{hr}$. The percent of growth (relative to DMSO-treated cells) at the highest concentration $(50 \mu \mathrm{M})$ is presented in this table. Data are presented as the mean \pm SD of three independent experiments $(n=3$ experiments with one biological replicate). $\mathrm{IC}_{50}$ values were calculated and are presented in Table 2.3.3. The data presented here are the same as in Fig. 2.3.14. 
Figure. 2.3.15. Growth inhibition curves of $\operatorname{mad} 2 \Delta$ and $t u b 2$ mutant strains treated with laulimalide

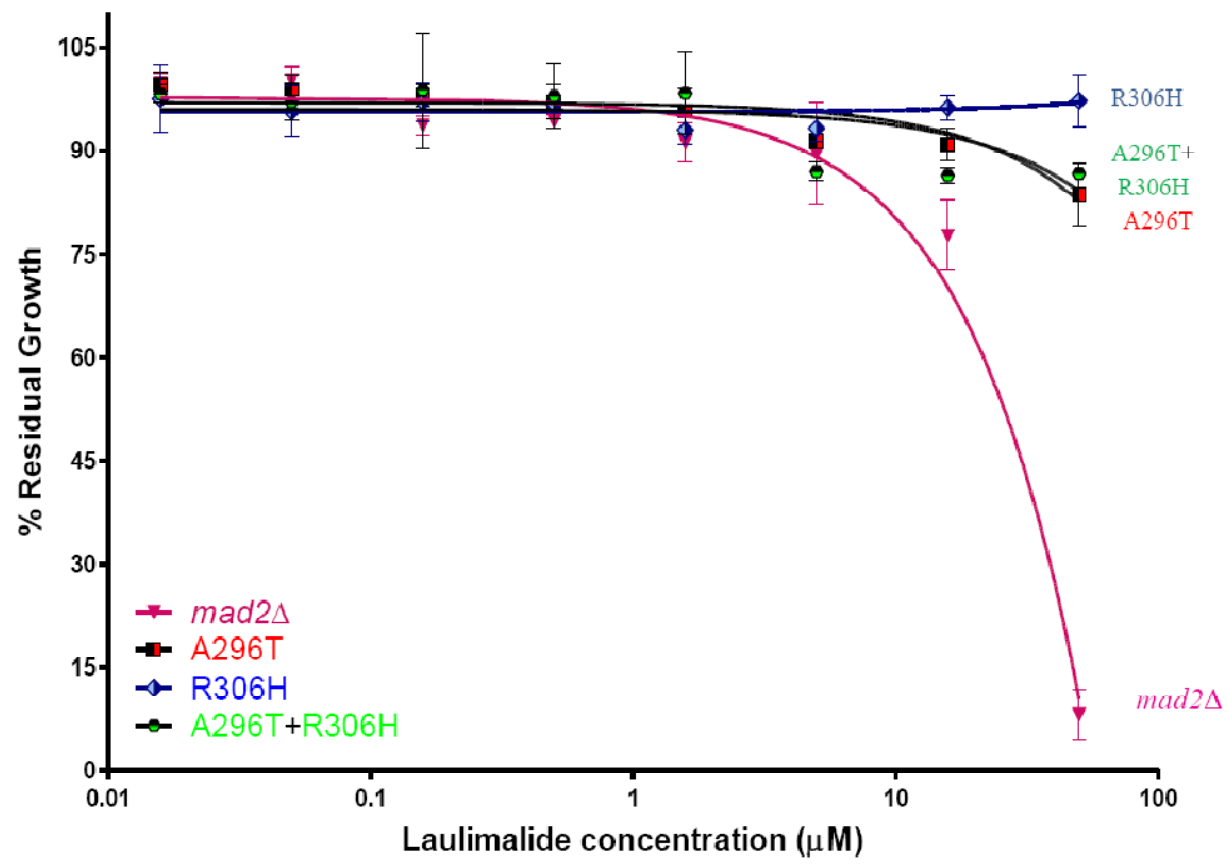

The three PelA-mutant strains (A296T, R306H, and A296T+R306H), and the haploid deletion mutant background strain $\operatorname{mad} 2 \Delta$ (positive control) were treated with up to $50 \mu \mathrm{M}$ laulimalide for $18 \mathrm{hr}$. Data are presented as the mean $\pm \mathrm{SD}$ of three independent experiments $(\mathrm{n}=3$ experiments with one biological replicate).

Figure. 2.3.16. Growth inhibition curves of the predicted $t u b 2$ point mutation strains treated with $50 \mu \mathrm{M}$ laulimalide

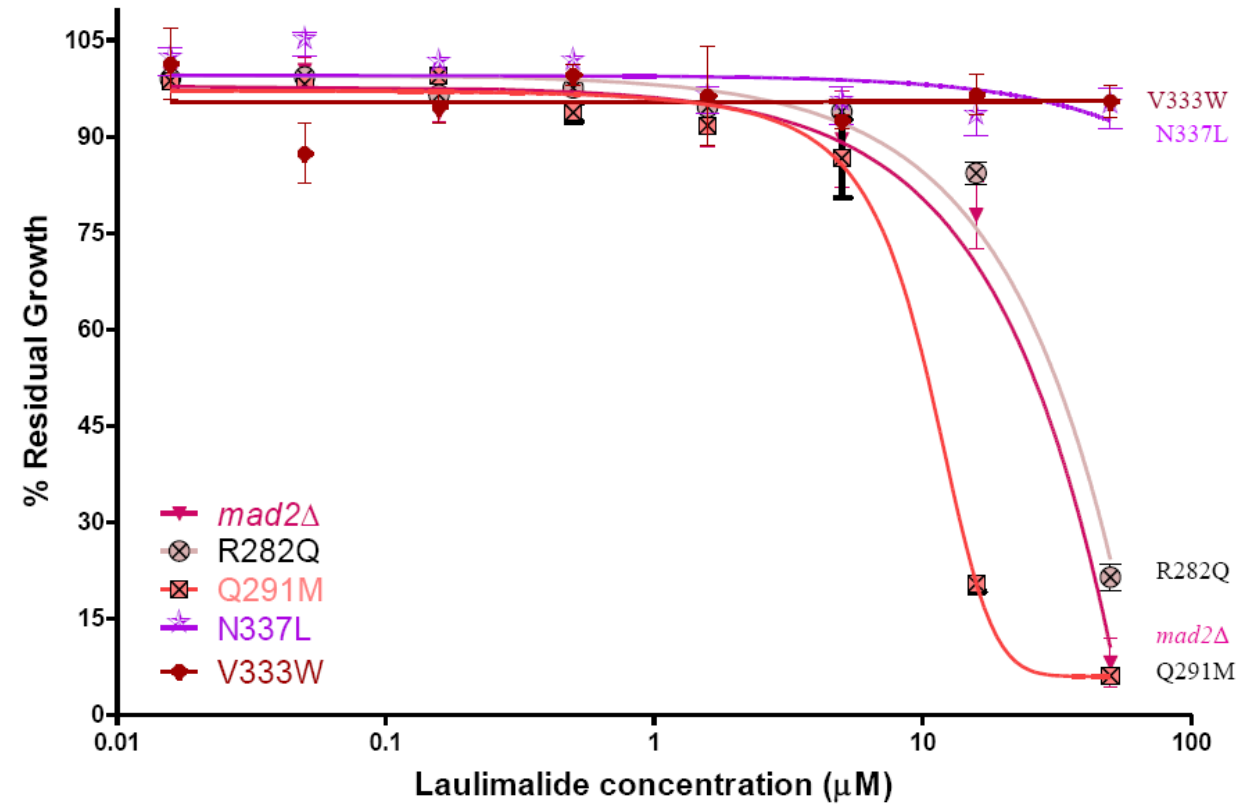

Dose-response curves for laulimalide were generated for the four predictive PelA-mutant strains (Q291M, N337L, and V333W and R282Q), and the haploid deletion mutant background strain mad2A (positive control) treated with up to $50 \mu \mathrm{M}$ laulimalide for $18 \mathrm{hr}$. Data are presented as the mean \pm SD of three independent experiments ( $n=3$ experiments with one biological replicate). Please note that the $\operatorname{mad} 2 \Delta$ growth curve is the same as presented in Fig. 2.3.15, and the mutant strain curves were done along with the other three mutants, but the results are graphed separately for clarity. 
Table. 2.3.3. $\mathrm{IC}_{50}$ values of yeast strains treated with $50 \mu \mathrm{M}$ PelA and/or laulimalide

\begin{tabular}{|c|c|c|c|}
\hline Drug & PelA & Laulimalide & $\begin{array}{c}\text { Ratio } \\
\text { PelA/Lau }\end{array}$ \\
\hline \multicolumn{4}{|l|}{ Strains \pm SD } \\
\hline $\mathrm{WT} \pm \mathrm{SD}$ & $49 \pm 1 \mu \mathrm{M}$ & $36 \pm 1 \mu \mathrm{M}$ & 1 \\
\hline $\operatorname{mad} 2 \Delta \pm \mathrm{SD}$ & $36 \pm 1 \mu \mathrm{M}$ & $24 \pm 1 \mu \mathrm{M}$ & 1.5 \\
\hline$p d r 5 \Delta \pm \mathrm{SD}$ & $29 \pm 1 \mu \mathrm{M}$ & $3 \pm 1 \mu \mathrm{M}$ & 10 \\
\hline$p d r 1 \Delta \& p d r 3 \Delta \pm \mathrm{SD}$ & $22 \pm 1 \mu \mathrm{M}$ & $2 \pm 1 \mu \mathrm{M}$ & 11 \\
\hline
\end{tabular}

$\mathrm{IC}_{50}$ values were calculated from dose-response curves for both PelA and laulimalide using SigmaPlot software (v10.0).

\subsubsection{The effect of PelA on the yeast cell cycle using bud index and flow cytometry assays}

To determine the PelA effect on the yeast cell cycle, and to verify whether PelA blocks yeast mitotic division at $\mathrm{G}_{2} / \mathrm{M}$ phase (similar to mammalian cell lines), two different assays were carried out. The first assay took advantage of the yeast cell cycle analysis. S. cerevisiae divides by budding and shows specific cell bud morphologies at different stages of the cell cycle (Qaddouri et al. 2009). Unbudded cells are in the $\mathrm{G}_{1}$ phase, small budded cells are in the $\mathrm{S}$ phase, and large budded cells are in the $\mathrm{G}_{2} / \mathrm{M}$ phase (Fig. 2.2.3). Thus, it is easy to monitor cell-cycle progression by simply observing cells using differential interference contrast microscopy. The effect of PelA on the bud index of the haploid deletion strain mad2 $\Delta$ was determined in PelA-treated cells vs. untreated (Fig. 2.3.17). At $40 \mu \mathrm{M}$ PelA, treated mad2 $\Delta$ cells showed an increase in the stage 4 (large budded cells) cells compared to untreated cells. The percentage of cells present in $\mathrm{G}_{2} / \mathrm{M}$ almost doubled in PelA-treated (34 $\pm 1 \%$ ) compared to DMSO-treated (control) cells (18 \pm 4\%) (Fig. 2.3.18), providing evidence that PelA has a similar mode of action in yeast to mammalian cells. A summary of bud-index percentage results is presented in Table. 2.3.4.

Another type of cell cycle analysis was then undertaken to determine whether PelA causes cell-cycle perturbation by measuring DNA content using FluorescenceActivated Cell Sorting (FACS). After $6 \mathrm{hr}$, PelA caused more cells (53\%) to be in $\mathrm{G}_{2} / \mathrm{M}$ in the treated sample compared to the untreated sample (16\%) (Fig. 2.3.19), demonstrating a blockage at $\mathrm{G}_{2} / \mathrm{M}$ in the treated sample compared to the untreated control, consistent with the bud index results. Two different flow cytometry 
experiments were performed, one in which the yeast cells were treated with $40 \mu \mathrm{M}$ PelA for $6 \mathrm{hr}$ and another in which treatment was for $18 \mathrm{hr}$. The $18 \mathrm{hr}$ experiment did not exhibit block at $\mathrm{G}_{2} / \mathrm{M}$ in PelA-treated cells relative to DMSO-treated control cells (data not presented).

Figure. 2.3.17. Bud index for $40 \mu \mathrm{M}$ PelA-treated and untreated $\operatorname{mad} 2 \Delta$ cells Untreated $40 \mu \mathrm{M}$ PelA, $6 \mathrm{hr}$

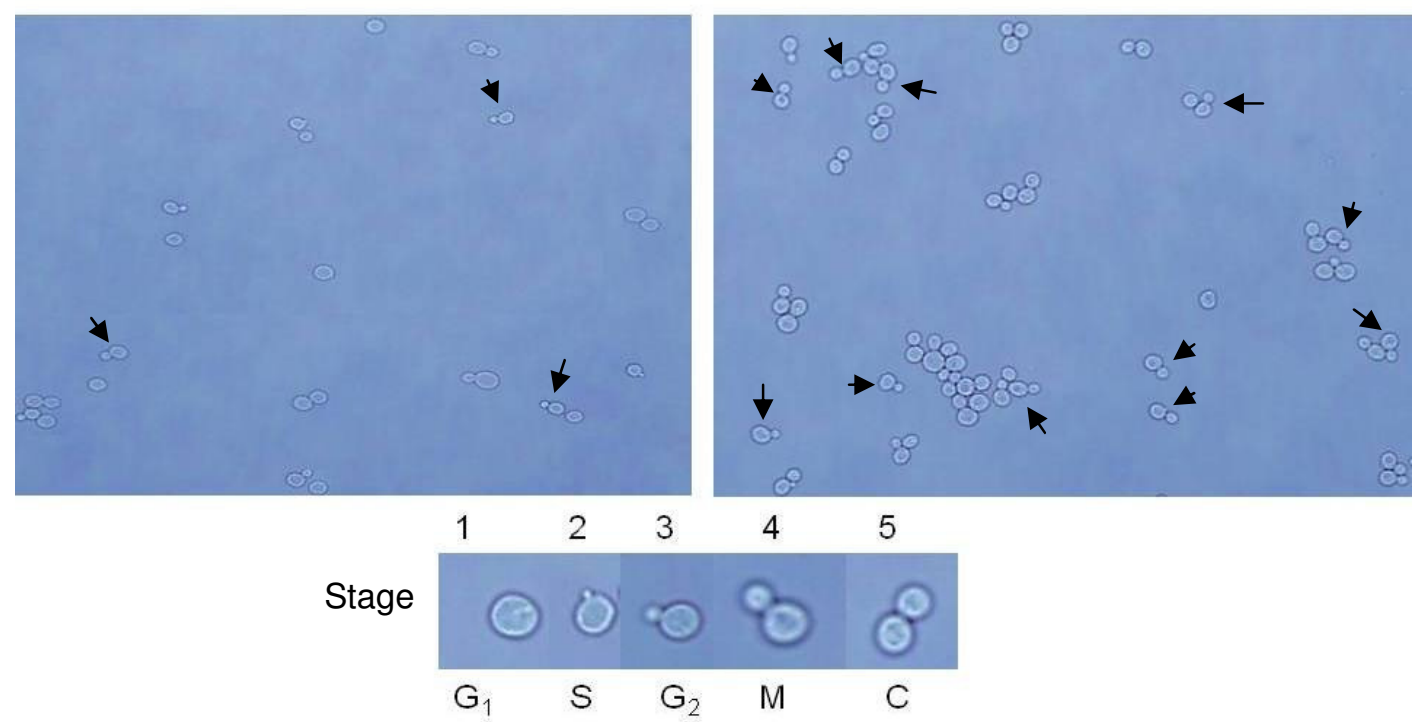

Phenotypic analysis of the yeast cell-cycle bud morphology stages. Bud index was measured for the growing haploid deletion mutant strain mad2 $\Delta$. The upper left image shows an untreated sample, and a $40 \mu \mathrm{M}$ PelA-treated sample is shown on the right. There was greater increase in the number of the large budded cells (stage 4) -black arrowheads- in the treated sample than in the untreated sample. Note that although there appear to be more cells in the treated sample than the untreated sample, the difference is due to sample pipetting error and not differences in cell number in the samples. The lower image classifies the buds according to their size and to the corresponding phase of the cell cycle. Cell cycle stages are $1=G_{1}, 2=S, 3=G_{2}, 4=$ mitosis $(M)$, and $5=$ cytokinesis $(C)$.

Figure. 2.3.18. Budding index histogram for $\operatorname{mad} 2 \Delta$ strain treated with $40 \mu \mathrm{M}$ PelA

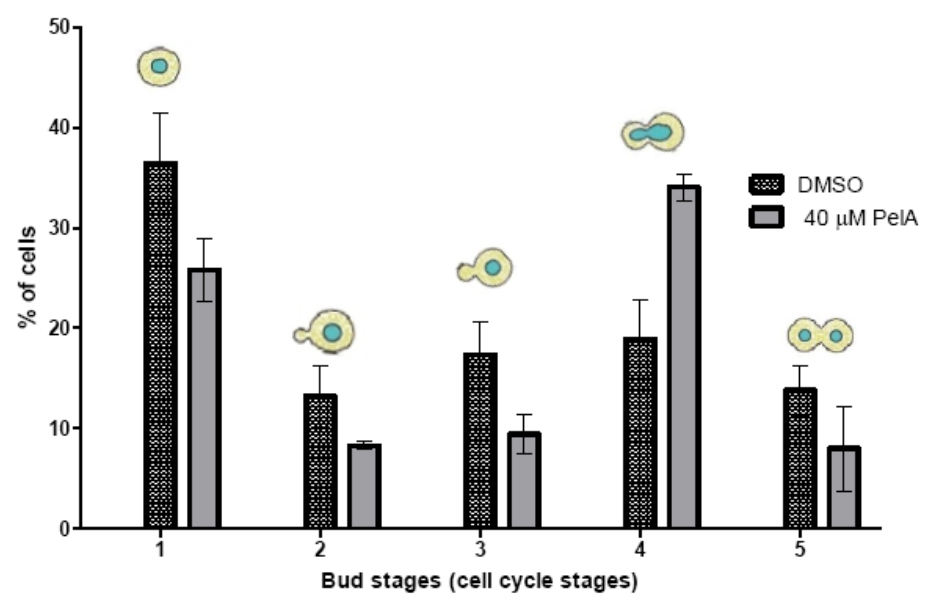

The haploid deletion mutant $\operatorname{mad} 2 \Delta$ cells were treated with $40 \mu \mathrm{M}$ PelA for $6 \mathrm{hr}$ at $30^{\circ} \mathrm{C}$. The histogram shows the percentage of cells present in each stage of the cell cycle. Cells were counted in each of three experiments for each stage, and the mean of the three independent experiments \pm SD is presented ( $n=3$ experiments with one biological replicate). Cell cycle stages are $1=G_{1}, 2=S, 3=G_{2}$, 4=mitosis (M), and 5= cytokinesis (C). Refer to Table. 2.3.4 for a summary of bud-index percentage results. 
Table. 2.3.4. Bud-index summary

\begin{tabular}{|l|c|c|c|c|c|}
\cline { 2 - 6 } \multicolumn{1}{c|}{} & $\begin{array}{c}\mathbf{G}_{1} \\
\text { (Unbudded) }\end{array}$ & $\begin{array}{c}\text { S } \\
\text { ( small bud) }\end{array}$ & $\begin{array}{c}\mathbf{G}_{2} \\
\text { (medium bud) }\end{array}$ & $\begin{array}{c}\text { M } \\
\text { (large bud) }\end{array}$ & $\begin{array}{c}\text { C } \\
\text { Cytokinesis }\end{array}$ \\
\hline DMSO & $37 \pm 5 \%$ & $13 \pm 3 \%$ & $17 \pm 3 \%$ & $18 \pm 4 \%$ & $14 \pm 3 \%$ \\
\hline PelA & $26 \pm 3 \%$ & $8 \pm 1 \%$ & $9 \pm 2 \%$ & $34 \pm 1 \%$ & $8 \pm 4 \%$ \\
\hline
\end{tabular}

Budding index percentages were calculated for growing $\operatorname{mad} 2 \Delta$ cells. There was 2 -fold increase in cell number in stage 4 . Results are presented as the mean of three independent experiments $\pm \operatorname{SD}(n=3$ experiments with one biological replicate). Data are the same as in Fig. 2.3.14.

Figure. 2.3.19. Flow cytometry for mad2 $\Delta$ cells treated with $40 \mu \mathrm{M}$ PelA

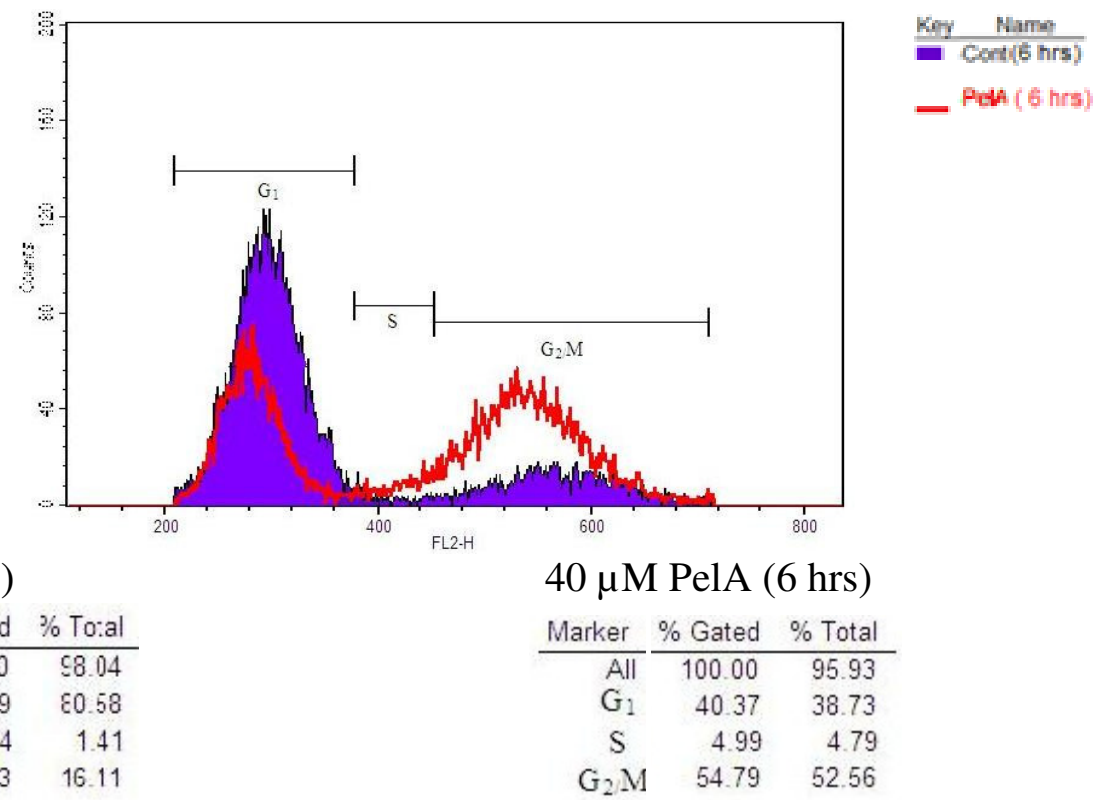

Flow cytometry analysis for the haploid $\operatorname{mad} 2 \Delta$ strain treated with $40 \mu \mathrm{M}$ PelA. After $6 \mathrm{hr}$, PelA caused a 3.5 -fold increase in cells to be in $\mathrm{G}_{2} / \mathrm{M}(53 \%)$ in the treated sample (red line) compared to the untreated sample (16\%) (purple shade). Only a single experiment was carried out due to the limited supply of the drug. 


\subsubsection{The effect of PelA on microtubule morphology}

Reporter proteins are commonly used as markers in biotechnology to study various aspects of the gene expression machinery and thereby improve visualisation of gene expression. In S. cerevisiae, two genes encode alpha-tubulin: TUB1 and TUB3. Unlike $T U B 1$ which is essential for growth, TUB3 is expressed at low levels and is not essential for growth. The $\alpha$-tubulin genes were chosen to be labelled with GFP because yeast cells are relatively insensitive to the level of expression of $\alpha$-tubulin, whereas overexpression of $\beta$-tubulin is lethal (Burke et al. 1989; Katz et al. 1990; Weinstein and Solomon, 1990). TUB1 and TUB3 encode functionally identical $\alpha-$ tubulin proteins (Schatz et al. 1986b). In this section, a strain of cells that express green fluorescence protein (GFP)-TUB3 was used. For reasons unrelated to the present study, these cells also express red fluorescent protein (RFP) as a nuclear localisation signal and mCherry as cytoplasmic signal (data gathered from the RFP and mCherry was not used in this study). Fluorescent cell images were collected in an Opera confocal laser microscope. There was a 3-fold increase in the number of cells containing microtubular-spindles after treatment with $50 \mu \mathrm{M}$ PelA for $5 \mathrm{hr}$ at $30^{\circ} \mathrm{C}$ relative to untreated (Fig. 2.3.21). A similar effect was observed after $7 \mathrm{hr}$, but the GFP expression seemed to be lost after $10 \mathrm{hr}$. The microtubule-spindles were more easily visualised in black and white images than in coloured images (Fig. 2.3.20 vs. Fig. 2.3.21). The spindles were mostly visible in large budded cells in which the microtubule spindle is shared between the mother and daughter cells. In the PelA-treated sample, the microtubule-spindles were more pronounced or distinct compared to the spindles seen in the untreated samples. The percentage of cells with spindles vs. non-spindles was calculated manually from visual examination of the images (Table. 2.3.5). The number of cells present in the untreated sample ranged from 400 to 500 cells per image, and in the treated sample from 600 to 700 cells per image. Five images were counted per sample, and all cells in the image were included in the analysis. The GFP results are consistent with the bud-index experimental results, since an increase in the large budded cells in the bud index assay was also seen at $\mathrm{G}_{2} / \mathrm{M}$ stage. 
Figure. 2.3.20. Alpha-Tubulin (TUB3)-GFP, RFP and mCherry colour images.
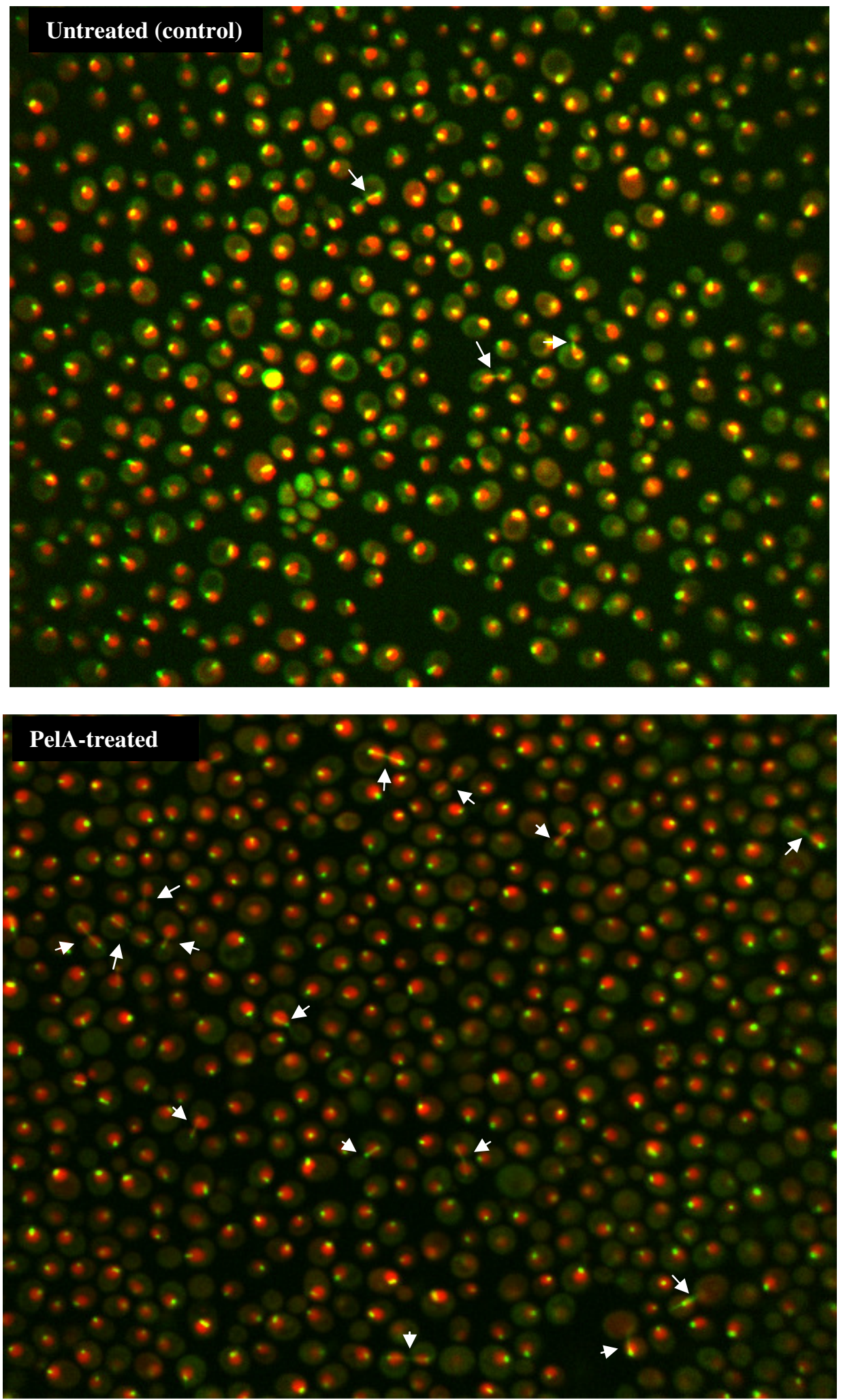

An example of yeast TUB3-GFP and RFP images under the Opera microscope. Cells were treated with or without $50 \mu \mathrm{M}$ PelA. Red fluorescence is the nuclear localisation signal; green labels the microtubule-spindles. The spindle in large budded cells can be visualised as an elongated yellowgreen set of spindle fibres surrounded by the red fluorescence of the nucleus. The microtubule-spindle is shared between the daughter and the mother yeast cell. Yeast cells at $\mathrm{G}_{2} / \mathrm{M}$ stage are labelled by white arrow heads. Based on two biological replicates. 
Figure. 2.3.21. Alpha-Tubulin (TUB3)-GFP grayscale images
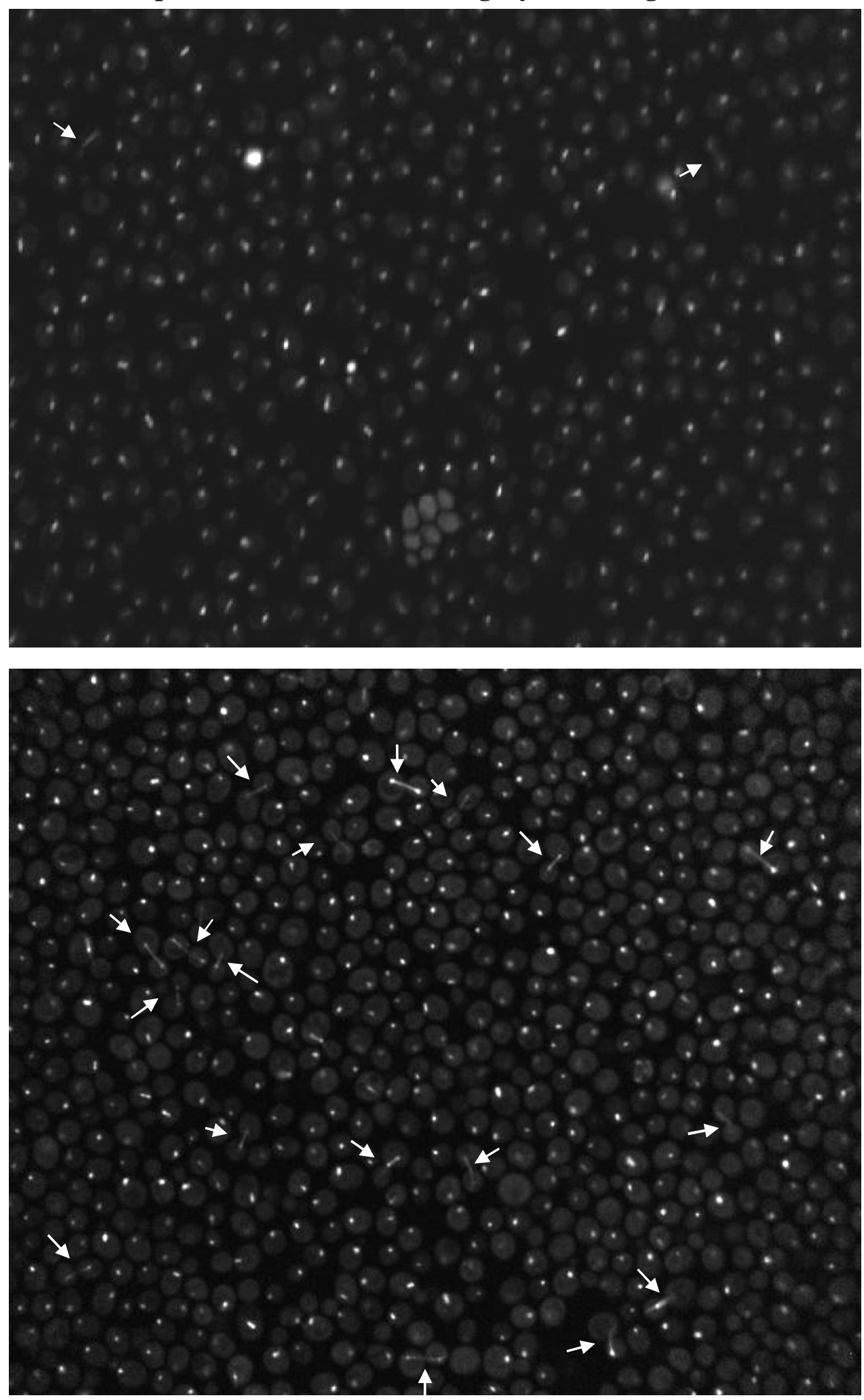

The top image shows untreated cells (medium alone), and the bottom image shows $50 \mu \mathrm{M}$ PelAtreated cells. Cells were treated for $6 \mathrm{hr}$ before taking images. There was an increase in the number of yeast cells at $\mathrm{G}_{2} / \mathrm{M}$ stage (white arrows) compared to untreated cells. These large budded cells display microtubule-spindles that are shared between the daughter and the mother yeast cell. Based on two biological replicates. 
Table. 2.3.5. Percentage of cells with a spindle in PelA-treated and untreated TUB3-GFP cells

\begin{tabular}{|l|c|}
\cline { 2 - 2 } \multicolumn{1}{c|}{} & Cells with spindle ( \pm SEM) \\
\hline Untreated cells & $2 \pm 1 \%$ \\
\hline Treated cells & $6 \pm 1 \%$ \\
\hline
\end{tabular}

The percentage of cells containing cells with a microtubular-spindle in $50 \mu \mathrm{M}$ PelA-treated vs. untreated cultures. There was a 3-fold increase in the number of spindle-containing cells in the PelAtreated sample compared to the untreated sample. Data are based on the total number of cells counted per image from two biological replicates. 


\subsection{Discussion}

\section{Mapping PelA binding-site}

To start with, it was important to prove that PelA exerted its effect on yeast growth via targeting the microtubules, since a secondary, microtubule-independent target could also be involved in its action. It was also very important to at least indirectly confirm that PelA actually binds to yeast tubulin in the region predicted by Huzil et al. (2008), and therefore mapping the binding site on yeast tubulin would provide useful information about the mammalian binding site for PelA. Thus, by mutating amino acids in the proposed Huzil et al. binding site, it was expected that the action of PelA would be altered, and this would provide indirect evidence that PelA actually interacted with $\beta$-tubulin in this region.

Site-directed mutations in yeast were based on a computer modelling study being carried out by Jim Snyder et al. (unpublished data) at Emory University in Atlanta that showed PelA participating in 4 hydrogen bonds to 4 different residues in the proposed tubulin-binding site (refer to Fig. 2.1.2 in the introduction section of this chapter). Previous studies in mammalian cell lines (Paraskevi Giannakakou, unpublished data) showed that a mutation in $\beta$-tubulin residue Arg306 to either histidine or cytosine resulted in loss of PelA activity, indicating that this residue may have a direct interaction with PelA in its binding site. The Snyder group computer docking studies suggested that Arg306 interacts with the 7-OMe group of PelA. A similar argument applies for Ala296 when changed to threonine (Wilmes $\mathrm{PhD}$ thesis, 2008). Our results were consistent with that seen in mammalian cell lines (Fig. 2.3.11).

Based on the Snyder model, however, another predicted hydrogen bonding interaction that should block PelA binding was Gln291. However, changing Gln291 to methionine resulted in a hypersensitive colony, rather than a resistant colony. Glutamine is an amino acid with a hydrophilic side chain that may interact with PelA through H-bonding (from the amide group). The rationale was to change Gln to an amino acid that has a hydrophobic side group like Met in order to examine the importance of the H-bonding between Gln291 and PelA. Gln291Met resulted in a hypersensitive colony (Fig. 2.3.12) (where it was supposed to be resistant due to the loss of H-bonding, not sensitive). This might be due to either a lack of H-bond interaction between this residue and PelA or a poor choice of the amino acids for the 
mutation. In the case of another mutation that was expected to reduce PelA binding, conversion of Asn337 to leucine, the rationale for the choice was made based on changing an amino acid with an H-binding (active amide group in Asn) to some other amino acid with no H-binding like Leu. This change resulted in a PelAresistant colony (Fig. 2.3.12); thus, the loss of PelA activity (resistance) may indicate a direct interaction of this residue with the 2-OH of PelA. According to the Snyder model, the C-16 methyl group of PelA may have limited contact with Val333 of $\beta$ tubulin, thus changing it to another amino acid (e.g. Trp) might create a steric clash in this area due to the change in the size of the amino acid with Trp being larger than Val (Table. 2.4.1.). This alteration was tested in our study, and the mutation conferred resistance to PelA (Fig. 2.3.12). It was proposed in the Snyder model, as stated earlier, that PelA has only very limited contacts with hydrophobic residues; thus, changing the amino acid Val333 to Trp, a large-neutral amino acid, proved that loss of the hydrophobic contact reduced the binding of PelA and therefore conferred resistance to the drug.

Table. 2.4.1. Amino acids properties used in this study and their phenotype with other MSA

\begin{tabular}{c|c|c|c|c|c|c} 
Residues & Abbrev. & Residue property & $\begin{array}{c}\text { Altered } \\
\text { Residue }\end{array}$ & Abbrev. & Residue property & $\begin{array}{c}\text { Effect with other } \\
\text { MSA (i.e. } \\
\text { laulimalide) }\end{array}$ \\
\hline Ala296 & A & $\begin{array}{c}\text { Acyclic, small, } \\
\text { neutral, } \\
\text { hydrophobic }\end{array}$ & Thr & $\mathrm{T}$ & $\begin{array}{c}\text { Acyclic, medium, } \\
\text { neutral, polar }\end{array}$ & $\mathrm{IC}_{50}>50 \mu \mathrm{M}$ \\
\hline Arg282 & $\mathrm{R}$ & $\begin{array}{c}\text { Acyclic, basic, } \\
\text { charged, large, } \\
\text { polar, positive }\end{array}$ & His & $\mathrm{H}$ & $\begin{array}{c}\text { Aromatic, basic, } \\
\text { charged, cyclic, } \\
\text { large, neutral, } \\
\text { polar, positive }\end{array}$ & $\mathrm{IC}_{50}>50 \mu \mathrm{M}$ \\
\hline Asn337 & $\mathrm{N}$ & $\begin{array}{c}\text { Acyclic, basic, } \\
\text { charged, large, } \\
\text { polar, positive }\end{array}$ & Gln & $\mathrm{Q}$ & $\begin{array}{c}\text { Acyclic, neutral, } \\
\text { large, polar }\end{array}$ & $\mathrm{IC}_{50}<50 \mu \mathrm{M}$ \\
\hline Acyclic, neutral, \\
Gln291
\end{tabular}

This table summarizes the chemical properties of the amino acids that should be involved in PelA binding, based on the computer modelling data of Snyder and Thepchatri (unpublished data). It also presents the chemical properties of the replacement amino acid in the mutated tubulin.

Based on the current Snyder and Huzil models, other residue mutations that might be worth exploring are: F296, Y312, Val315, Y342, and V335 since models of laulimalide (Thepchatri and Snyder, unpublished data) suggest these residues play an 
important part in hydrophobic anchoring and suggests that laulimalide is greatly affected by these mutations, but PelA is not affected. The Snyder model of PelA binding does not propose interactions with any of these residues. If the activity of PelA is altered by mutation of these residues, the model will need to be modified to reflect these contacts (Thepchatri and Snyder, unpublished data). Perhaps one of these would have been a better negative mutation than amino acid R282Q, the epothilone-resistance mutation.

\section{Growth inhibition effects of ixabepilone and laulimalide on PelA-resistance strains}

Paclitaxel is known to require five amino acid mutations before it can interact with the microtubules of yeast in vitro (Gupta et al. 2003); thus, it did not inhibit the proliferation of yeast at concentrations up to $150 \mu \mathrm{M}$, and it did not lead to $\mathrm{G}_{2} / \mathrm{M}$ block as detected by FACS analysis (Bode et al. 2002). According to Bode et al. (2002), epothilone B was also not effective in inhibiting yeast proliferation, possibly due either to metabolic transformation of the drug by the cells or inability of the drug to cross the yeast cell membrane. In the current study, aza-epothilone B (ixabepilone) was ineffective at concentrations up to $300 \mu \mathrm{M}$ in various yeast strains including the drug efflux pump knockout strains ( $p d r 5 \Delta$ and $p d r 1 \Delta$ ) (Fig. 2.3.13). Moreover, the addition of a cell membrane permeable agent SDS to the treated cells along with the drug did not aid in uptake of the drug i.e. there was still no inhibition of yeast proliferation. One should keep in mind that ixabepilone is a derivative of epothilone $\mathrm{B}$, and the modification to its chemical structure makes it less toxic. The modification may also reduce its binding to isolated yeast tubulin, although this possibility has not been tested. Drug development certainly requires generating a number of analogs of drug candidates. Some of these analogs may have the same activity as the parent compound in a pharmacological assay but show reduced activity towards the tested organism in vivo. Others may show reduced activity toward the pharmacologically relevant target but similar activity towards the tested organism (Roberge, 2008).

Preliminary screens with laulimalide showed that this drug was even more potent than PelA in the PelA-sensitive yeast strains (Fig. 2.3.10). More specifically, it was very potent in the pump knockout strains, shifting their growth curves to a lower $\mu \mathrm{M}$ concentration by almost 12-fold (Fig. 2.3.14). When this drug was tested against the site-directed point mutation strains, the results were similar to PelA, except for the 
Arg282Gln mutation. This point mutation was initially included in this study as a negative control for PelA, but a positive control for epothilone derivatives, as it is an epothilone B-resistant point mutation in mammalian cells (Giannakakou et al. 2000). According to Giannakakou et al. (2000) amino acid Arg282 sits on the M loop in $\beta$ tubulin. The $\mathrm{M}$ loop is believed to be important for lateral contacts between protofilaments and is located near the taxane binding site. However, since ixabepilone was not effective in yeast at concentrations up to $300 \mu \mathrm{M}$, no resistance could be measured. Nevertheless, this specific point mutation was semi-sensitive to laulimalide (Fig. 2.3.16) but not to PelA (Fig. 2.3.12), indicating that there might be some differences in the binding site between these two drugs. This is the first direct experimental evidence that PelA and laulimalide may bind differently to tubulin. Previous studies in mammalian cells by Gaitanos et al. (2004) showed that PelA and laulimalide bound to a similar or overlapping site on the microtubules, based on binding competition experiments. It is worthwhile to keep in mind that point mutations may change conditions globally in the molecule and as such, cause shifts in the 'energy landscape' since a resistance was also seen when an amino acid outside this site was altered, and this might reflect a global conformation change in the $\beta$-tubulin protein. They may also alter the distributions of the conformational substates in a way similar to that of an external agent, such as temperature, $\mathrm{pH}$, ionic strength, or pressure, or they may mimic a change in the binding conditions of a drug (Tsai et al. 1999; Kumar et al. 2000). Thus, effects of the mutations on drug sensitivities do not prove the amino acid involved is located at the binding site.

\section{Microtubule morphology changes}

Cell-cycle analysis of $S$. cerevisiae using bud index analysis showed specific cell morphologies at different stages of the cell cycle. The proportion of unbudded $\left(\mathrm{G}_{1}\right)$, small budded $(S)$, and large budded $\left(\mathrm{G}_{2} / \mathrm{M}\right)$ cells in the presence or absence of PelA was determined. As shown in Table. 2.3.4 and in comparison with untreated cells, more cells (2- fold) in the PelA-treated group were at the $\mathrm{G}_{2} / \mathrm{M}$ stage (34\% large budded compared to $18 \%$ in the untreated sample), and fewer cells were in $G_{1}$ or $S$ and $\mathrm{C}$ phases of the cell cycle. The use of flow cytometry to monitor the cell cycle of individual cells in a population has been a standard tool for cell cycle studies in both mammalian cells and yeast cells. Flow cytometry analysis showed that after PelA treatment for $6 \mathrm{hr}$, a 3-fold increase in the proportion of cells in the $\mathrm{G}_{2} / \mathrm{M}$ stage was seen $(53 \%$ in the treated sample compared to $16 \%$ in the untreated sample). A similar 
effect was not seen with a longer PelA exposure of $18 \mathrm{hr}$. The early triggering of a reversible growth arrest may eventually lead to cell death with longer exposures. The short-term $6 \mathrm{hr}$ exposure data are consistent with the bud index analysis. Together, these results suggest that treatment with PelA blocks cells at $\mathrm{G}_{2} / \mathrm{M}$ and prevents or slows further progression through the cell cycle. Cell cycle block supports the hypothesis that PelA binds and stabilises microtubules in yeast in a similar manner to that seen in mammalian cells (Hood et al. 2002).

\section{Observing yeast GFP-tubulin}

Other confirmation that PelA actually binds yeast tubulin comes from the yeast microtubule morphology changes seen upon addition of PelA in yeast with GFPtagged tubulin fusion protein. When PelA was added (Fig. 2.3.21), there was 3-fold (Table. 2.3.5) increase in the number of budded cells with long microtubule fibers or 'spindles' shared between the mother and daughter cells. Thus, as with the cell cycle block results, PelA behaved in a similar way to mammalian cells, presumably binding to and stabilising polymerised microtubules. Finally, the other evidence that the PelA targets tubulin in yeast comes from the fact that mutations in the putative tubulin-binding site (Huzil et al. 2008; Snyder and Thepchatri, unpublished results) conferred resistance to PelA in both yeast and mammalian cells.

In conclusion, we found that of the six point mutations generated, only Q291M failed to confer resistance in yeast. One of the mutations near the taxoid site (R282Q) that was not expected to confer resistance to PelA gave resistance to PelA but not to laulimalide. Overall, our data suggest that PelA binds to yeast tubulin in the region predicted by the published model of the binding site in mammalian cells (Huzil et al. 2008) and that proposed by Snyder and Thepchatri (unpublished results). Our data support a binding site on $\beta$-tubulin rather than the $\alpha$-tubulin site predicted by Pineda et al. (2004) and Jimenez-Barbero et al. (2006). Therefore, mapping the site on yeast tubulin could provide useful information about the mammalian binding site for PelA and laulimalide. This hypothesis is supported by the evolutionary conservation of sequence in these areas. Comparing PelA and laulimalide, a number of differences were seen. First, the two MSA had different $\mathrm{IC}_{50}$ values, with laulimalide being 10fold more potent in the pump knockout strains, equipotent in the haploid wild-type and $50 \%$ more potent in the haploid deletion mutant $\operatorname{mad} 2 \Delta$. Second, there were different sensitivities to the R282Q mutation (the epothilone resistance site in 
mammalian cells), and third, there was a greater effect of the efflux pump mutants on sensitivity to laulimalide. Hence, a single altered amino acid can affect PelA binding but not laulimalide binding, and vice versa, if their binding sites overlap but are not identical. Moreover, the definition of the PelA binding site needs to be considered in view of the evidence of unique binding interactions between purportedly similar drug that bind to the same site as PelA like laulimalide or any other drug that has the same effect as PelA on yeast microtubule. From our results using flow cytometry and bud index comparisons and the fact that mutations at a proposed tubulin-binding site confer resistance to PelA, we conclude that the PelA mode of action is similar to that in mammalian cells with regard to microtubule stabilisation leading to cell cycle arrest at $\mathrm{G}_{2} / \mathrm{M}$.

\section{Future studies}

Additional experiments that could help to clarify the PelA and laulimalide mode of action in yeast would include in situ cellular tubulin polymerisation measurements by Western blotting (Hood et al. 2002) and tubulin immunocytochemistry to obtain better images of the effects of the drugs on the polymerised tubulin cytoskeleton. These studies had already been started, but due to the timeline of this project being limited, the studies were discontinued as a part of this thesis. Other future studies could continue with mapping the amino acids at, and outside, the PelA/laulimalide binding region in more detail to obtain unique binding profiles for the different MSA. Although paclitaxel and ixabepilone were not effective in yeast, a new MSA discovered recently with regard to its microtubule-stabilising activity, zampanolide (Field et al. 2009), may provide additional useful information on MSA interactions with specific amino acid residues on $\alpha$ - or $\beta$-tubulin. Experiments are currently in progress on determining the binding site of this new MSA. Preliminary experiments in yeast using zampanolide have revealed that the drug mode of action is similar to PelA in blocking cell cycle at $\mathrm{G}_{2} / \mathrm{M}$ (Natelle Quek, MSc student, Victoria University of Wellington, personal communication). It would be particularly useful if it was active in yeast and bound to the taxane site or even a totally unique site, since at present, none of the taxoid site drugs tested are effective in yeast. Finally, it would be helpful to take advantage of the ability to genetically manipulate yeast and use errorprone PCR to generate a set of resistant yeast strains. The information from these strains could then be used to better understand PelA and laulimalide interactions and mechanisms that cells use to escape the action of these drugs. 


\section{Chapter 3. Finding the secondary targets of peloruside via chemical genetics microarray profiling analysis.}

\subsection{Introduction}

\subsubsection{Introduction to microarray}

In the past decade, the development of chemical genomic profiling (DNA microarray) technology has widely contributed towards the rapid progress in the research of genetic network analysis. Establishing genetic interaction profiling for a bioactive compound has become relatively easy especially in yeast due to the small genomic size of this organism. The yeast genome was fully sequenced in 1996 (SGD Stanford). By the year 2001, a deletion mutant strain for every gene in yeast was available (Giaever et al. 2002), and this particularly aided in the rapid progress of the field of genetic analysis of networks and provided a wide range of genomic tools. One of the most important genetic tools was the collection of yeast deletion mutants for nonessential genes (Winzeler et al. 1999). These deletion strains have led to a wide range of microarray data that have been collected from numerous studies, enhancing our understanding of many biological processes like gene expression during essential cellular processes such as in cell division (Simon et al. 2001; Spellman et al. 1998), meiosis and spore formation (Rabitsch et al. 2001), cellular responses to altered nutrient conditions (Gelling et al. 2004), and responses to a wide range of stresses and drug treatments (Gasch et al. 2000; Alic et al. 2004).

The emergence of the new era of modern high-throughput genome-wide technologies like DNA microarray (and SGA) has revealed that a given function in our biological system is a result of multiple genetic interactions through networks and pathways. These networks or pathways of genes consist of modular units or nodes in which a group of genes commonly behave in the same manner across a set of experiments; therefore, these genes usually share a common cellular function (Bar-Joseph et al. 2003). From these studies, it has turned out that co-expressed gene nodes are usually regulated by common transcriptional regulators or regulatory networks. 


\subsubsection{Introduction to homozygous deletion profiling (HOP)}

The yeast knockout (YKO) deletion mutants strains were created by homologous recombination in which each gene was deleted from start to stop codon and replaced with a kanamycin resistance (KanMX) cassette that carries the G418-resistance marker, which is required for the selection of transformants (Giaever et al. 2002). (Fig. 3.1.1). Specifically, the KanMX cassette is about $56 \mathrm{bp}$ and is comprised of a unique 20 bp barcode 'TAG', flanked by shared (universal) primer sites for amplification by PCR, located immediately 5' of every mutant strains. These primers are common to all strains and are used for the amplification of the barcodes from a pooled culture with changes in individual strain abundance measured simultaneously in a DNA microarray. In all but 192 knockouts, a second cassette with similar structure but a different pair of universal primer sites is situated immediately 3 ' (Yuan et al. 2005).

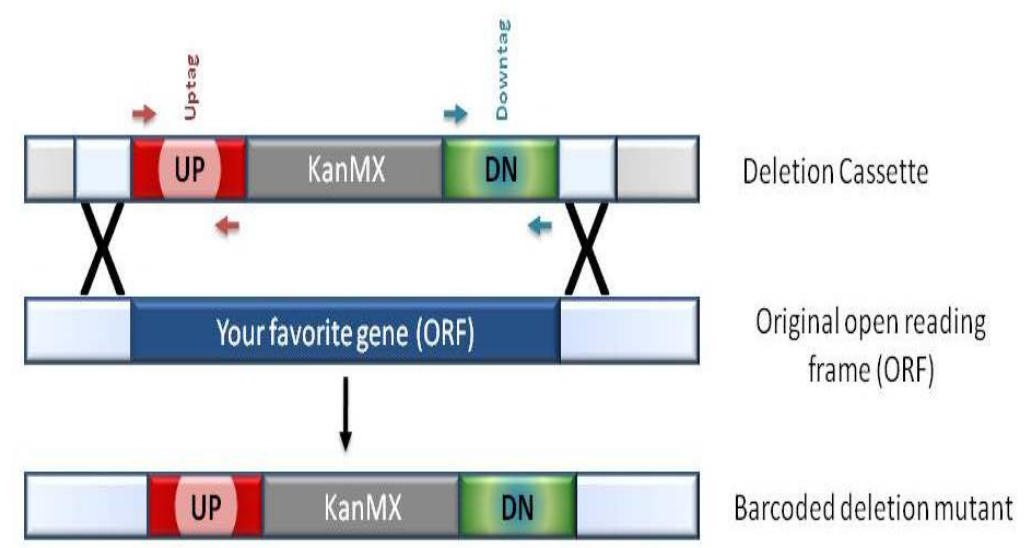

Figure. 3.1.1. Constructing yeast deletion mutant collection (YKO). This figure shows the KanMX deletion cassette flanked by the barcodes that are in turn flanked by four universal primer sites (coloured arrows) (figure adopted from Pierce et al. 2007).

Approximately a complete set of yeast gene deletion mutants (96\% of all open reading frames) is available for screening (Winzeler et al. 1999). In total 6000 genes have been deleted of which 1000 proved to be essential for growth; therefore, the gene deletion set consists of 5000 mutant strains (Giaever et al. 2002). Taking advantage of the unique barcode system, screening for the entire yeast gene deletion pool was made possible in a single experiment using chemical genomic profiling (microarray analysis). The DNA microarray contains complementary oligomers to the barcode sequences.

HOP makes use of a set of deletion mutants in which every ORF has been individually replaced with an antibiotic resistance marker, either as a haploid or 
homozygous diploid. The HOP assay can only be used for non-essential genes since a haploid mutation of an essential gene by definition will not grow (Armour and Lum 2005). The HOP assay normally generates a larger number of genetic interactions, and these interactions are functionally connected to the target but are not the target itself "friends of the target". In HOP, functional interactions between pathways targeted by the drug are revealed through the concept of synthetic lethality (Armour and Lum 2005). Synthetic lethality is a set of genetic enhancements (Hartman et al. 2001) in which two mutations come together to cause a significant growth defect, though each mutation separately has an observable phenotype on its own (Fig. 3.1.2). A phenotypic characteristic is generally determined by more than a single gene product.

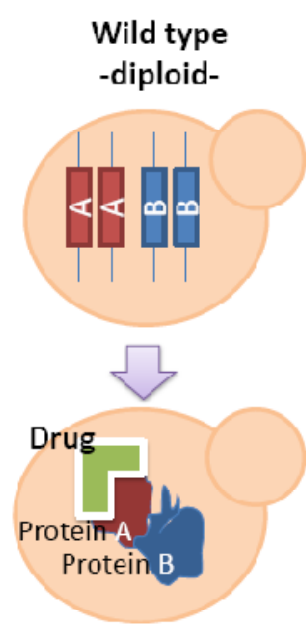

Growth

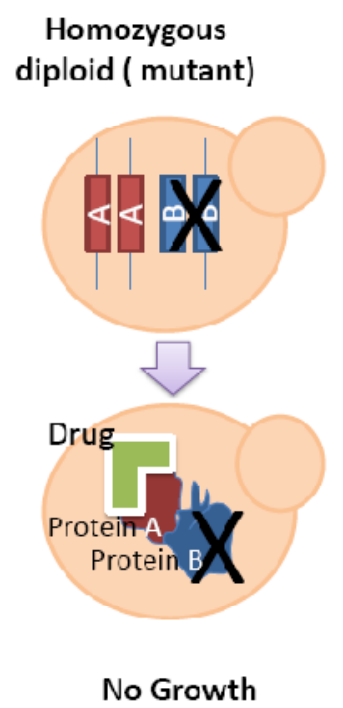

Figure. 3.1.2. Haploid homozygous mutants are used in the HOP assay. The diploid wild type has two copies of gene A and B; their protein products interact with each other and lead to the same function. In the addition of the drug that interacts with gene A, and inhibits gene A protein transcription. Absence of gene A protein products can be compensated for by gene B); therefore, the cell remain viable in the addition of the drug. In the homozygous diploid, both copies of gene B are deleted, the addition of the drugs exerts a synthetic lethal (synthetic chemical genetics) effect on the cell by acting as a second mutation to create a non-viable double mutant.

Yet, there are significant challenges facing the integration of large-scale analysis data sets of network, but the rapidly developing field suggests that this approach will be of enormous value in near future. As results of that, the wider emerging field of 'systems biology' that we are approaching today, where the regulation and standards that underlines the genome-wide regulation of gene modules and the greater regulatory network, currently are well understood. This information has major implications for biological and medical research. 


\subsubsection{Aims of this chapter}

The aim of this chapter is to use the HOP microarray, which uses homozygous diploid deletion strains (BY4743), to deduce functional information about the mechanism by which small molecules interact with particular genetic interactions pathways i.e. to reveal synthetic lethal interactions among genes (or pathways) that are normally required to buffer cellular responses against the cytotoxic effects of a drug. Different deletion mutant strains will display sensitivity towards the drug (PelA in the present study) i.e. reduced growth. The HOP screen will give functional information about the deleted genes, identify the mechanism of action of the drug, and reveal functionally related or connected genes that buffer the yeast cell against the drug's cytotoxic effect. The identification of the PelA-sensitive gene is made by noting the absence of the hybridisation signal (utilising the barcode identification system) in the drug-treated sample, thus revealing sensitivity of the corresponding deletion strain to the drug. Our hypothesis is that the HOP microarray will not identify the secondary targets of PelA but will link PelA to specific networks or biochemical pathways in the cells. 


\subsection{Materials and Methods}

\subsubsection{Yeast competitive growth assay}

Preliminary experiments of yeast half-logarithmic growth inhibition curves of the haploid wild type strain (BY4741) were performed by Anja Wilmes during her PhD study at Victoria University of Wellington (Wilmes PhD thesis, 2008) to work out an optimal concentration of PelA for the microarray. Concentrations of drug that only affect the wild type cells to a minimum extent $\left(\mathrm{IC}_{10}-\mathrm{IC}_{20}\right)$ are typically used for fitness profiling tests. The HOP microarray experiment was performed in duplicate (biological replicates were done one at a time) each time following a protocol provided by Dr. Rosemary Heathcote (ESR, Wellington) that was originally adopted from Yuan et al. (2004) and Parsons et al. (2006). A homozygous yeast knockout library pool (Invitrogen/Research Genetics Hom YKO pools) was stored at $-80^{\circ} \mathrm{C}$ at a cell concentration of $3.5 \times 10^{7}$ cells $/ 0.5 \mathrm{~mL}$. A $0.5 \mathrm{~mL}$ aliquot of this suspension was grown at $30^{\circ} \mathrm{C}$ in $10 \mathrm{~mL}$ of synthetic complete (SC) medium (Appendix I) supplemented with $2 \%$ glucose, $25 \mathrm{mM}$ HEPES and $0.1 \%$ G418 antibiotic (Geneticin, Gibco, Invitrogen). The cells were incubated overnight in a BioLane shaker incubator (Edwards Instrument Company, Australia). In order to ensure 1000fold coverage of each mutant, $5 \times 10^{6}$ cells were diluted into $10 \mathrm{~mL}$ SC medium containing $2 \%$ glucose and $25 \mathrm{mM}$ HEPES in the presence of $10 \mu \mathrm{M}$ PelA or a $0.1 \%$ DMSO control. After $15 \mathrm{hr}\left(\sim 10\right.$ generations), cells were re-diluted to $5 \times 10^{6}$ cells/10 mL and re-treated with PelA or DMSO for an additional $15 \mathrm{hr}(\sim 20$ generations total).

\subsubsection{Genomic DNA purification.}

The Master Pure ${ }^{\mathrm{TM}}$ yeast DNA purification kit (Epicentre Biotechnologies) was used following the manufacturer's instructions, followed by RNA degradation by addition of $1 \mu \mathrm{L}$ of RNase A $(5 \mu \mathrm{g} / \mu \mathrm{L})$ and incubation at $37^{\circ} \mathrm{C}$ for $30 \mathrm{~min}$. DNA was extracted by adding one volume of phenol/chloroform/isoamylalcohol (25:24:1), followed by vortexing and centrifuging at $16,000 \mathrm{~g}$ for $10 \mathrm{~min}$. DNA was further purified by taking the upper aqueous phase and adding one volume of chloroform, followed by vortexing and centrifugation at $16,000 \mathrm{~g}$ for $10 \mathrm{~min}$. The upper aqueous 
phase was again transferred into a new tube, and the DNA was precipitated with 2.5 volumes of ethanol (96\%) and 1/10 volume $3 \mathrm{M} \mathrm{Na}$ acetate $(\mathrm{pH} \mathrm{5.3).} \mathrm{The} \mathrm{samples}$ were incubated at $-20^{\circ} \mathrm{C}$ for $25 \mathrm{~min}$, followed by centrifugation at $16,000 \mathrm{~g}$ for 10 min. The DNA was washed with $70 \%$ ethanol and redissolved in $35 \mu \mathrm{L}$ TE buffer. DNA was quantified using Hoechst 33258 dye $(1 \mathrm{mg} / \mathrm{mL})$ (DNA Quantification kit DNA-QF, Sigma-Aldrich) following the manufacturer's instructions. Fluorescence was measured in a SpectraMax plate reader (Molecular Dynamics, Sunnyvale, CA) at $360 \mathrm{~nm}$ excitation and $460 \mathrm{~nm}$ emission wavelengths. A typical DNA concentration of $300 \mathrm{ng} / 5 \mu \mathrm{L}$ was obtained. DNA aliquots were adjusted to 25 $\mathrm{ng} / \mu \mathrm{L}$.

\subsubsection{Barcode amplification and $\mathrm{Cy} 3 / \mathrm{Cy} 5$-dye labelling by PCR}

PCR Master Mix was prepared in a DNA-free laminar flow hood. The composition of PCR Master Mix is given in Table 3.2.1. Four PCR reactions are required for each experiment. Up and Down tags were amplified in separate reactions for both the control and experimental DNA samples. DMSO-treated controls were labelled with primers containing $\mathrm{Cy} 3$, two reactions were prepared for control sample: the first reaction used UP tag PCR primers (Primers U1 and U2comp-Cy3), and the second one used DOWN tag PCR (Primers D1 and D2comp-Cy3) primers. PelA-treated samples were labelled with primers containing Cy5 using UP tag PCR primers (Primers U1 and U2comp-Cy5) in one reaction and DOWN tag PCR primers (Primers D1 and D2comp-Cy5) in the second reaction (see Table 3.2.2 for primer sequences). Negative controls for each reaction were included $\left(\mathrm{dH}_{2} \mathrm{O}\right.$ instead of DNA). In each PCR tube, $51.2 \mu \mathrm{L}$ of PCR Master Mix was mixed with $2.4 \mu \mathrm{L}$ labelled primer $(25 \mu \mathrm{M}$ stock) and $2.4 \mu \mathrm{L}$ unlabelled primer $(25 \mu \mathrm{M}$ stock). Final concentrations of primers were $1 \mu \mathrm{M}$. To all reactions, $4 \mu \mathrm{L}$ of $25 \mathrm{ng} / \mu \mathrm{L}$ DNA was added, except for negative controls in which $\mathrm{dH}_{2} \mathrm{O}$ was added instead. The final volume of each PCR reaction was $60 \mu \mathrm{L}$. PCR was carried out on a T-Gradient PCR machine $\left(\right.$ Biometra $\left.{ }^{\circledR}\right)$ with PCR settings as follows: $94^{\circ} \mathrm{C} 3 \mathrm{~min}, 94^{\circ} \mathrm{C} 30 \mathrm{sec}, 50^{\circ} \mathrm{C}$ $30 \mathrm{sec}, 72^{\circ} \mathrm{C} 30 \mathrm{sec}$ for 38 cycles, $72^{\circ} \mathrm{C} 5 \mathrm{~min}$ and pause at $10^{\circ} \mathrm{C}$. Following PCR, 5 $\mu \mathrm{L}$ of each PCR product was run on a $4 \%$ MetaPhor agarose gel for $1 \mathrm{~h}$ at $100 \mathrm{~V}$. The size of the amplified products for UP and DOWN tags was $56 \mathrm{bp}$. Tubes 
containing PCR products were wrapped in foil and stored at $-20^{\circ} \mathrm{C}$ (if hybridisation was not performed on the same day).

Table.3.2.1. PCR Master Mix

Reagent Volume in $\mu \mathrm{L}$ for $1 \mathrm{x} *$ reaction $\quad$ Final concentration

$10 \times$ Platinum taq buffer

$50 \mathrm{mM} \mathrm{MgCl} 2$

6

$1 \mathrm{x}$

dNTPs (10 mM each)

$1.8 \quad 1.5 \mathrm{mM}$

Platinum taq $(5 \mathrm{U} / \mu \mathrm{L})$

1.2

$0.2 \mathrm{mM}$

$\mathrm{dH}_{2} \mathrm{O}$

0.2

$1 \mathrm{U}$

Total Volume

$60 \mu \mathrm{L}$

${ }^{*}$ Reaction mixture for a single PCR reaction (9x master mix was prepared for one array).

Table. 3.2.2. Primer sequences for yeast microarray

Primer name

Down1

Up1

Down2 labelled Cy3 or Cy5

Up2 labelled $\mathrm{Cy} 3$ or $\mathrm{Cy} 5$
Primer sequence

5'-CGGTGTCGGTCTCGTAG
5'-GATGTCCACGAGGTCTCT
5'-Cy[3/5]-CGAGCTCGAATTCATCGAT
5'-Cy[3/5]-GTCGACCTGCAGCGTACG

5'-CGGTGTCGGTCTCGTAG

5'-Cy[3/5]-CGAGCTCGAATTCATCGAT

5'-Cy[3/5]-GTCGACCTGCAGCGTACG

PCR settings for yeast microarray

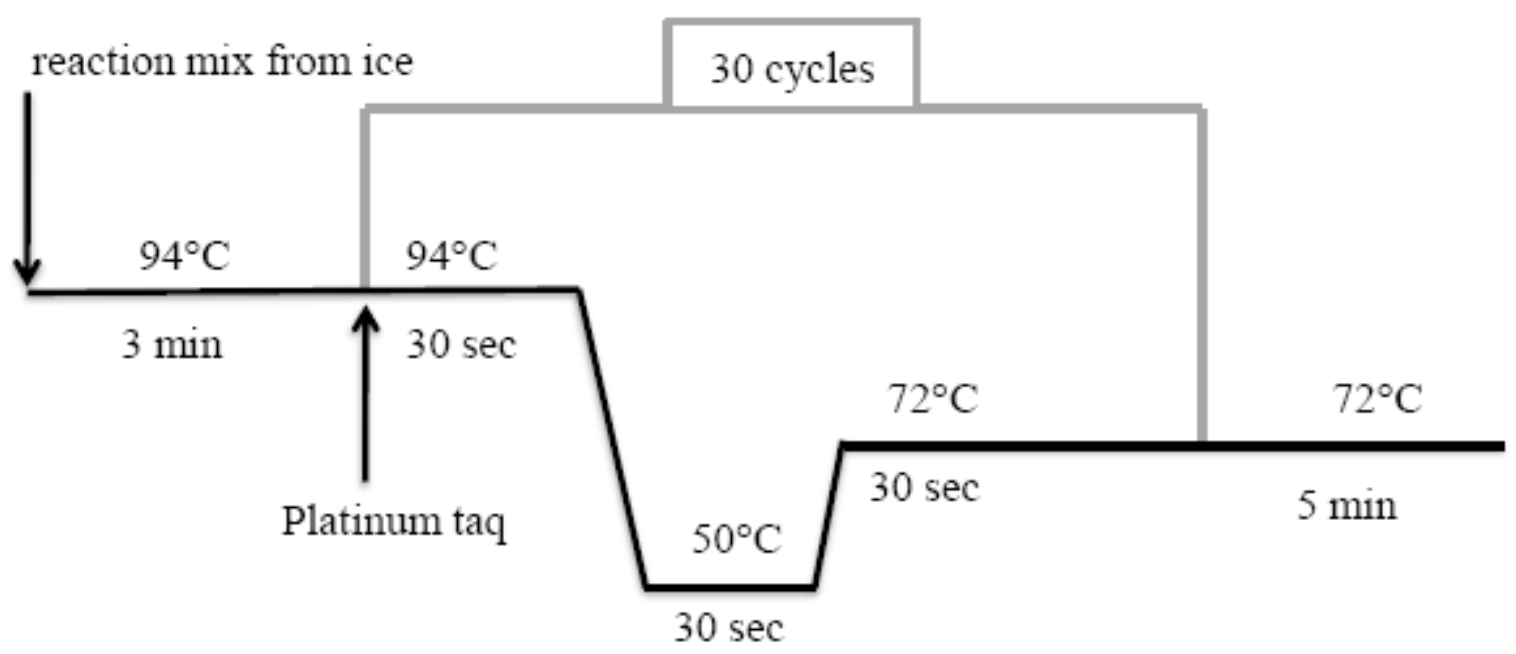




\subsubsection{Microarray hybridisation.}

The PCRs from Cy3-treated control and Cy5-drug-treated were hybridised onto the slide together for the duplicate microarrays (independent biological replicates done separately) (Yuan et al. 2005). Hybridisation mixture was prepared by adding $50 \mu \mathrm{L}$ of each of the 4 PCR products, and $20 \mu \mathrm{L}$ blocking solution $(100 \mu \mathrm{M} \mathrm{U} 1,100 \mu \mathrm{M}$ D1, $100 \mu \mathrm{M}$ U2 block [5'-CGTACGCTGCAGGTCGAC], $100 \mu \mathrm{M}$ D2 block [5'ATCGATGAATTCGAGCTCG]). Both blocking solution and 2x hybridisation buffer were filter-sterilised and stored at $4^{\circ} \mathrm{C}$. DTT was added to $2 \mathrm{x}$ hybridisation buffer to a final concentration of $1 \mathrm{mM}$ to prevent Cy-dye oxidation. The hybridisation mixture was denatured at $95^{\circ} \mathrm{C}$ for $2 \mathrm{~min}$ followed by cooling on ice. A microarray chamber was set up according to the Agilent microarray-hybridisation chamber user guide. The microarray slide is designed with four arrays, with 44,000 spots per array (Agilent), and 150 artificial tags as negative controls with tags replicated at least twice (Yuan et al. 2005). The microarray chamber was placed into a preheated $\left(42^{\circ} \mathrm{C}\right)$ hybridisation oven (Agilent technologies, Sheldon manufacturer, USA) at a rotation speed setting of 4 for $4 \mathrm{hr}$. The microarray slide was separated from the gasket slide in $300 \mathrm{~mL}$ of $6 x$ SSPE washing solution $(3 \mathrm{M} \mathrm{NaCl}, 0.2 \mathrm{M}$ $\mathrm{NaH}_{2} \mathrm{PO}_{4}, 20 \mathrm{mM}$ EDTA, $\mathrm{pH}$ 7.4). The microarray slide was then transferred quickly to $50 \mathrm{~mL}$ of $0.06 \mathrm{x}$ SSPE washing solution. Both wash solutions were filter-sterilised before use. The slide was then removed from the washing solution and centrifuged at RT for $2 \mathrm{~min}$ at $500 \mathrm{rpm}$ in a $50 \mathrm{~mL}$ Falcon tube with Cy-label at the bottom of the tube. The slides were then air-dried overnight and stored in the dark. Microarray slides were scanned with an Axon Microarray Scanner at the Otago Genomics Facility, Biochemisty Department, University of Otago, Dunedin, New Zealand. Scanning settings were $532 \mathrm{~nm}$ laser intensity for Cy-3 fluorescence i.e. DMSOtreated (control) sample, and $635 \mathrm{~nm}$ laser intensity for Cy-5 i.e. PelA-treated samples.

\subsubsection{Microarray analysis}

GenePix Pro 6.0 (Molecular Devices, Sunnyvale, CA, USA) was used for the analysis of the microarray hybridisation fluorescence pattern. Control and essential genes were filtered out i.e. removed. Signals for UP Tags were analysed separately from DOWN Tags. Only spots that had a signal that was at least $3 \mathrm{x}$ higher than the background were used to calculate a median of ratios $(\mathrm{Cy} 5 / \mathrm{Cy} 3)$. The median of 
ratios was then converted into a $\log 2$ ratio and normalised using SNOMAD webbased software (Standardization and Normalization of Microarray Data). Genes ratios with less than 500 in the Cy-3 fluorescence (control sample) were filtered out (not included in the analysis). Replicates were removed using a 'remove replicates' program designed by Cameron Jack (School of Biological Sciences, Victoria University of Wellington). The values of $\log 2$ ratio for each hit were averaged, and the mean and standard deviation of the $\log 2$ ratio was calculated. Finally, z-scores were calculated using the following equation: $\mathbf{Z}$-score $=(\mathrm{x}-\mathrm{mean}) /$ standard deviation . Values for all UP (or DOWN) tags were used for calculation of mean and Std. deviation. Z-scores greater than three Std. deviations were considered significant and defined as a 'hit'. Multidrug resistance (MDR) genes were filtered out from the final hit list using the Hillenmeyer-HOP-MDR list (Hillenmeyer et al. 2008)

\subsubsection{Database searches}

SGD Gene Ontology Slim Mapper web-based maps (SGD Stanford) were used to annotate/classify a group of genes to more general groups and/or bin them into broad categories or networks. Moreover, to classify ORF genes based on their molecular function, "Cellular Component" and biological function of the ORF were subjected to FunSpec, a web-based software program that groups genes into their listed categories. Physical and genetic interactions of genes/proteins were searched with the "interactions" tool on the Saccharomyces Genome database (SGD Stanford). Using Cytoscape software (v2.6.2) downloaded via the http://www.cytoscape.org/ website, genes were grouped into their biological processes using BiNGO implemented plugins (A Biological Network Gene Ontology tool). BiNGO is a Java-based tool to determine which Gene Ontology (GO) categories are statistically overrepresented in a set of genes or a subgraph of a biological network.

\subsubsection{Validation of HOP results: Growth inhibition experiment}

To validate the HOP microarray hits (that is, to confirm the genes with Z-scores greater than three standard deviations), homozygous deletion mutants strains were obtained from $-80^{\circ} \mathrm{C}$ stocks and streaked onto plates as previously stated in section 2.2.1. A single colony from each strain was inoculated in $2 \mathrm{~mL} \mathrm{SC}$ supplemented 
with $2 \%$ glucose and grown overnight at $30^{\circ} \mathrm{C}$ in a rotator. The diploid wild type strain (BY4743) was included as a positive control. The following day, the concentrations of the cultures were determined using a haemocytometer, and the cells were diluted in $10 \mathrm{~mL} \mathrm{SC}$ medium to a final cell concentration of $5 \times 10^{5}$ cells $/ \mathrm{mL}$. Then, $100 \mu \mathrm{L}$ of the diluted cells were plated out in BIOFIL ${ }^{\circledR}$ tissue culture 96-well plates, giving $5 \times 10^{4}$ cells per well final concentration. Cells were treated with $10 \mu \mathrm{M}$ PelA or $0.1 \%$ DMSO (control) for $15 \mathrm{hr}$ ( 10 generations) and were incubated at $30^{\circ} \mathrm{C}$ in a Contherm Digital series incubator (Contherm Z011, Contherm Scientific Ltd, New Zealand). Following this incubation, the cells were re-diluted in order to have a minimum of 1000 cells per well (the same procedure was followed as in the yeast microarray set up- refer to section 3.2.1) and were re-treated with $10 \mu \mathrm{M}$ PelA or DMSO for an additional $15 \mathrm{hr}$ ( 20 generations total). Plates were vortexed at $1000 \mathrm{rpm}$ for $15 \mathrm{sec}$ to resuspend the culture and the absorbance of the plates was read at $600 \mathrm{~nm}$ wavelength on a multilabel plate reader (PerkinElmer EnVision 2102, Waltham, Massachusetts, USA), and the residual growth for each gene was calculated relative to its positive control (DMSO-treated). As this validation technique utilises substantial amounts of PelA, and since the drug was only available in limited supply, this experiment was not repeated. 


\subsection{Results}

\subsubsection{HOP microarray hits}

Using the complete homozygous (BY4743) deletion mutant library for S. cerevisiae, a microarray screen was carried out against PelA in order to reveal functional related pathways or genes that interact with PelA primary targets. Mutants scoring greater than three z-score were considered as significant hits for this HOP microarray after $10 \mu \mathrm{M}$ treatment with PelA for 20 generations (Table 3.3.1). Thirty-three genes had $z$-scores of 3 or higher in at least one of the two HOP microarray screens. Eight of these genes were component genes of the PDR multidrug efflux system and therefore were not followed up further since they would not provide information on the specific action of PelA. Twenty-five strains (z-scores above 3) were significant in both microarrays, and these strains were validated individually (see Materials and Methods). ERG24 and ERG6 were excluded from the validation results because cells lacking these genes exhibit pleiotropic growth phenotypes (Gaber et al. 1989). Five strains showed significant $z$-scores for both the UP and DOWN tags (in both biological replicates of the microarray). Those strains were RTS1, SACl, MAD1, $M A D 2$ and LSM1. These results were consistent between experiments. In both microarray screens the $\log 2$ ratios and the z-scores of the hits were highly significant. The SGD Gene Ontology search that was performed using Funspec grouped the genes into eight major categories (Table 3.3.2) with mitosis being the most relevant category for what is known about the mode of action of PelA (Hood et al. 2002). Individual validation of each hit using growth inhibition experiments validated 10 out of 23 genes as sensitive to PelA-treatment, indicating that those genes reflect the possible "friends of PelA targets". The percentage of growth for each gene is presented in Table 3.3.3. The possible PelA genetic interactions are presented in the network shown in Fig. 3.3.1. The functions of the HOP gene hits are summarised in Appendix V. 
Table. 3.3.1. Microarray hits after $10 \mu \mathrm{M}$ PelA treatment.

\begin{tabular}{|c|c|c|c|c|}
\hline Strain & Gene name & $\begin{array}{l}\text { Median of ratios } \\
(\mathrm{Cy} 5 / \mathrm{Cy} 3)\end{array}$ & Log2 ratio & z-score \\
\hline YNL323W & LEM3 & $\mathbf{0 . 0 0 3}$ & -6.21 & -15.74 \\
\hline YNL280C & $E R G 24$ & 0.069 & -4.47 & -11.22 \\
\hline YCL029C & $B I K 1$ & 0.019 & -3.88 & $\begin{array}{l}-9.81 \\
\end{array}$ \\
\hline YOR014W & RTS1 & 0.037 & -3.32 & -8.42 \\
\hline YBR189W & RPS9B & 0.032 & -3.27 & -8.08 \\
\hline YKL212W & SACl & 0.049 & -3.40 & -8.07 \\
\hline YBL065W & - & 0.017 & -3.16 & -7.60 \\
\hline YML008C & ERG6 & 0.021 & -2.95 & -7.30 \\
\hline YOR153W & PDR5 & 0.047 & -2.63 & -6.69 \\
\hline YPL187W & $M F(A L P H A) 1$ & 0.068 & -2.51 & -6.07 \\
\hline YGL086W & MADI & 0.043 & -2.38 & -5.90 \\
\hline YJL030W & MAD2 & 0.06 & -2.31 & -5.64 \\
\hline YDL115C & IWRI & 0.116 & -2.33 & -5.60 \\
\hline YNL054W & VAC7 & 0.141 & -2.12 & -5.27 \\
\hline YNL187W & - & 0.075 & -2.06 & -4.92 \\
\hline YDR264C & $A K R 1$ & 0.099 & -1.90 & -4.83 \\
\hline YPL018W & CTF19 & 0.149 & -2.02 & -4.81 \\
\hline YOR292C & YOR292C & 0.065 & -1.86 & -4.71 \\
\hline YBR156C & SLI15 & 0.089 & -1.92 & -4.59 \\
\hline YBL054W & - & 0.164 & -1.66 & -4.14 \\
\hline YDR441C & APT2 & 0.094 & -1.74 & -4.13 \\
\hline YER087W & AIM10 & 0.176 & -1.71 & -4.11 \\
\hline YJL124C & LSM1 & 0.176 & -1.62 & -4.01 \\
\hline YGL012W & ERG4 & 0.093 & -1.62 & -3.98 \\
\hline YGL170C & SPO74 & 0.165 & -1.56 & -3.93 \\
\hline YLR085C & ARP6 & 0.082 & -1.55 & -3.92 \\
\hline YHR025W & THRI & 0.163 & -1.50 & -3.79 \\
\hline YOR019W & - & 0.102 & -1.46 & -3.67 \\
\hline YGR106C & - & 0.234 & -1.47 & -3.54 \\
\hline YOR161C & PNS1 & 0.106 & -1.45 & -3.51 \\
\hline YMR202W & ERG2 & $\mathbf{0 . 0 9 8}$ & -1.38 & -3.32 \\
\hline YIL157C & COA1 & 0.122 & -1.35 & -3.23 \\
\hline YDR017C & KCS1 & & -1.22 & -3.10 \\
\hline
\end{tabular}

The BY4743 homozygous deletion mutant set was treated for 20 generations with $10 \mu \mathrm{M}$ PelA. Thirty-three gene deletion mutants strains returned z-scores of 3 or greater in two experiments. Genes in bold are multi-drug resistance genes and were removed from the final hit list. Based on 2 biological replicates with arrays carried out in duplicate for each preparation (the $\log 2$ ratios and $\mathrm{z}$-score values shown here were obtained from averaging the results of the two biological replicates). An example on the $\log 2$ ratio and the $\mathrm{z}$-scores values (from the two biological replicate) is shown below:

\begin{tabular}{lllll} 
& \multicolumn{2}{c}{ replica one } & \multicolumn{2}{c}{ replica two } \\
LEM3 & $\log 2$ ratio & $\mathrm{Z}$-score & $\log 2$ ratio & Z-score \\
& -6.95 & -17.0 & -5.45 & -14.46
\end{tabular}


Table. 3.3.2. Funspec Gene ontology by biological process-Pel A

\begin{tabular}{|l|c|c|}
\hline \multicolumn{1}{|c|}{ Category } & p-value & $\begin{array}{c}\text { Genes in } \\
\text { category from } \\
\text { cluster }\end{array}$ \\
\hline Mitosis & 0.001642 & $\begin{array}{c}\text { BIK1 MAD1 } \\
\text { MAD2 CTF19 }\end{array}$ \\
\hline Meiotic sister chromatid cohesion, centromeric & 0.003786 & RTS1 \\
\hline RNA splicing, via transesterification reactions & 0.003786 & LSM1 \\
\hline Steroid biosynthetic process & 0.004231 & ERG6 ERG24 \\
\hline Ergosterol biosynthetic process & 0.004898 & ERG6 ERG24 \\
\hline Mating & 0.007559 & MF(ALPHA)1 \\
\hline Prolyl-tRNA aminoacylation & 0.007559 & $A I M 10$ \\
\hline $\begin{array}{l}\text { RNA splicing, via transesterification reactions with } \\
\text { bulged adenosine as nucleophile }\end{array}$ & 0.007559 & LSM1 \\
\hline
\end{tabular}

The Funspec gene ontology classified the genes into their biological processes. The p-values represent the probability that the intersection of a given list with any given functional category occurs by chance. The Bonferroni-correction divides the p-value threshold that would be considered significant for an individual test, by the number of tests conducted and thus accounts for false significance due to multiple testing over the categories of a database. 
Figure. 3.3.1. PelA-HOP genetic interactions network

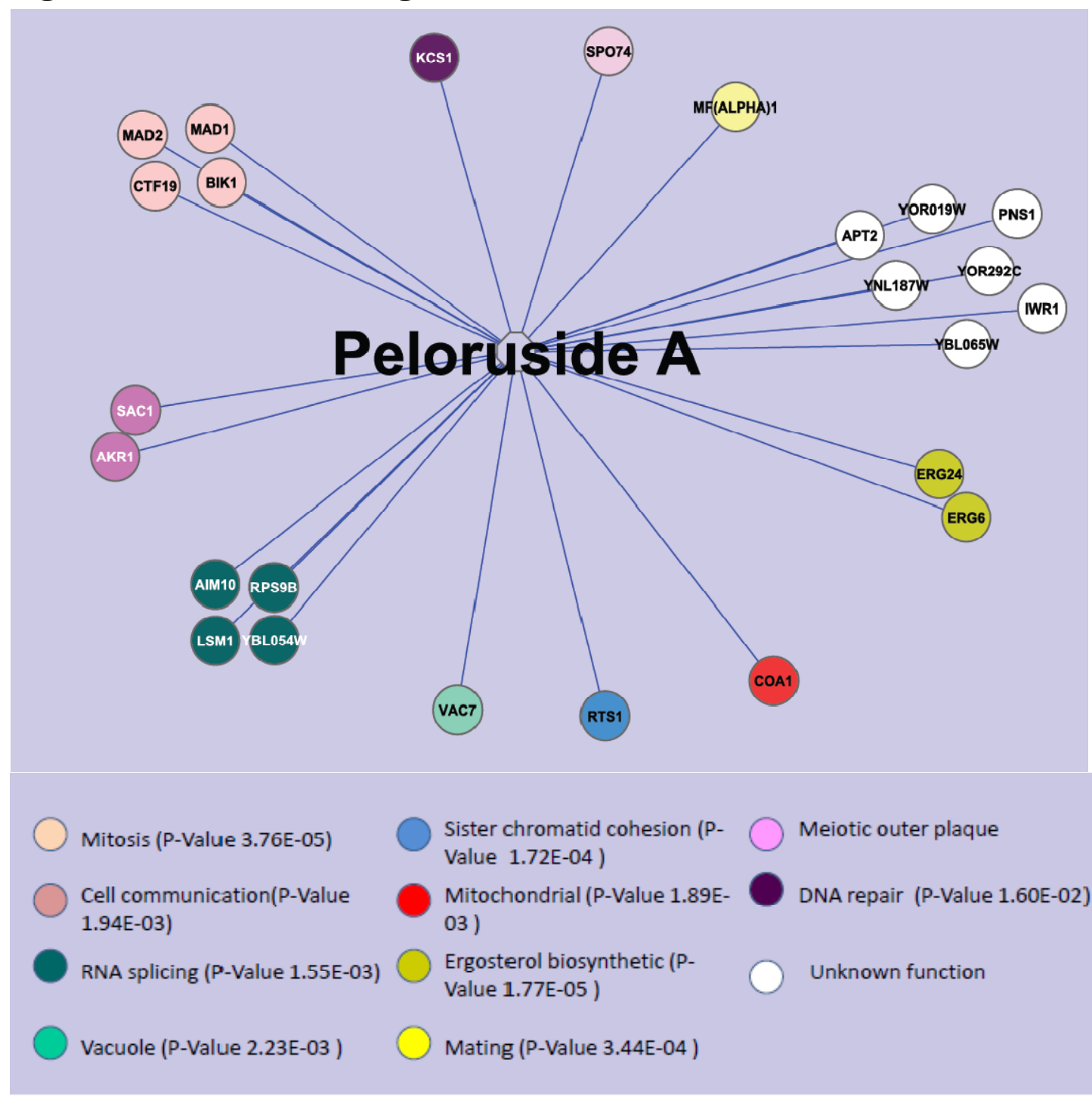

The PelA-HOP network is presented. Hits were obtained from the microarray analysis. The network was constructed by Cytoscape 2.6.1 software, and p-values were calculated using the BiNGO 2.3. plugin that is implemented within the cytoscape software. 
Table.3.3.3. Individual validation of HOP-microarray hits.

\begin{tabular}{|c|c|c|}
\hline Gene Name & 10 gen. & 20 gen. \\
\hline KCS1 & $86 \%$ & $26 \%$ \\
\hline MAD1 & $65 \%$ & $30 \%$ \\
\hline BIK1 & $77 \%$ & $31 \%$ \\
\hline RTS1 & $71 \%$ & $33 \%$ \\
\hline LSMI & $92 \%$ & $36 \%$ \\
\hline SAC1 & $62 \%$ & $42 \%$ \\
\hline CTF19 & $81 \%$ & $45 \%$ \\
\hline$M A D 2$ & $85 \%$ & $49 \%$ \\
\hline RPS9B & $99 \%$ & $71 \%$ \\
\hline$V A C 7$ & $77 \%$ & $73 \%$ \\
\hline$Y B L 054 W$ & $104 \%$ & $78 \%$ \\
\hline$M F(A L P H A) 1$ & $95 \%$ & $79 \%$ \\
\hline PNS1 & $101 \%$ & $82 \%$ \\
\hline YOR019W & $103 \%$ & $87 \%$ \\
\hline COAl & $94 \%$ & $88 \%$ \\
\hline$A P T 2$ & $98 \%$ & $89 \%$ \\
\hline YNL187W & $104 \%$ & $93 \%$ \\
\hline YOR292C & $102 \%$ & $94 \%$ \\
\hline$A K R l$ & $89 \%$ & $96 \%$ \\
\hline AIM10 & $104 \%$ & $97 \%$ \\
\hline IWRI & $98 \%$ & $98 \%$ \\
\hline SPO74 & $99 \%$ & $104 \%$ \\
\hline$Y B L 065 \mathrm{~W}$ & $105 \%$ & $110 \%$ \\
\hline
\end{tabular}

Twenty-three homozygous deletion mutant strains were treated individually with $10 \mu \mathrm{M}$ PelA or DMSO (as control) for up to 20 generations. Percentage of residual growth was calculated relative to DMSO-treated (control) samples for $15 \mathrm{hr}$ (10 generations) incubation and $30 \mathrm{hr}$ total growth (20 generations). Only 10 genes (in bold) out 23 genes showed a significant decrease in their growth after 20 generations (Residual growth of less than $80 \%$ of the control was considered a significant effect). Results are ranked according to percentage growth after 20 generations. Results are based on only one experiment due to the limited supply of the drug; hence, no statistical analysis could be performed. 


\subsection{Discussion}

\section{Chemical genomic profiling of PelA}

Chemical-genetic profiles (HIP and HOP microarrays) screen for primary and secondary biological targets, have the potential of revealing the mode-of-action of the drugs being tested. Technically HIP and HOP microarrays each follow the same methodology; however, in a HOP screen, nothing can be learnt about the drug targets since only homozygous deletion mutants are used in this screen and these strains are characterised by complete loss of function of the deleted gene in the mutants. HOP microarrays therefore only find friends of the target, rather than the target itself, but HOP microarrays are important because they reveal genes that are important for the survival of the yeast in the presence of a drug (Nislow and Giaever, 2007), and therefore identify functionally related pathways of the drug of interest (genes that associate with the drug target). Barcode-based chemical genomic profiling in budding yeast is relatively straightforward and robust and can be generally applied to any compound with growth inhibitory activity (Parsons et al. 2006).

In contrast to chemical genomic profiling of haploid deletion mutants like SGA, which often identifies tens to hundreds of deletion mutant hypersensitive strains, the microarray (HIP and HOP) usually identifies a reasonably manageable number of potential drug target genes (HIP) or genes that associate with the drug target (HOP). Microarray genome-wide screens often identify fewer than 20 genes per screen, in which gene deletion leads to compound hypersensitivity (Baetz et al. 2004; Giaever et al. 1999, Giaever et al. 2004; Lum et al. 2004). Hence, the HOP assay is a powerful complement to the HIP assay as it allows the identification of genes and pathways required for protection of the cell from inhibition of a particular target. However, in some cases the HOP microarray technique generates discrepancies in the data within and between independent experiments (replicates), and therefore, because of lack of consistency, a substantial number of hits (genes) must be excluded from the analysis. In this case, HOP screens are incomplete because they do not highlight some genes that might play an important role in the drug pathway. This often results from a problem with the PCR efficiency of Up and DN tags (collectively or separately) in which some strains have a low DNA (template) quantity to start with. In the present study, the results were relatively consistent between experiments. In both microarray screens, the $\log 2$ ratios and the z-scores of 
the hits were highly significant, and few genes were excluded from the analysis because they only showed up as hits in one of the two replicates.

\section{PelA HOP microarray hits}

The HOP microarray analysis for the complete homozygous diploid (BY4743) strain treated with $10 \mu \mathrm{M}$ PelA for 20 generations disclosed 23 genes with z-scores greater than three. The Go Biological Process grouped these genes according to their biological process into eight categories.

In the first category, the $B I K 1, M A D 1, M A D 2$ and $C T F 19$ genes were grouped into the mitosis group. Synthetic lethal studies by others have revealed that $\alpha$ - and $\beta$ tubulin have genetic interactions with BIKl (Berlin et al. 1990). This gene seems to be required for nuclear fusion, chromosome disjunction, and nuclear segregation during mitosis and the protein product of BIKl co-localises with tubulin to the spindle pole body and mitotic spindle (Berlin et al. 1990). The strain that is a double mutant containing a mutation in the $B I K 1$ gene and either the $\alpha$ - or $\beta$-tubulin gene is synthetic lethal. The synthetic lethal findings are consistent with what has been observed from direct physical interactions between this BIKl and tubulin (Berlin et al. 1990). Validation of the homozygous deletion diploid strain that lacks BIKI showed that this strain was sensitive to PelA treatment, with only $31 \%$ growth $(69 \%$ inhibition) in the presence of PelA (Table. 3.3.3.).

Besides $B I K 1, M A D 1$ and MAD2 were also present in the same mitosis group. The mad mutants were initially isolated in a study that used benomyl, an inhibitor of microtubule polymerisation. These mutants showed increased sensitivity when treated with the drug (Hardwick et al. 1999), failing to arrest in mitosis, and dying rapidly (Li and Murray, 1991; Hardwick and Murray, 1995; Hardwick et al. 1999). These observations suggest that the defects in microtubule polymerisation have activated the spindle checkpoint (Hardwick et al. 1999). Previous studies between mad mutants and $\beta$-tubulin have shown that the combination of the mad mutations with the $t u b 2$ mutation increases the rate at which cells, which cannot polymerise microtubules, and die (Hardwick et al. 1999). The outcome of these observations demonstrated that the $M A D$-dependent spindle checkpoint is essential to arrest cells that have a defect in microtubule assembly (Hardwick et al. 1999). The MADI and MAD2 are non-essential genes that encode components of the spindle checkpoint ( $\mathrm{Li}$ 
and Murray 1991; Hardwick and Murray 1995). MAD2 forms a tight complex with MADl throughout the cell cycle. In the present study, the HOP growth inhibition assay confirmed that both madl $\Delta$ (30\% growth) and mad $2 \Delta$ (49\% growth) strains were quite sensitive to $10 \mu \mathrm{M}$ PelA. This sensitivity of a mad2s strain confirms earlier studies by Anja Wilmes who showed that PelA sensitivity was increased in this strain over wild type (Wilmes PhD thesis, 2008). In a HIP microarray study carried out in our laboratory by Anja Wilmes (Wilmes PhD thesis, 2008), CIK1, a kinesin-associated protein required for both karyogamy and mitotic spindle organisation (SGD Stanford), was identified as one of the hits and potential targets of PelA. CIKI also has been shown to have a synthetic lethal interaction with MADIand MAD2 (Daniel et al. 2006; Collins et al. 2007; Sarin et al. 2004). Nevertheless, the mad mutants came as a hit in the HOP microarray screen and when both mutant strains were individually treated with $10 \mu \mathrm{M}$ PelA for 20 generations, they showed 30-49\% growth i.e. 51-70\% inhibition (Table. 3.3.3). Besides the genes listed above, CTF19 was also included in the mitosis group. This gene codes for an outer kinetochore protein, and individual growth validation of the homozygous diploid strain that lacks this gene showed that this strain had only $45 \%$ growth $(55 \%$ inhibition) in the presence of $10 \mu \mathrm{M}$ of PelA after 20 generations (Table. 3.3.3).

The second Go Biological Process category consisted of a single gene (RTS1) that is involved in sister chromatid cohesion and is a B-type regulatory subunit of protein phosphatase 2A (SGD Stanford). This gene rtsl was identified as an extragenic suppressor of tub2-104. Tub2-104 is a cold-sensitive allele of the gene encoding $\beta$ tubulin in S. cerevisiae (Reijo et al. 1993). Individual growth validation of the homozygous diploid strain that lacks this gene showed that this strain had only $33 \%$ growth (67\% inhibition) in the presence of $10 \mu \mathrm{M}$ of PelA after 20 generations (Table. 3.3.3). CIK1, one of the HIP microarray hits as mentioned earlier (Wilmes $\mathrm{PhD}$ thesis, 2008), has a phenotypic enhancement type of genetic interaction with LSM1 and RTS1 (Collins et al. 2007). Phenotypic enhancement is a genetic interaction that is inferred when mutation or overexpression of one-gene results in enhancement of any phenotype (other than a lethality/growth defect) associated with mutation or overexpression of another gene (SGD Stanford). Our validations showed that gene LSM1, which belongs to the third Go Biological Process category (the RNA splicing group) and is involved in sister chromatid cohesion (SGD Standford), had only $36 \%$ growth (64\% inhibition). Another gene was also picked up in the HIP 
microarray hits of Anja Wilmes, TOP1 (Topoisomerase I) that functions in replication, transcription, and recombination (SGD Stanford), and was also shown to have a phenotypic enhancement genetic interaction with LSM1 (Collins et al. 2007; Fiedler et al. 2009). Overlaps between other genes found in this study and the HIP study were not found.

The other Go Biological Process categories involved steroid or ergosterol biosynthesis, including ERG6 and ERG24, two genes are involved in multidrug resistance and were eliminated from the validation list. Of the twenty-three identified genes, seven had no known function, including IWR1, YNL187W, YOR019W, PNS1, YBLO65W, APT2 and YOR292C.

\section{Validation of HOP microarray results by individual strain confirmation}

Validation of the HOP microarray hits is quite important, because it will confirm the results by using independent measurements. The validation of the strains that are identified in genome-wide assays need to be carried out in individual liquid cultures before the results are considered complete. When the HOP hits were individually validated by growth inhibition assay, 10 out of the 23 genes were very sensitive to 10 $\mu \mathrm{M}$ PelA after 20 generations (less than $80 \%$ of residual growth). Those genes were SAC1, MAD1, MAD2, LSM1, RTS1, CTF19, BIK1, KCS1, RPS9B and VAC7 with growth inhibition values for PelA ranging from $26 \%$ to $73 \%$ after 20 generations (Table. 3.3.3). Some of these genes have been discussed in more detail earlier (BIK1, MAD1, MAD2, LSM1, RTS1, and CTF19); therefore, they will not be mentioned in this part of the discussion. $S A C l$ is a transmembrane protein involved in trafficking, processing, and secretion, as well as cell wall maintenance (SGD Stanford). This strain had $42 \%$ growth relative to the control (i.e. 58\% inhibition) in response to $10 \mu \mathrm{M}$ PelA after 20 generations. The human homologue to SAC1 is human Sac1 (hSac1), a member of a family of phosphatases that are involved in protein trafficking and processing (SGD Stanford). The other three strains whose growth was also decreased after 20 generations were KCS1 (26\%), RSP9B (71\%) and VAC7 (73\%). These genes are involved in DNA repair, and vacuolar biogenesis respectively (Appendix V). 


\section{Other techniques that can reveal functionally related genes}

Parsons et al. (2004) employed the SGA method to uncover cellular pathways affected by various compounds in yeast (Parson et al. 2004). In preliminary studies, the authors treated the haploid yeast deletion collection with twelve diverse inhibitory compounds to create chemical-genetic interaction profiles for each drug. Strains that showed hypersensitivity towards a specific compound were identified by arraying the strains onto agar plates containing a sub-lethal dose of each compound and looking for reduced colony formation. The SGA technique concepts are similar to the HOP microarray. The only difference between the two is that SGA is carried out on a solid phase; whereas, HOP is carried out in a small liquid volume or 'pool' (Pan et al. 2004). These studies identified 35 new synthetic genetic interactions for the 12 drugs. Comparing the data that have been collected from various chemicalgenetic screens with a compendium of fifty-seven genetic interaction screens of query genes indicated that the genetic interaction profile of many query genes clustered with the chemical-genetic profile of the drug affecting them. For example, the profile of TUB2 and MAD2 in the Parson et al. (2004) study clustered with the profile of benomyl (the microtubule-depolymerising drug). Thus, these genetic interaction profiles can provide useful information for interpreting chemical-genetic interaction profiles and therefore can identify the cellular targets or pathways of compounds (Parsons et al. 2004).

In a modification of the SGA method, Pan et al. (2004) developed a microarraybased technique called dSLAM (diploid based synthetic lethality analysis with microarrays) to generate haploid mutants for probing gene-chemical and gene-gene interactions (Parsons et al. 2006). In this modified version of SGA, into a pool of 5,896 heterozygous diploid deletion strains were used to generate haploidconvertible heterozygous diploids via the integration of SGA reporters. These haploids were generated after sporulation and selection on appropriate media. In order to test the resistance of the converted haploids, they were treated with benomyl, a microtubule depolymerising drug that is known to affect 78 non-essential genes (Parsons et al. 2006), to test for their resistance. The haploid pool was grown with and without the drug, and the DNA was isolated, amplified and subsequently hybridised to an oligonucleotide array of sequences complementary to the molecular barcodes of each strain (Winzeler et al. 1999; Baudin et al. 1993). The microarray barcode analysis showed that the mutant strains for genes that are directly involved 
in microtubule biogenesis knocked out, such as CIN1, TUB3, and PAC10, were hypersensitive to benomyl treatment (Parsons et al. 2004; Pan et al. 2004).

In conclusion, the HOP results in our study indicated that the PelA genetic interactions are genes mainly involved in the regulation of mitosis and cell cycle, protein transport and secretion, and steroid biosynthesis pathways. Thus, genes in these pathaways buffer the cellular response against the PelA effect and, when mutated, increase the growth inhibitory effects of PelA. The individual validation assay data largely confirmed what was seen in the HOP microarray experiments. However, the results of the validation experiments should be repeated as each strain was done only once because the PelA supply was limited. To confirm these results another technique needs to be carried out as well e.g. SGA that uses PelA to identify strains that are synthetically lethal in the presence of the drug. It would also be useful to apply the drug in excess to validate the HOP hits.

The advantage of microarray analysis is that this technique is comprehensive and examines the involvement of nearly every non-essential nuclear protein-encoding gene in a drug response. The technique is therefore unbiased since it does not make assumptions about the drug's mechanism of action, as would be the case if selected genes were investigated. In general, the technique is applicable to any compound that is bioactive and inhibits yeast growth (Parsons et al. 2006). It is also technically easy and inexpensive, other than the cost of the drug itself. It helps in reducing the number of potential targets, although it might be difficult to disentangle the primary targets from the secondary targets. The disadvantage of a HOP microarray screen in particular is that a substantial fraction of the homozygous diploid deletion strains might be slow-growth strains in the absence of a drug. This can lead to uninformative screen results as these strains become gradually depleted in the pool and therefore give false positives. Sometimes, a HOP microarray may identify what appear to be secondary targets that are completely unrelated to (or associated with) the primary drug target(s), or it may identifies genes that are only relevant to yeast and have no mammalian counterpart. Despite these disadvantages, microarray analyses (HIP and HOP) will remain an attractive and alternative approach for many laboratories. 


\section{Chapter 4. Overall discussion and future experiments}

\subsection{Discussion and conclusions from the study}

Many essential cellular processes are conserved between yeast and humans. About 20 percent of human disease genes have counterparts in yeast. This means that yeast can be exploited to look at functional relationships involving these genes, and to test new drugs for their mode of action. A yeast mutant that has lost the functional equivalent of a human disease gene can be screened with thousands of potential drugs in order to identify compounds that restore normal function to the yeast cell.

The generation of mutants via the use of mutagenesis is a useful element of any drug discovery study for determining interactions between the drug and its target. Understanding the drug and target protein relationship is potentially informative as it underlines the principles behind protein structure-function relationships. Mutant generation is a valuable tool in discovering the connection between a drug and its protein target since a change in an amino acid can disrupt the three-dimensional conformation of a protein and provide information about the functional pathways that this protein acts in. There are different forms of mutagenesis. Classically mutants are generated by treating the organism with mutagens (chemical or physical agents) that modify the DNA. This method is an extremely successful mutagenesis method, but suffers from a number of disadvantages. For example, any gene in the organism can be mutated, and the mutation that has occurred might not be in the gene of interest. However, a more direct approach is to change a selected base in a DNA sequence by site-directed mutagenesis and thus alter a particular amino acid that you suspect is in the binding site of the drug. Since the discovery of this technique, it has become a basic tool of gene manipulation and has simplified the manipulations of DNA that in the past required a great deal of ingenuity and hard work. The importance of sitedirected mutagenesis goes beyond the understanding of gene structure-function relationships. This technique enables mutant proteins with valuable novel properties to be created. Generating PelA-resistance mutants is one of the effective ways to provide support for the hypothesis that the main target of PelA is $\beta$ - not $\alpha$-tubulin. In the presence of the drug, generated mutants in the $\beta$-tubulin binding site region were completely resistant to PelA. If PelA does not bind to the site on $\beta$-tubulin where the 
mutated amino acid resides, then the only other explanation for resistance is that the three-dimensional structure of the protein was disrupted; therefore, its function was disrupted in a non-specific, global sense. The proof that the Huzil et al. (2008) model of the PelA binding site is correct requires the analysis of mutants that have amino acid changes at key residues. The PelA mutants could also be tested against some other drugs that target the microtubule, but bind to a different, perhaps bettercharacterised site. In our study, phenotypic and quantitative analysis of the yeast cell cycle proved to be effective and informative about the mode of action of PelA, showing that its mode of action in yeast was similar to that in mammalian cell lines, with a $\mathrm{G}_{2} / \mathrm{M}$ block in the cell cycle.

Drug discovery usually faces a major challenge to identify the cellular targets that are responsible for the activity of a drug candidate. Drugs rarely or perhaps never target only one gene. The primary goal of chemical-genomic profiling studies like microarray is to identify pharmacologically relevant primary and secondary drug targets (Roberge, 2008). The primary target of PelA is well established as the microtubule that has a major and essential role in mitosis. The PelA chemical genetic interaction profile in our study confirmed an activity associated with the cell cycle, but also suggested a potential activity in protein transport, secretion, cell wall synthesis, and steroid biosynthesis. It is not known for certain, however, whether these other responses are downstream effects from the primary target or independent secondary target effects.

The overall conclusion from our study is that peloruside interacts with yeast tubulin, more specifically $\beta$ - not $\alpha$ - tubulin. Our results indicated that PelA binds to the site proposed by Huzil et al. (2008) on tubulin, since site-directed mutation in specific $\beta$ tubulin residues at this site-conferred resistance to PelA. Some resistance was also seen when an amino acid outside this site was altered, and this might reflect a global conformation change in the $\beta$-tubulin protein. Further site-directed mutagenesis studies are needed to clarify these possibilities. For example, it would be interesting to see if a mutation in $\alpha$-tubulin could also confer resistance to PelA, especially since an $\alpha$-tubulin binding site has been proposed by others (Pineda et al. 2004; JimenezBarbero et al. 2006). The PelA mode of action in yeast appeared to be similar to that of mammalian cell lines i.e. $\mathrm{G}_{2} / \mathrm{M}$ block. Furthermore, its secondary targets or downstream pathways of action were mostly involved in the cell cycle, indicating that peloruside targets genes or gene networks that primarily act in cell cycling. This 
conclusion is consistent with the known action of PelA on the microtubule and its major role in cell mitosis.

\subsection{Future experiments}

Confirmation of the PelA binding site in yeast is a very important task as it is difficult to use mammalian cells for generating mutations that confer resistance. A resistant yeast cell line would be easier and faster to generate. PelA-resistant cells that carry mutations in the tubulin gene may provide valuable information for modelling studies of PelA-tubulin interactions and for defining the PelA pharmacophore. Our experiments have shown several candidate haploid deletion strains that are hypersensitive to PelA that could be used for random mutagenesis by a chemical carcinogen like ethylmethanesulfonate (EMS). The best approach would be to treat the haploid deletion strain with EMS to induce random mutations in the tubulin genes. The surviving cells can then be grown on a plate containing PelA in the medium to screen for mutants that are able to grow in the presence of the compound (resistant mutants). Tubulin genes of resistant yeast strains can be easily sequenced, and if the resistance is due to the altered tubulin, further details of the PelA binding site would be obtained. Random mutagenesis by PCR can also be used, taking advantage of error-prone PCR (EP-PCR) by further decreasing the fidelity of Taq DNA polymerase (by adding $\mathrm{Mn}^{2+}$ and increasing the $\mathrm{Mg}^{2+}$ conc.) and using unequal dNTP concentrations. The level of mutagenesis can be "controlled" chemically and by the number of "doublings". The disadvantage of this technique is that it needs a series of optimisation reactions to ensure non-specific primer annealing is not an issue and to determine amplification efficiency for doubling estimates. However, both of the above suggestions require significant amounts of PelA, and proceeding with these studies at this time is not possible because the PelA supply in our laboratory is very scarce.

Other experiments that need to be carried out are in situ tubulin polymerisation and immunohistochemistry experiments. The in situ polymerisation would test whether PelA actually polymerises tubulin inside the cell. This could be coupled with PelA effects on purified yeast tubulin, as has been carried out for Ptx and Epo by other researchers (Barnes et al. 1992; Bode et al. 2002). Purification of yeast tubulin protein could be accomplished through the use of a novel tandem affinity purification (TAP) tag. In brief, this method requires that endogenous tubulin protein in the cell 
be replaced with a tagged tubulin version. The gene can be replaced by homologous recombination in haploid cells (Rigaut et al. 1999). Tubulin could be TAP-tagged on either the C- or N-terminus of the protein. The TAP-tag is then used to pull-down tubulin from a yeast homogenate, following which the TAG is cleaved off, yielding purified tubulin. Both $\alpha$ - and $\beta$-tubulin would need to be purified in this way to support in vitro polymerisation experiments with PelA.

More refined immunocytochemistry studies could be used to further confirm that PelA binds to and alters microtubular structure in yeast cells. The resolution of the Opera confocal microscope to pick up GFP-tubulin structural changes was not sufficient to determine if microtubule structure was altered by PelA in yeast, as it is in mammalian cells (i.e. bundling, multiple asters and spindles). Use of a highresolution confocal microscope and immunofluorescent staining of tubulin may provide more information on microtubule structure in the cells.

Another very valuable approach that could be used to identify secondary targets of PelA is the use of DARTS (drug affinity responsive target stability). This is a very interesting new technique that was first described at the end of 2009 (Lomenick et al. 2009) (Fig. 4.1).

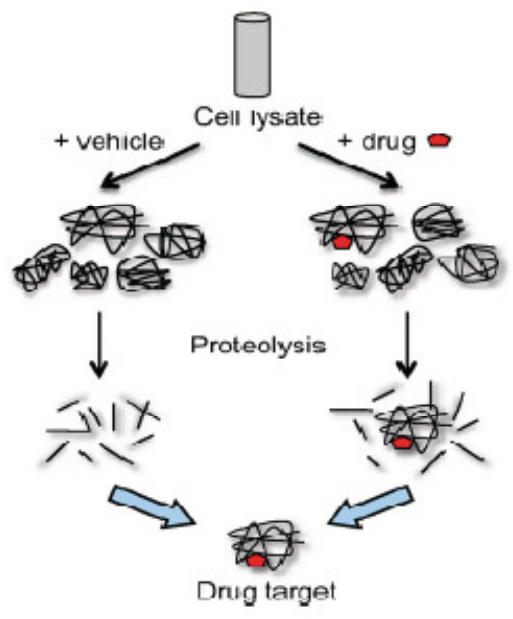

Figure. 4.1. Schematic view of DART. Binding of drugs is proposed to stabilise target proteins, either globally or locally, e.g. in a specific conformation or by simply masking protease recognition sites, thereby reducing protease sensitivity of the target protein (from Lomenick et al. 2009).

The technique is based on the idea that binding of a drug to a protein results in a pronounced and specific protection of its target protein from protease digestion. This specificity can be exploited to identify unknown binding targets of a small molecule with any cell lysate or protein mixture, followed by mass spectrometry analysis to identify which proteins were protected by the presence of the drug from protease 
digestion. DARTS does not require labelled ligands and instead uses "native" (i.e. unmodified) small molecules for binding, it is not limited by the chemistry of the molecule, and can potentially be used for any small molecule.

The future of PelA in advancing into clinical trials will depend on increasing total synthesis of PelA to supply large amounts of the compound. This would also provide a valuable resource for further mapping of the binding site in yeast tubulin by providing sufficient amounts to carry out random mutagenesis experiments, and by performing DART. 


\section{References}

Alic N, Felder T, Temple MD, Gloeckner C, Higgins VJ, Briza P, and Dawes IW. Genomewide transcriptional responses to a lipid hydroperoxide: Adaptation occurs without induction of oxidant defenses. Free. Radic. Biol. Med. 37: 23-35, 2004.

Amberg DC, Burke DJ, and Strathern JN. "Logarithmic Growth" Techniques and Protocols 20, in Methods in Yeast Genetics, Cold Spring Harbor Laboratory, Cold Spring. Harbor, New York, USA 2005ed.

Anders KR, and Botstein D. Dominant-lethal $\alpha$-tubulin mutants defective in microtubule depolymerization in yeast. Mol. Biol. Cell. 12:3973-3986, 2001.

Armour CD, and Lum PY. From drug to protein: Using yeast genetics for high-throughput target discovery. Curr. Opin. Chem. Biol. 9:20-24, 2005.

Baetz K, McHardy L, Gable K, Tarling T, Reberioux D, Bryan J, Andersen RJ, Dunn T, Hieter P, and Roberge M. Yeast genome-wide drug-induced haploinsufficiency screen to determine drug mode of action. Proc. Natl. Acad. Sci. USA. 101:45254530, 2004.

Bai RB, Pettit GR, and Hamel E. Binding of dolastatin 10 to tubulin at a distinct site for peptide antimitotic agents near the exchangeable nucleotide and Vinca alkaloid sites. J. Biol. Chem. 265:17141-17149, 1990.

Barberis A, Gunde T, Berset C, Audetat S, and Lüthi U. Yeast as a screening tool. Drug Discov. Today: Technologies. 2:187-192, 2005.

Bar-Joseph Z, Gerber GK, Lee TI, Rinaldi NJ, Yoo JY, Robert F, Gordon DB, Fraenkel E, Jaakkola TS, Young RA, and Gifford DK. Computational discovery of gene modules and regulatory networks. Nat. Biotechnol. 21: 1337-1342, 2003.

Barnes G, Louie KA, and Botstein D. Yeast proteins associated with microtubules in vitro and in vivo. Mol. Biol. Cell. 3:29-47, 1992.

Baudin A, Ozier-Kalogeropoulos O, Denouel A, Lacroute F, and Cullin C. A simple and efficient method for direct gene deletion in Saccharomyces cerevisiae. Nucleic Acids Res. 21:3329-3330, 1993.

Berlin V, Styles CA, and Fink GR. BIK1, a protein required for microtubule function during mating and mitosis in Saccharomyces cerevisiae, colocalizes with tubulin. J. Cell Biol. 111:2573-86, 1990.

Biotechlearn. org

(www.biotechlearn.org.nz/news_and_events/news_archive/sea_sponge_product_reduces_ch emotherapy_side_effects)

Birrell GW, Giaever G, Chu AM, Davis RW, and Brown JM. A genome-wide screen in Saccharomyces cerevisiae for genes affecting UV radiation sensitivity. Proc. Natl. Acad. Sci. USA. 98:12608-12613, 2001.

Bode CJ, Gupta ML, Jr, Reiff EA, Suprenant KA, Georg GI, and Himes RH. Epothilone and paclitaxel: Unexpected differences in promoting the assembly and stabilization of yeast microtubules. Biochem. 41:3870-3874, 2002.

Bollag DM, McQueney PA, Zhu J, Hensens O, Koupal L, Liesch J, Goetz M, Lazarides E, and Woods C. Epothilones a new class of microtubule-stabilizing agents with a Taxol-like mechanism of action. Cancer Res. 55:2325-2333, 1995. 
Boone C, Bussey H, and Andrews BJ. Exploring genetic interactions and networks with yeast. Nat. Rev. Genet. 8:437-449, 2007.

Buey RM, Barasoain I, Jackson E, Meyer A, Giannakakou P,Paterson I, Mooberry S, Andreu JM, and Díaz JF. Microtubule interactions with chemically diverse stabilizing agents: Thermodynamics of binding to the paclitaxel site predicts cytotoxicity. Chem. Biol. 12: 1269-1279, 2005.

Burke D, Gasdaska P, and Hartwell L. Dominant effects of tubulin overexpression in Saccharomyces cerevisiae. Mol. Cell Biol. 9:1049-1059, 1989.

Carminati JL, and Stearns T. Microtubules orient the mitotic spindle in yeast through dyneindependent interactions with the cell cortex. J. Cell Biol. 138: 629-641, 1997.

Collins SR, Miller KM, Maas NL, Roguev A, Fillingham J, Chu CS, Schuldiner M, Gebbia M, Recht J, Shales M, Ding H, Xu H, Han J, Ingvarsdottir K, Cheng B, Andrews B, Boone C, Berger SL, Hieter P, Zhang Z, Brown GW, Ingles CJ, Emili A, Allis CD, Toczyski DP, Weissman JS, Greenblatt JF, and Krogan NJ. Functional dissection of protein complexes involved in yeast chromosome biology using a genetic interaction map. Nature. 446:806-810, 2007.

Court DL, Sawitzke JA, and Thomason LC. Genetic engineering using homologous recombination. Ann. Rev. Genet. 36: 361-388, 2002.

Daniel JA, Keyes BE, Ng YP, Freeman CO, and Burke DJ. Diverse functions of spindle assembly checkpoint genes in Saccharomyces cerevisiae. Genet. 172:53-65, 2006.

Derry WB, Wilson L, and Jordan M. A. Substoichometric binding of taxol suppresses microtubule dynamics. Biochem. 34:2203-2211, 1995.

Eisenhauer EA, and Vermorken JB. The taxoids comparative clinical pharmacology and therapeutic potential. Drugs. 55:5-30, 1998.

Fiedler D, Braberg H, Mehta M, Chechik G, Cagney G, Mukherjee P, Silva AC, Shales M, Collins SR, van Wageningen S, Kemmeren P, Holstege FC, Weissman JS, Keogh MC, Koller D, Shokat KM, and Krogan NJ. Functional organization of the $S$. cerevisiae phosphorylation network. Cell. 136:952-963, 2009.

Field JJ, Singh AJ, Kanakkanthara A, Halafihi T, Northcote PT, and Miller JH. Microtubulestabilizing activity of zampanolide, a potent macrolide isolated from the Tongan marine sponge Cacospongia mycofijiensis. J. Med. Chem. 52: 7328-7332, 2009.

Gaber RF, Copple DM, Kennedy BK, Vidal M, and Bard M. The yeast gene ERG6 is required for normal membrane function but is not essential for biosynthesis of the cell-cycle-sparking sterol. Mol. Cell. Biol. 9:3447-3456, 1989.

Gasch AP, Spellman PT, Kao CM, Carmel-Harel O, Eisen MB, Storz G, Botstein D, and Brown PO. Genomic expression programs in the response of yeast cells to environmental changes. Mol. Biol. Cell. 11:4241-4257, 2000.

Gaitanos TN, Buey RM, Díaz JF, Northcote PT, Teesdale-Spittle P, Andreu JM, and Miller JH. Peloruside A does not bind to the taxoid site on $\beta$-tubulin and retains its activity in multidrug-resistant cell lines. Cancer Res. 64:5063-5067, 2004.

Gelling CL, Piper MD, Hong SP, Kornfeld GD, and Dawes IW. Identification of a novel one-carbon metabolism regulon in Saccharomyces cerevisiae. J. Biol. Chem. 279: 7072-7081, 2004.

Giaever G, Shoemaker DD, Jones TW, Liang H, Winzeler EA, Astromoff A, and Davis RW. Genomic profiling of drug sensitivities via induced haploinsufficiency. Nat. Genet. 21:278-283, 1999. 
Giaever G, Chu AM, Ni L, Connelly C, Riles L, Veronneau S, Dow S, Lucau-Danila A, Anderson K, Andre B, Arkin AP, Astromoff A, El-Bakkoury M, Bangham R, Benito R, Brachat S, Campanaro S, Curtiss M, Davis K, Deutschbauer A, Entian KD, Flaherty P, Foury F, Garfinkel DJ, Gerstein M, Gotte D, Güldener U, Hegemann JH, Hempel S, Herman Z, Jaramillo DF, Kelly DE, Kelly SL, Kötter P, LaBonte D, Lamb DC, Lan N, Liang H, Liao H, Liu L, Luo C, Lussier M, Mao R, Menard P, Ooi SL, Revuelta JL, Roberts CJ, Rose M, Ross-Macdonald P, Scherens B, Schimmack G, Shafer B, Shoemaker DD, Sookhai-Mahadeo S, Storms RK, Strathern JN, Valle G, Voet M, Volckaert G, Wang CY, Ward TR, Wilhelmy J, Winzeler EA, Yang Y, Yen G, Youngman E, Yu K, Bussey H, Boeke JD, Snyder M, Philippsen P, Davis RW, and Johnston M. Functional profiling of the Saccharomyces cerevisiae genome. Nature. 418:387-39, 2002.

Giaever G, Flaherty P, Kumm J, Proctor M, Nislow C, Jaramillo DF, Chu AM, Jordan MI, Arkin AP, and Davis RW. Chemogenomic profiling: Identifying the functional interactions of small molecules in yeast. Proc. Natl. Acad. Sci. USA.101:793-798, 2004.

Giannakakou P, Sackett DL, Kang YK, Zhan Z, Buters JT, Fojo T, and Poruchynsky MS. Paclitaxel resistant human ovarian cancer cells have mutant beta-tubulins that exhibit impaired paclitaxel-driven polymerization. J. Biol. Chem. 272:17118-25, 1997.

Giannakakou P, Gussio R, Nogales E, Downing KH, Zaharevitz D, Bollbuck B, Poyi G, Sackett D, Nicolaou KC, and Fojo T. A common pharmacophore for epothilone and taxanes: Molecular basis for drug resistance conferred by tubulin mutations in human cancer cells. Proc. Natl. Acad. Sci. USA. 97: 2904-2909, 2000.

Gietz RD, and Woods RA. Transformation of yeast by the Liac/Ss carrier DNA/PEG Method. Meth. Enzymol. 350: 87-96, 2002.

Goncalves A, Braguer D, Kamath K, Martello L, Briand C, Horwitz S, Wilson L, and Jordan MA. Resistance to Taxol in lung cancer cells associated with increased microtubule dynamics. Proc. Natl. Acad. Sci. USA. 98:11737-11742, 2001.

Gupta ML, Jr, Bode CJ, Georg GI, and Himes RH. Understanding tubulin-Taxol interactions: Mutations that impart Taxol binding to yeast tubulin. Proc. Natl. Acad. Sci. USA. 100:6394-6397, 2003.

Haase SB and Reed SI. Improved flow cytometric analysis of the budding yeast cell cycle. Cell Cycle. 1:132-136, 2002.

Haase SB. Cell cycle analysis of budding yeast using SYTOX green. Curr. Prot. Cytometry. 7.23.1-7.23.4, 2003.

Hardwick K, and Murray AW. Mad1p, a phosphoprotein component of the spindle assembly checkpoint in budding yeast. J. Cell Biol. 131: 709-720, 1995.

Hardwick KG, Li R, Mistrot C, Chen RH, Dann P, Rudner A, and Murray AW. Lesions in many different spindle components activate the spindle checkpoint in the budding yeast Saccharomyces cerevisiae. Genet. 152: 509-518, 1999.

Hartman JL IV, Garvik B, and Hartwell L. Principles for the buffering of genetic variation. Science. 291:1001-1004, 2001.

Hartwell LH. Nobel Lecture: Yeast and cancer. Biosci. Rept. 22:373-394, 2002.

He L, Orr GA, and Horwitz SB. Novel molecules that interact with microtubules and have functional activity similar to Taxol ${ }^{\mathrm{TM}}$. Drug Discovery Today. 6:1153-1164, 2001.

Herskowitz I. Life cycle of the budding yeast Saccharomyces cerevisiae. Microbiol. Rev. 52: 536-553, 1988. 
Hillenmeyer ME, Fung E, Wildenhain J, Pierce SE, Hoon S, Lee W, Proctor M, St.Onge RP, Tyers M, Koller D, Altman RB, Davis RW, Nislow C, and Giaever G. The chemical genomic portrait of yeast: Uncovering a phenotype for all genes. Science. 320: 362- 365, 2008.

Hood KA, West LM, Rouwé B, Northcote PT, Berridge MV, Wakefield St J, and Miller JH. Peloruside A, a novel antimitotic agent with paclitaxel-like microtubule-stabilizing activity. Canc. Res. 62:3356-3360, 2002.

Horwitz SB. Mechanism of action of Taxol. Trend. Pharm. Sci. 13:134-136, 1992.

Hughes TR. Yeast and drug discovery. Funct. Integ.r Genomics. 2:199-211, 2002.

Huzil JT, Chik JK, Slysz GW, Freedman H, Tuszynski J, Taylor RE, Sackett DL, and Schriemer DC. A unique mode of microtubule stabilization induced by peloruside A. J. Mol. Biol. 378:1016-1030, 2008.

Janke C, Magiera MM, Rathfelder N, Taxis C, Reber S, Maekawa H, Moreno-Borchart A, Doenges G, Schwob E, Schiebel E, and Knop M. A versatile toolbox for PCRbased tagging of yeast genes: New fluorescent proteins, more markers and promoter substitution cassettes. Yeast. 21:947-962, 2004.

Jimenez-Barbero J, Canales A, Northcote PT, Buey RM, Andreu JM, and Díaz JF. NMR dteremination of the bioactive conformation of peloruside $\mathrm{A}$ bound to microtubules. J. Am. Chem. Soc. 128:3301-3310, 2006.

Jordan MA, and Wilson L. Microtubule and action filaments: Dynamic targets for cancer chemotherapy. Curr. Opin. Cell Biol. 10:123-130, 1998.

Jordan MA. Mechanism of action of antitumor drugs that interact with microtubules and tubulin. Curr. Med. Chem. Anti-Canc. Agents. 2:1-17, 2002.

Jordan MA, and Wilson L. Microtubules as a target for anticancer drugs. Nature Rev. Canc. 4:253-256, 2004.

Katz W, Weinstein B, and Solomon F. Regulation of tubulin levels and microtubule assembly in Saccharomyces cerevisiae: Consequences of altered tubulin gene copy number. Mol. Cell Biol. 10:5286-5294, 1990.

Knop M, Pereira G, and Schiebel E. Microtubule organization by the budding yeast spindle pole body. Biol. Cell. 91:291-304, 1999.

Kowalski RJ, Giannakakou P, and Hamel E. Activities of the microtubule stabilizing agents epothilones A and B with purified tubulin and in cells resistant to paclitaxel (Taxol). J. Biol. Chem. 272: 2534-2541, 1997.

Kumar S, Ma B, Tsai CJ, Sinha N, and Nussinov R. A systematic study of the vibrational free energies of polypeptides in folded and random states. Protein Sci. 9:10-19, 2000 .

Lee FYF, Covello KL, Castaneda S, Hawken DR, Kan D, Lewin A, Wen ML, Ryseck RP, Fairchild CR, Fargnoli J, and Kramer R. Synergistic antitumor activity of Ixabepilone (BMS-247550) plus Bevacizumab in multiple in vivo tumor models. Clin. Canc. Res. 14:8123-8131, 2008.

Li R, and Murray AW. Feedback control of mitosis in budding yeast. Cell. 66: 519-531, 1991.

Lomenick B, Hao R, Jonai N, Chin RM, Aghajan M, Warburton S, Wang J, Wu RP, Gomez F, Loo JA, Wohlschlegel JA, Vondriska TM, Pelletier J, Herschman HR, Clardy

$\mathrm{J}$, Clarke CF, and Huang $\mathrm{J}$. Target identification using drug affinity responsive target stability (DARTS). Proc. Natl. Acad. Sci. USA. 106:21984-21989, 2009. 
Long BH, Carboni JM, Wasserman AJ, Cornell LA, Casazza AM, Jensen PR, Lindel T, Fenical W, and Fairchild CR. Eleutherobin a novel cytotoxic agent that induces tubulin polymerization is similar to paclitaxel (Taxol). Canc. Res. 58:1111-1115, 1998.

Löwe J, Li H, Downing KH, and Nogales E. Refined structure of $\alpha \beta$-tubulin at $3.5 \AA$ resolution. J. Mol. Biol. 313:1045-1057, 2001.

Lum PY, Armour CD, Stepaniants SB, Cavet G, Wolf MK, Butler JS, Hinshaw JC, Garnier P, Prestwich GD, and Leonardson A. Discovering modes of action for therapeutic compounds using a genome-wide screen of yeast heterozygotes. Cell. 116:121-137, 2004.

Marchionni L, Wilson RF, Wolff AC, Marinopoulos S, Parmigiani G, Bass EB, and Goodman SN. Systematic Review: Gene expression profiling assays in early-stage breast cancer. Ann. Intern. Med. 148:358 -369, 2008.

Menacho-Márquez M, and Murguía JR. Yeast on drugs: Saccharomyces cerevisiae as a tool for anticancer drug research. Clin. Transl. Oncol. 9:221-228, 2007.

Miller JH, Rouwé B, Gaitanos TN, Hood KA, Crume KP, Bäckström BT, La Flamme AC, Berridge MV, and Northcote PT. Peloruside A enhances apoptosis in H-rastransformed cells and is cytotoxic to proliferating T-cells. Apoptosis.9:785-796, 2004.

Mooberry SL, Tien G, Hernandez AH, Plubrukarn A, and Davidson BS. Laulimalide and isolaulimalide new paclitaxel-like microtubule-stabilizing agents. Canc. Res. 59:653-660, 1999.

Mushegian AR, Bassett DE, Jr, Boguski MS, Bork P, and Koonin EV. Positionally cloned human disease gene patterns of evolutionary conservation and functional motifs. Proc. Natl. Acad. Sci. USA. 94:5831-5836, 1997.

Neff N, Thomas JH, Grisafi P, and Botstein D. Isolation of the $\beta$-tubulin gene from yeast and demonstration of its essential function in vivo. Cell. 33:211-219, 1983.

Nislow C, and Giaever G. Chemical genomic tools for understanding gene function and drug action. Meth. Microbiol. 36:387-414, 2007.

Northcote PT, Blunt JW, and Munro MHG. Pateamine: A potent cytotoxin from the New Zealand marine sponge, Mycale sp. Tetrahedron Lett. 32:6411-6414,1991.

Orr GA, Verdier-Pinard P, McDaid H, and Horwitz SB. Mechanisms of Taxol resistance related to microtubules. Nature. 22:7280-7295, 2003.

Page M, West L, Northcote P, Battershill C, and Kelly M. Spatial and temporal variability of cytotoxic metabolites in populations of the New Zealand sponge Mycale hentscheli. J. Chem. Ecol. 31: 1161-1174, 2005a.

Page MJ, Northcote PT, Webb VL, Mackey S, and Handley SJ. Aquaculture trials for the production of biologically active metabolites in the New Zealand sponge Mycale hentscheli (Demospongiae: Poecilosclerida). Aquaculture. 250:256-269, 2005b.

Pan X, Yuan DS, Xiang D, Wang X, Sookhai-Mahadeo S, Bader JS, Hieter P, Spencer F, and Boeke JD. A robust toolkit for functional profiling of the yeast genome. Mol. Cell. 16: 487-496, 2004.

Pannunzio V, Burgos H, Alonso M, Mattoon J, Ramos E, and Stella C. A Simple chemical method for rendering wild-type yeast permeable to Brefeldin A that does not require the presence of an erg6 mutation. J. Biomedicine Biotech. 3: 150-155, 2004. 
Parsons AB, Brost RL, Ding H, Li Z, Zhang C, Sheikh B, Brown GW, Kane PM, Hughes $\mathrm{TR}$, and Boone $\mathrm{C}$. Integration of chemical-genetic and genetic interaction data links bioactive compounds to cellular target pathways. Nature Biotech. 22:62-69, 2004.

Parsons AB, Lopez A, Givoni IE, Williams DE, Gray CA, Porter J, Chua G, Sopko R, Brost RL, Ho CH, Wang J, Ketela T, Brenner C, Brill JA, Fernandez GE, Lorenz TC, Payne GS, Ishihara S, Ohya Y, Andrews B, Hughes TR, Frey BJ, Graham TR, Andersen RJ, and Boone C. Exploring the mode-of-action of bioactive compounds by chemical-genetic profiling in yeast. Cell. 126: 611-625, 2006.

Perry NB, Blunt JW, Munro MHG, and Pannel LK. Mycalamide A, an antiviral compound from a New Zealand sponge of the genus Mycale. J. Am. Chem. Soc. 110:48504851, 1988.

Pierce SE, Davis RW, Nislow C, and Giaever G. Genome-wide analysis of barcoded Saccharomyces cerevisiae gene-deletion mutants in pooled cultures. Nature Prot. 2:2958-2974, 2007.

Pineda O, Farras J, Maccari L, Manetti F, Botta M, and Vilarrasa J. Computational comparison of microtubule-stabilising agents laulimalide and peloruside with Taxol and colchicine. Bioorg. Med. Chem. Lett. 14:4825-4829, 2004.

Pryor DE, O’Brate A, Bilcer G, Díaz JF, Wang Y, Wang Y, Kabaki M, Jung MK, Andreu JM, Ghosh AK, Giannakakou P, and Hamel E. The microtubule stabilizing agent laulimalide does not bind in the taxoid site, kills cells resistant to paclitaxel and epothilones and may not require its epoxide moiety for activity. Biochem. 41:91099115, 2002.

Qaddouri B, Guaadaoui A, Bellirou A, Hamal A, Melhaoui A, Brown GB, and Bellaoui M. The budding yeast 'Saccharomyces cerevisiae' as a drug discovery tool to identify plant-derived natural products with anti-proliferative properties. Evid Based Compl. Alternat. Med. 1-5, 2009.

Rabitsch KP, Tóth A, Gálová M, Schleiffer A, Schaffner G, Aigner E, Rupp C, Penkner AM, Moreno-Borchart AC, Primig M, Esposito RE, Klein F, Knop M, and Nasmyth K. A screen for genes required for meiosis and spore formation based on wholegenome expression. Curr. Biol. 11: 1001-1009, 2001.

Rao S, Horwitz SB, and Ringe I. Direct photoaffinity labeling of tubulin with Taxol. J. Natl. Cancer Inst. 84:785-788, 1992.

Reijo RA, Cho DS, and Huffaker TC. Deletion of a single-copy tRNA affects microtubule function in Saccharomyces cerevisiae. Genet. 135:955-962, 1993.

Rigaut G, Shevchenko A, Rutz B, Wilm M, Mann M, and Séraphin B. A generic protein purification method for protein complex characterization and proteome exploration. Nature Biotechnol. 17:1030-1032, 1999.

Roberge M. Defining drug targets in yeast haploinsufficiency screens: Application to human translational pharmacology. Sci. Signal. 1:5, 2008.

Saccharomyces Genome Database (SGD Stanford): http://www.yeastgenome.org/

Sarin S, Ross KE, Boucher L, Green Y, Tyers M, and Cohen-Fix O. Uncovering novel cell cycle players through the inactivation of securin in budding yeast. Genet. 168:1763-1771, 2004. 
Schatz PJ, Pillus L, Grisafi P, Solomon F, and Botstein D. Two functional $\alpha$-tubulin genes of the yeast Saccharomyces cerevisiae encode divergent proteins. Mol. Cell. Biol. 6:3711-3721, 1986a.

Schatz PJ, Solomon F, and Botstein D. Genetically essential and non-essential $\alpha$-tubulin genes specify functionally interchangeable proteins. Mol. Cell. Biol. 6: 3722-3733, 1986b.

Schiff PB, Fant J, and Horwitz SB. Promotion of microtubule assembly in vitro by Taxol. Nature. 277:665-667, 1979.

Schiff PB, and Horwitz SB. Taxol stabilizes microtubules in mouse fibroblast cells. Proc. Natl. Acad. Sci. USA. 77:1561-1565, 1980.

Sherman F. An introduction to the genetics and molecular biology of the yeast saccharomyces cerevisiae. Encycl. Mol. Biol. Mol. Med. 6: 302-325, 1998.

Simon I, Barnett J, Hannett N, Harbison CT, Rinaldi NJ, Volkert TL, Wyrick JJ, Zeitlinger J, Gifford DK, Jaakkola TS, and Young RA. Serial regulation of transcriptional regulators in the yeast cell cycle. Cell. 106: 697-708, 2001.

Snyder JP, Nettles JH, Cornett B, Downing KH, and Nogales E. The binding conformation of Taxol in beta-tubulin: A model based on electron crystallographic density. Proc. Natl. Acad. Sci. USA. 98:5312-5316, 2001.

Spellman PT, Sherlock G, Zhang MQ, Iyer VR, Anders K, Eisen MB, Brown PO, Botstein D, and Futcher B. Comprehensive identification of cell cycle-regulated genes of the yeast Saccharomyces cerevisiae by microarray hybridization. Cell. 9: 32733297, 1998.

Spring DR. Chemical genetics to chemical genomics: Small molecules offer big insights. Chem. Soc. Rev. 34: 472-482, 2004.

Stachel SJ, Biswas K, and Danishefsky J. The epothilones, eleutherobines and related types of molecules. Curr. Pharm. Des. 7:1277-1290, 2001.

Statistics New Zealand

http://www2.stats.govt.nz/domino/external/pasfull/pasfull.nsf/173371ce38d7627b4c2568090 0046f25/4c2567ef00247c6acc256e7b007a3829? OpenDocument

Stockwell BR. Chemical genetics ligand-based discovery of gene function. Nature Rev. Genet. 1:116-125, 2000.

Symington L. Role of RAD52 epistasis group genes in homologous recombination and double-strand break repair. Am. Soc. Microbiol. 66:630-670, 2002.

Taylor EW. The mechanism of colchicine inhibition of mitosis. J. Cell Biol. 25:145-160, 1965.

Ter Haar E, Kowalski RJ, Hamel E, Lin CM, Longley RE, Gunasekera SP, Rosenkranz HS, and Day BW. Discodermolide a cytotoxic marine agent that stabilizes microtubules more potently than Taxol. Biochem. 35:243-250, 1996.

Tinley TL, Randall-Hlubek DA, Leal RM, Jackson EM, Cessac JW, Quada JC, Jr., Hemscheidt TK, and Mooberry SL. Taccalonolides E and A: Plant-derived steroids with microtubule-stabilizing activity. Cancer Res. 63:3211-3220, 2003. 
Tong AHY, Evangelista M, Parsons $\mathrm{AB}, \mathrm{Xu} \mathrm{H}$, Bader GD, Pagé N, Robinson M, Raghibizadeh S, Hogue CWV, Bussey H, Andrews B, Tyers M, and Boone C. Systematic genetic analysis with ordered arrays of yeast deletion mutants. Science. 294:2364-2368, 2001.

Tsai CJ, Ma B, and Nussinov R. Folding and binding cascades: Shifts in energy landscapes. Proc. Natl. Acad. Sci. USA. 96:9970-9972, 1999.

Wan Lab. Website : http://www4.utsouthwestern.edu/wanlab/index.htm

Wang Z, Yang D, Mohanakrishnan AK, Fanwik PE, Nampoothiri P, Hamel E, and Cushman M. Synthesis of B-ring homologated estradiol analogues that modulate tubulin polymerization and microtubule stability. J. Med. Chem. 43:2419-2429, 2002.

Weinstein B, and Solomon F. Phenotypic consequences of tubulin overproduction in Saccharomyces cerevisiae: Differences between alpha-tubulin and beta-tubulin, Mol. Cell Biol. 10:5295-5304, 1990.

Werner BioAgents: http://www.webioage.de/eng/

West LM, Northcote PT, and Battershill CN. Peloruside A, a potent cytotoxic macrolide isolated from the New Zealand marine sponge Mycale sp. J. Org. Chem. 65:445449, 2000.

Williams DR, Nag PP, and Zorn N. Strategies for the synthesis of the novel antitumor agent peloruside A. Curr. Opin. Drug Discov. Devel. 11: 251-271, 2008.

Wilmes A. Differences in mode of action between peloruside A and paclitaxel, two microtubule stabilizing agents. $\mathrm{PhD}$ Thesis, Victoria University of Wellington, 2008.

Wilson L, and Jordan MA. Microtubule dynamics: Taking aim at a moving target. Chem. Biol. 2:569-573, 1995.

Wilson L, and Jordan MA. New microtubule/tubulin targeted anticancer drugs and novel chemotherapeutic strategies. J. Chemother. 16:83-85, 2004.

Winzeler EA, Shoemaker DD, Astromoff A, Liang H, Anderson K, Andre B, Bangham R, Benito R, Boeke JD, Bussey H, Chu AM, Connelly C, Davis K, Dietrich F, Dow SW, El Bakkoury M, Foury F, Friend SH, Gentalen E, Giaever G, Hegemann JH, Jones T, Laub M, Liao H, Liebundguth N, Lockhart DJ, Lucau-Danila A, Lussier M, M'Rabet N, Menard P, Mittmann M, Pai C, Rebischung C, Revuelta JL, Riles L, Roberts CJ, Ross-MacDonald P, Scherens B, Snyder M, Sookhai-Mahadeo S, Storms RK, Véronneau S, Voet M, Volckaert G, Ward TR, Wysocki R, Yen GS, Yu K, Zimmermann K, Philippsen P, Johnston M, and Davis RW. Functional characterization of the $S$. cerevisiae genome by gene deletion and parallel analysis. Science. 285: 901-906, 1999.

World Health organisation (WHO)

http://www.who.int/mediacentre/factsheets/fs297/en/index.html

Workman P. Changing times: Developing cancer drugs in genomeland. Curr. Opin. Investig. Drugs. 2:1128-1135, 2001.

Yuan DS, Pan X, Ooi1 SL, Peyser BD, Spencer FA, IrizarryRA, and Boeke JD. Improved microarray methods for profiling the yeast knockout strain collection. Nucleic Acids Res. 33:2-9. 2005.

Zhou J, and Giannakakou P. Targeting microtubules for cancer chemotherapy. Curr. Med. Chem. 5:65-71. 2005. 


\section{Appendices}

\section{Appendix I \\ Media}

YPD 1L

Yeast Extract

$10 \mathrm{~g}$

Peptone

Adenine

$20 \mathrm{~g}$

Agar

$0.12 \mathrm{~g}$

$20 \mathrm{~g}$ (to YPD plates)

After autoclaving add $50 \mathrm{~mL}$ of $40 \%$ glucose solution and the desired antibiotic (G418 $200 \mu \mathrm{g} / \mathrm{mL}$, CloneNat $100 \mu \mathrm{g} / \mathrm{mL}$ ). The antibiotics were added after autoclaving and cooling of the medium to approximately $60 \circ \mathrm{C}$.

\section{SD Media 1L}

Yeast Nitrogen Base without amino acid

MSG

$1.7 \mathrm{~g}$

Amino Acid Mixture to suit

$1 \mathrm{~g}$

Agar

$2 \mathrm{~g}$

$20 \mathrm{~g} \quad$ (to SD plates)

After autoclaving add $50 \mathrm{~mL}$ of $40 \%$ glucose solution and the desired antibiotic (G418 $200 \mu \mathrm{g} / \mathrm{mL}$, CloneNat $100 \mu \mathrm{g} / \mathrm{mL}$ ). The antibiotics were added after autoclaving and cooling of the medium to approximately $60{ }^{\circ} \mathrm{C}$.

\section{$1 \%$ agarose gel $(35 \mathrm{~mL})$}

agarose powder

$0.35 \mathrm{~g}$

1x TBE buffer

$35 \mathrm{~mL}$

\section{4\% MetaPhor agarose gel}

MetaPhor agarose

chilled TBE buffer

$1.6 \mathrm{~g}$

$40 \mathrm{~mL}$

Wait $15 \mathrm{~min}$ before heating. After polymerization store at $4^{\circ} \mathrm{C}$ for at least $30 \mathrm{~min}$ (prior to electrophoresis).

\section{0x TBE (Tris borate EDTA) buffer (1 L)}

$\begin{array}{ll}\text { Tris }(121.14 \mathrm{~g} / \mathrm{mol}) & 108 \mathrm{~g} \\ \text { boric acid }(61.84 \mathrm{~g} / \mathrm{mol}) & 55 \mathrm{~g} \\ \text { EDTA }(292.25 \mathrm{~g} / \mathrm{mol}) & 5.8 \mathrm{~g}\end{array}$

Working concentration: Make 1x. Dissolve initially in $800 \mathrm{~mL}$ of $\mathrm{dH}_{2} \mathrm{O}$ and then adjust to pH 8 with $\mathrm{HCl}$. Then make up volume to $1 \mathrm{~L}$.

\section{LB Medium 1L}

Bacto-Tryptone

Bacto-yeast extract

$\mathrm{NaCl}$

Bacto-agar

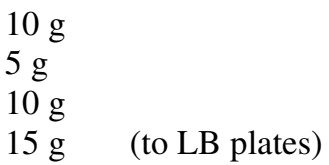

The $100 \mathrm{mg} / \mathrm{ml}$ filter-sterilised ampicillin antibiotic was added after autoclaving and cooling of the medium to approximately $60 \circ \mathrm{C}$. 


\section{Appendix II}

\section{Primer sequences for TUB2 point mutation: Primer A (forward) have a sequence as follow:}

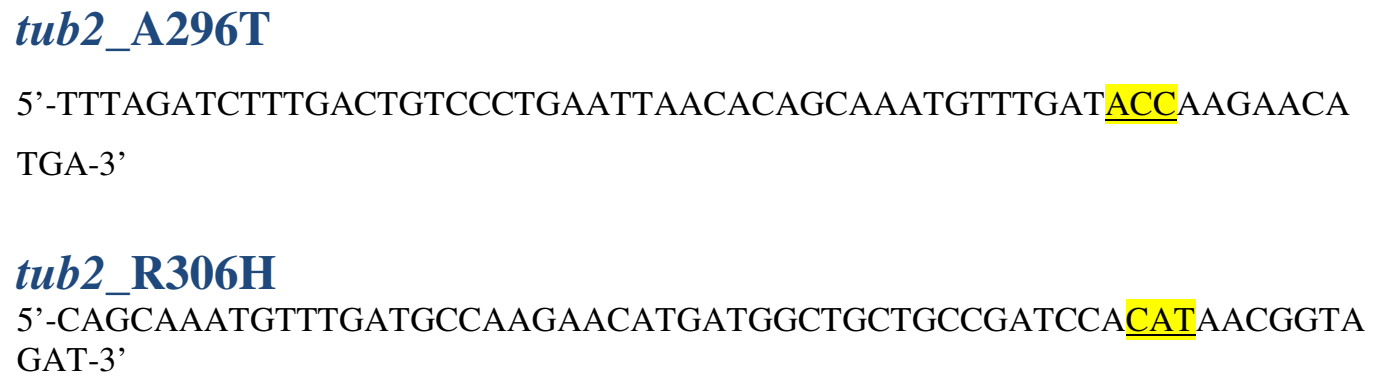

\section{Primer B (Reverse)}

5'-GGGTATTCTGGGCCTCCATGTCTATATTCACTAATACTCGGGGTGT-3'

\section{Primer C (Forward)}

5'-ACACCCCGAGTATTAGTGAATATAGACATGGAGGCCCAGAATACCC-3'

(Blue-coloured letters designate homology to nat-resistance cassette region on the plasmid, and black-coloured letters are the region homolog to gDNA)

\section{Primer D (Reverse)}

5'-AAATCCCTGATCTGCGTAATATTGCAAGTTCTTTTTTATCGGCCCCAGTATAGCGAC CAGCATTCAC- 3

(Green colour coded letters represent homology to natMX-cassette region on the plasmid (as explained earlier); however, black colour letters represent homology to gDNA) 


\section{Transformation confirmation primer:}

Forward primer: Primer A (400 bp upstream of point mutation) 5'-GATGGCCACCTTCTCCGT-3'

Reverse primers:

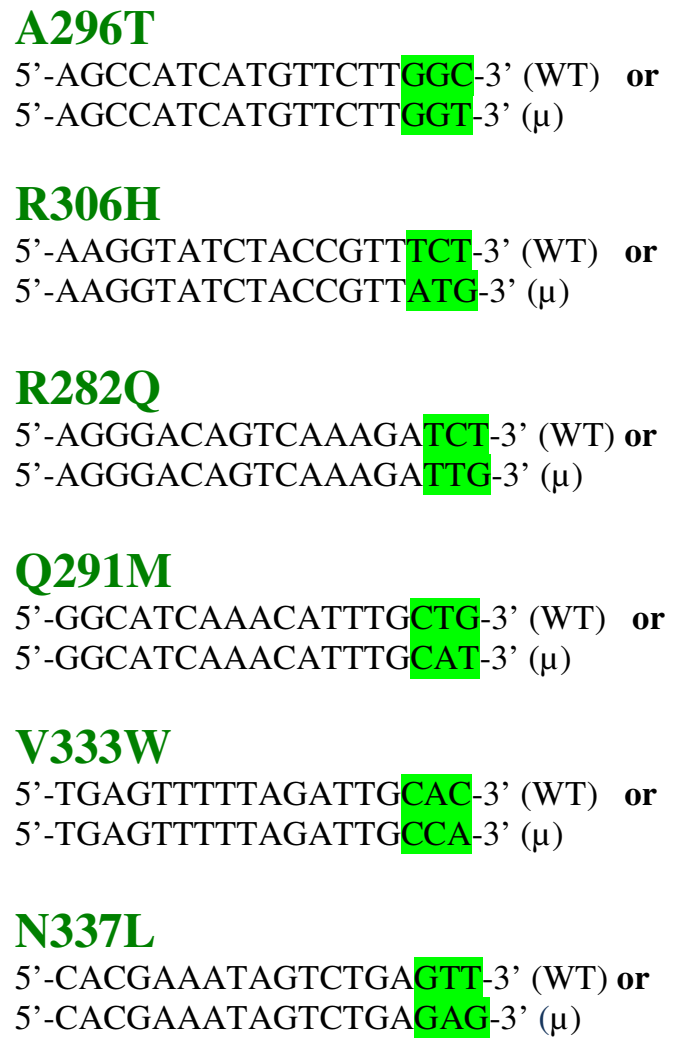




\section{Appendix III}

\section{The NatMX cassette}

Frozen bacterial cultures containing the plasmid p4339 (see figure below) for the NatMX cassette were streaked on LB plates containing $100 \mu \mathrm{g} / \mathrm{ml}$ ampicillin and grown at $37^{\circ} \mathrm{C}$ overnight under shaking. The following day, a single colony was inoculated in $2 \mathrm{~mL} \mathrm{LB}$ medium (Appendix I) containing $100 \mu \mathrm{g} / \mathrm{ml}$ ampicillin and grown at $37^{\circ} \mathrm{C}$ overnight under shaking. The plasmid purification was accomplished using the QIAprep ${ }^{\circledR}$ Miniprep Kit (Qiagen) according to the manufacturer's protocol. The NatMX cassette was then PCR-amplified using forward primer $\mathrm{C}$ and reverse primer D refer to Materials and Methods -in chapter 2- section 2.2.2 (primer sequences are Appendix II)

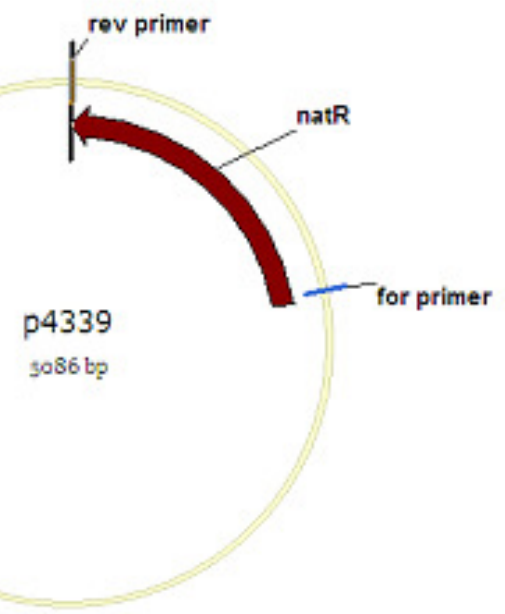

The figure illustrates the p4339 plasmid that encodes for NatMX antibiotic resistant marker. 


\section{Appendix IV}

\section{PelA-mutant strains glycerol stock number}

\begin{tabular}{|c|c|c|}
\hline Point mutation & Glycerol Stock \# & Genotype \\
\hline A296T & YCG248 & $\begin{array}{l}\text { MAT a mad2A::G418 tub2-A296T:: NatMX ura3 } 40 \\
\text { leu2 } 40 \text { his } 3 \Delta 1 \text { met } 15 \Delta 1\end{array}$ \\
\hline $\mathrm{R} 306 \mathrm{H}$ & YCG249 & $\begin{array}{l}\text { MAT a mad2A::G418 tub2- R306H:: NatMX ura3 } \Delta 0 \\
\text { leu2 } 20 \text { his } 3 \Delta 1 \text { met } 15 \Delta 1\end{array}$ \\
\hline $\mathrm{A} 296 \mathrm{~T}+\mathrm{R} 306 \mathrm{H}$ & YCG243 & 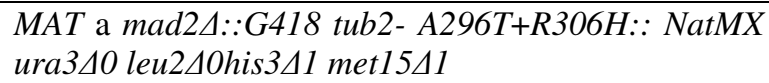 \\
\hline R282Q & YCG257 & 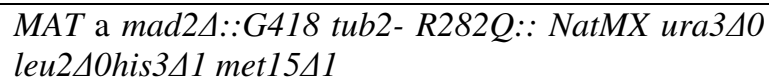 \\
\hline Q291M & YCG258 & 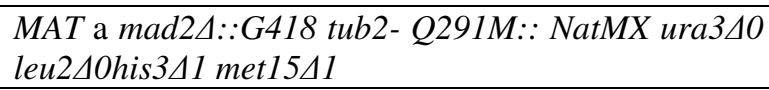 \\
\hline V333W & YCG279 & 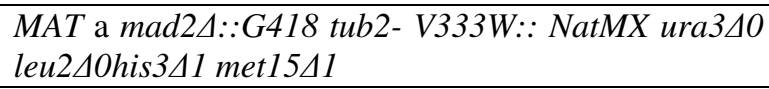 \\
\hline N337L & YCG259 & 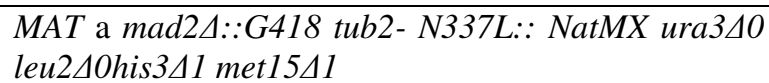 \\
\hline
\end{tabular}

Yeast gene and protein nomenclature

\begin{tabular}{|l|l|}
\hline Type Description & Example \\
\hline Yeast wild type genes Capital letters, italics & $M A D 2$ \\
\hline Yeast mutant genes Small letters, italics, $\Delta$ & mad2 $\Delta$ \\
\hline Yeast proteins Capitalised first letter & Mad2 \\
\hline
\end{tabular}




\section{Appendix V}

\section{Gene description obtained from SGD Stanford for HOP hit list:}

\begin{tabular}{|c|c|c|}
\hline ORF & Gene Name & Description \\
\hline YBL065W & - & Dubious open reading frame unlikely to encode a protein. \\
\hline YBL054W & TOD6 & Protein involved in rRNA and ribosome biogenesis. \\
\hline YBR189W & RPS9B & Protein component of the small (40S) ribosomal subunit. \\
\hline YCL029C & BIK1 & $\begin{array}{l}\text { Microtubule-associated protein, involved in sister chromatid } \\
\text { separation. }\end{array}$ \\
\hline YDL115C & IWRI & Protein of unknown function. \\
\hline YDR017C & KCS1 & $\begin{array}{l}\text { Encodes one of two yeast inositol pyrophosphate synthases, } \\
\text { required vacuolar biogenesis, the stress response, DNA repair, cell } \\
\text { wall synthesis, telomere maintenance, and phosphate homeostasis. }\end{array}$ \\
\hline YDR264C & $A K R 1$ & $\begin{array}{l}\text { Palmitoyl transferase involved in protein palmitoylation; acts as a } \\
\text { negative regulator of pheromone response pathway }\end{array}$ \\
\hline YDR441C & APT2 & $\begin{array}{l}\text { Apparent pseudogene, not transcribed or translated under normal } \\
\text { conditions. }\end{array}$ \\
\hline YER087W & AIM10 & $\begin{array}{l}\text { Protein with similarity to tRNA synthetases; null mutant is viable } \\
\text { and displays elevated frequency of mitochondrial genome loss. }\end{array}$ \\
\hline YGL086W & MAD1 & $\begin{array}{l}\text { Coiled-coil protein involved in the spindle-assembly checkpoint, } \\
\text { forms a complex with Mad2p. }\end{array}$ \\
\hline YGL170C & SPO74 & $\begin{array}{l}\text { Component of the meiotic outer plaque of the spindle pole body, } \\
\text { involved in modifying the meiotic outer plaque that is required } \\
\text { prior to prospore membrane formation. }\end{array}$ \\
\hline YIL157C & COA1 & $\begin{array}{l}\text { Mitochondrial inner membrane protein required for assembly of } \\
\text { the cytochrome c oxidase complex (complex IV) }\end{array}$ \\
\hline YJL030W & MAD2 & $\begin{array}{l}\text { Component of the spindle-assembly checkpoint complex, forms a } \\
\text { complex with Madlp. }\end{array}$ \\
\hline YJL124C & LSM1 & $\begin{array}{l}\text { Lsm (Like Sm) protein; forms heteroheptameric complex (with } \\
\text { Lsm2p, Lsm3p, Lsm4p, Lsm5p, Lsm6p, and Lsm7p) involved in } \\
\text { degradation of cytoplasmic mRNAs. (Lsm) proteins are a highly } \\
\text { conserved family of ancient origin, found in bacteria, archaea, and } \\
\text { eukaryotes. }\end{array}$ \\
\hline YKL212W & $S A C 1$ & $\begin{array}{l}\text { Encodes a lipid phosphatase that is involved in many cellular } \\
\text { processes, such as cell wall maintenance and membrane and } \\
\text { protein trafficking. }\end{array}$ \\
\hline YML008C & ERG6 & $\begin{array}{l}\text { Converts zymosterol to fecosterol in the ergosterol biosynthetic } \\
\text { pathway by methylating position C- } 24 \text {. Cells lacking ERG6 are } \\
\text { viable but unable to methylate sterols on C- } 24 \text {, and exhibit } \\
\text { pleiotropic growth phenotypes. }\end{array}$ \\
\hline YNL054W & $V A C 7$ & $\begin{array}{l}\begin{array}{l}\text { Integral vacuolar membrane protein involved in vacuole } \\
\text { inheritance and morphology. }\end{array} \\
\end{array}$ \\
\hline YNL187W & SWT21 & Protein of unknown function. \\
\hline YNL280C & ERG24 & $\begin{array}{l}\text { Encodes C-14 sterol reductase, an enzyme that acts in ergosterol } \\
\text { biosynthesis. }\end{array}$ \\
\hline YOR014W & RTS1 & $\begin{array}{l}\text { B-type regulatory subunit of protein phosphatase } 2 \mathrm{~A} \text { (homolog of } \\
\text { the mammalian B' subunit of PP2A). }\end{array}$ \\
\hline YOR019W & - & Protein of unknown function. \\
\hline YOR161C & PNS1 & Protein of unknown function. \\
\hline YOR292C & - & Putative protein of unknown function. \\
\hline YPL018W & CTF19 & $\begin{array}{l}\text { Outer kinetochore protein, required for accurate mitotic } \\
\text { chromosome segregation. }\end{array}$ \\
\hline YPL187W & MF(Alpha)1 & Mating pheromone alpha-factor, made by alpha cells. \\
\hline
\end{tabular}

